\title{
Welding and Joining of NiTi Shape Memory Alloys: A Review
}

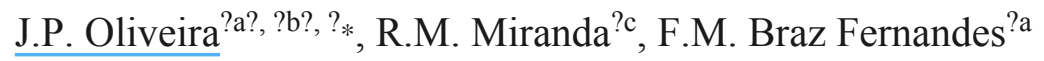 \\ ${ }^{a}$ CENIMAT/I3N, Departamento de Ciencias dos Materiais, Faculdade de Ciências e Tecnologia, Universidade Nova de Lisboa, 2829-516 Caparica, Portugal \\ ${ }^{\mathrm{b}}$ Department of Materials Science and Engineering, The Ohio State University, 1248 Arthur E. Adams Drive, Columbus, OH 43221, USA \\ ${ }^{\mathrm{c}}$ UNIDEMI, Departamento de Engenharia Mecânica e Industrial, Faculdade de Ciências e Tecnologia, Universidade Nova de Lisboa, $2829-516$ Caparica, \\ Portugal
}

\section{A R T I C L E I N F O}

\section{Article history}

Received 15 March 2017

Accepted 6 April 2017

Available online xxx

Keywords:

NiTi shape memory alloys

Welding

Joining

Dissimilar joints

Superelasticity

Shape memory effect

\begin{abstract}
A B S T R A C T
NiTi is an increasingly applied material in industrial applications. However, the difficulties faced when welding and joining is required, limits its broader use in the production of complex shaped components. The main weldability problems associated with NiTi are: strength reduction, formation of intermetallic compounds, modification of phase transformation and transformation temperatures, as well as, changes in both superelastic and shape memory effects. Additionally, NiTi is envisaged to be joined to other materials, in dissimilar joints with more complex problems depending on the other base material. Thus, intensive research in welding and its effects on the joints performance has been conducted since the early stages of NiTi. This paper presents a detailed review of welding and joining processes applied to NiTi, in similar and dissimilar combinations considering both fusion and solid-state processes. Since laser is the most studied and applied welding process, a special section is devoted to this technique.
\end{abstract}

(C) 2016 Published by Elsevier Ltd.

\section{Introduction}

The demand for shape memory alloys (SMAs) has increased in recent years due to their functional properties, namely shape memory effect and superelasticity, present unique solutions for state-of-the-art applications. As a consequence of intensive research activity, shape memory alloys have been used in a wide variety of fields, mainly biomedical, automotive and aeronautical, taking advantage of their smart functionalities and a good actuation force-to-weight ratio [1].

Shape memory alloys are functional materials that present two very distinct properties: superelasticity and shape memory effect. Among these alloys, NiTi is the most important one, not only because of its functional properties, but also because it presents high strength and ductility [2].

The functional properties exhibited by these alloys are due to a reversible martensitic transformation. SMAs have two phases: a low temperature one, known as martensite $(\mathrm{M})$, and a high temperature one, known as austenite (A) or parent phase.

Abbreviations: A, austenite; BM, base material; EDS, energy dispersive spectroscopy; FIB, focused ion beam; FSW, friction stir welding; FZ, fusion zone; GTAW, gas tungsten arc welding; HAZ, heat affected zone; HI, heat input; M, martensite; MIG, metal inert gas; MAG, metal active gas; MRW, micro-resistance welding; Nd:YAG, neodymium-doped yttrium aluminium garnet; R, crystal growth rate; T, temperature gradient; SEM, scanning electron microscopy; SMAs, shape memory alloys; TEM, transmission electron microscopy; TIG, tungsten inert gas; UTS, ultimate tensile strength. USA.

* Corresponding author at: Department of Materials Science and Engineering, The Ohio State University, 1248 Arthur E. Adams Drive, Columbus, OH 43221,

Department of Materials Science and Engineering The Ohio State University 1248 Arthur E. Adams Drive Columbus OH 43221 USA

Email address: jp.oliveira@campus.fct.unl.pt, desousaoliveira.1@osu.edu (J.P. Oliveira) 
When cooling the material from the austenitic domain, it starts to transform into martensite at a given $\mathrm{M}_{?_{\mathrm{s}}}$ temperature. This austenite to martensite transformation (referred in the literature as forward or direct transformation), finishes at the $\mathrm{M}_{\text {?f }}$ temperature.

Starting with the material in the low temperature phase, by heating it up to a given $\mathrm{A}_{? \mathrm{~s}}$ temperature, austenite starts to form. Such transformation from martensite to austenite by heating (referred in the literature as reverse transformation) finishes when the $A_{? f}$ temperature is reached. $M_{? s}, M_{? f}, A_{? s}$ and $A_{? f}$, are designated as the transformation temperatures of a given shape memory alloy, where $\mathrm{M}$ and A designate the phase (martensite or austenite) and the subscripts " $\mathrm{s}$ " and " $\mathrm{f}$ " apply for start and finish of transformation, respectively.

Martensitic transformations, as those taking place in shape memory alloys, are diffusionless transformations [3]. When such transformations occur only by effect of temperature, the macroscopic shape change is negligible.

In these alloys, each martensitic crystal has a given different orientation, called variant. An assembly of martensitic variants may exist in two distinct forms: twinned martensite or detwinned martensite. The former is created by the combination of self-accommodated martensitic variants to keep the overall shape when martensite is thermally induced, while in the latter a specific variant is dominant in the system, usually as a result of an applied external load [4].

The reversibility of transformation between austenite and martensite, and vice versa, is the basis of the peculiar behaviour of this class of alloys.

The martensitic transformation may also be stress-induced, giving rise to superelastic effect. Superelasticity occurs by the application of stress when the material is in the temperature range of thermally stable austenite. Such property allows for the material to undergo a significant deformation during loading (up to 10\% strain) with full recovery of its shape upon unloading [5], as shown in Fig. 1. Consider a given fixed temperature, above $\mathrm{A}_{? \mathrm{~F}}$, where the material is tested under an applied uniaxial tensile load. Firstly, there is elastic deformation of austenite (along the A-B path in Fig. 1). At B, for a given stress $\sigma_{\text {?Ms }}$, the martensitic transformation starts to occur. Such stress induced transformation from austenite to martensite occurs at an approximately constant stress level, up to a $\sigma_{\text {?Mf }}$ stress. When $\sigma_{\text {?Mf }}$ is reached, the material is fully martensitic. When the transformation from austenite to martensite occurs, this martensite may turn instantly into detwinned martensite, depending on the relative orientation of the crystallographic variants and the imposed external solicitation. From C to D, elastic deformation of the detwinned martensite occurs. If the material is not strained beyond point $\mathrm{D}$, in theory, full recovery of the imposed strain can be obtained. From $\mathrm{D}$ to $\mathrm{E}$ the martensite elastically unloads. At point $\mathrm{E}$, for a $\sigma_{\text {? As }}$ stress level the martensite to austenite transformation starts to occur and proceeds until it is finished (at point F). Complete removal of the imposed stress allows for the elastic unloading of austenite (along the path $\mathrm{F}-\mathrm{A}$ ).

Opposite to superelasticity, the shape memory effect occurs starting from the material in the martensitic state [7]. Consider a shape memory alloy with a given form in the austenitic phase. Cooling it down so that martensite (in the twined state) is stable, will not promote any shape alteration in the material. However, if a given deformation is imposed to the material in the martensitic state, it will be retained by the material, as long as it remains in the temperature range where martensite is the stable phase. As a consequence of the applied deformation, martensite detwinning occurs. It is possible to recover the original shape when the material is heated above the $\mathrm{A}_{\text {?f }}$ temperature. When the $\mathrm{A}_{\text {? }}$ temperature is crossed, the shape memory effect starts to occur, that is, the material starts to recover its initial shape, and this proceeds until the $A_{? f}$ temperature is reached, when full recovery of the imposed deformation has occurred. Further cooling into the martensite domain will occur with no significant macroscopic shape change of the material. Fig. 2 depicts the schema of both superelastic and shape memory effects in a stress-strain-temperature diagram.

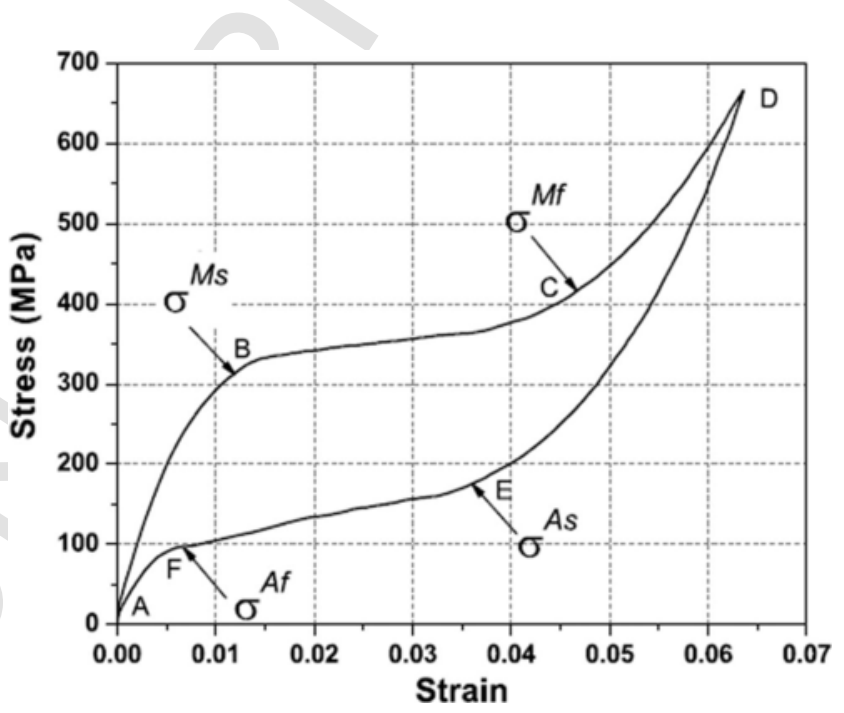

Fig. 1. Typical superelastic behaviour of a shape memory alloy [6]. 


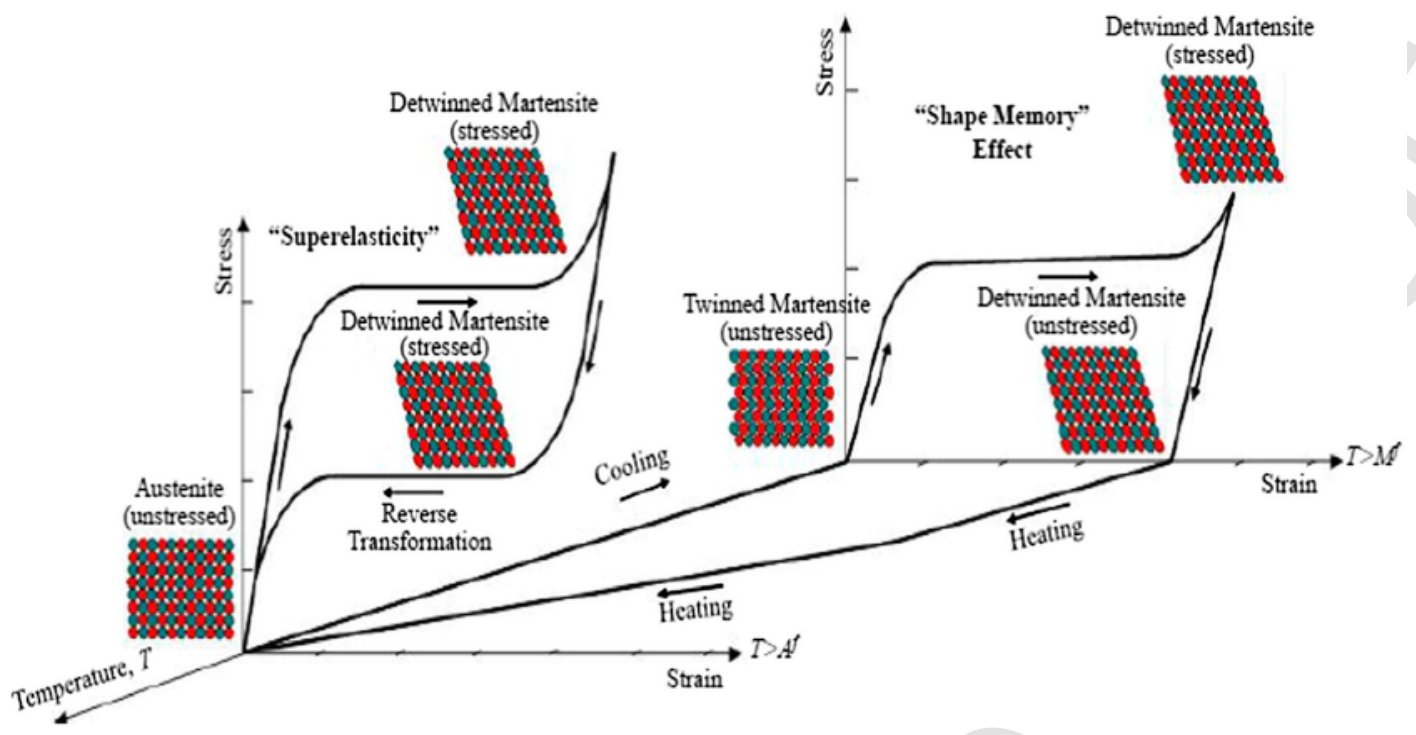

Fig. 2. Stress-strain-temperature plot exhibiting superelasticity and shape memory effect [8].

Though superelasticity and shape memory effect have been discussed separately, they are closely related. It is expected that any shape memory alloy exhibits both superelastic and shape memory properties, depending on the temperature at which they are tested and as long as the critical stress for dislocation slip is not reached.

The critical stress for stress-induced martensite follows a Clausius-Clapeyron relationship [9]: $d \sigma / d T=-\Delta S / \varepsilon$ (being $\sigma$ the applied stress, $\mathrm{T}$ the temperature, $\Delta \mathrm{S}$ the variation in entropy and $\varepsilon$ the applied strain). Increasing the temperature, a higher stress is required to trigger the stress-induced transformation. On the other hand, the critical stress to induce slip, and therefore plastic deformation, decreases with increasing temperature. As such, it is possible that, at a given temperature, the critical stress for dislocation slip occurs earlier than the superelastic effect, thus inhibiting this property. The temperature above which the stress-induced martensitic transformation is no longer favored is designated by $\mathrm{M}_{\text {?d }}$. However, it is possible to manipulate the critical stress for inducing dislocations slip at a given temperature: by softening or hardening the material, the critical stress for slip decreases or increases, respectively.

Another functional property exhibited by these materials is the two-way shape memory effect [4]. When the material is trained to have this property, it "remembers" a given geometrical shape in the parent phase and another in the martensitic phase. These two shapes are obtained without the help of any mechanical loading.

Besides austenite (with a B2 structure of cubic symmetry) and martensite (with a B19' monoclinic structure), NiTi may present another phase: R-phase, with a trigonal structure, that may exist between austenite and martensite in special circumstances, as it will be discussed latter. The crystal structures of both austenite and martensite are depicted in Fig. 3. The crystal structure of R-phase can be viewed as a stretch of the austenite crystal structure along the $\left\langle\begin{array}{llll}1 & 1 & 1\rangle & \text { direction. }\end{array}\right.$

The Ti-Ni phase diagram is depicted in Fig. 4. It can be seen that NiTi, above a certain temperature, is not a line compound with a fixed composition, but rather has a certain solubility, that is much larger on the Ni side than on the Ti. Other compounds, namely precipitates $\mathrm{Ti}_{2} \mathrm{Ni}_{2} \mathrm{Ni}_{93} \mathrm{Ti}_{1} \mathrm{Ni}_{93} \mathrm{Ti}_{? 2}$ and $\mathrm{Ni}_{94} \mathrm{Ti}_{93}$ are also observed for this system.

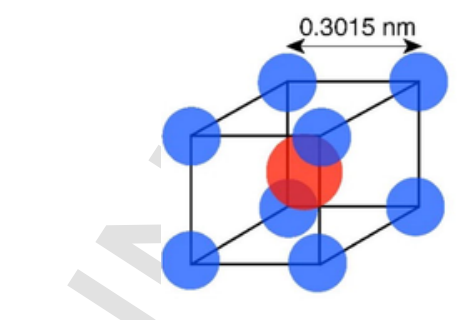

Austenite

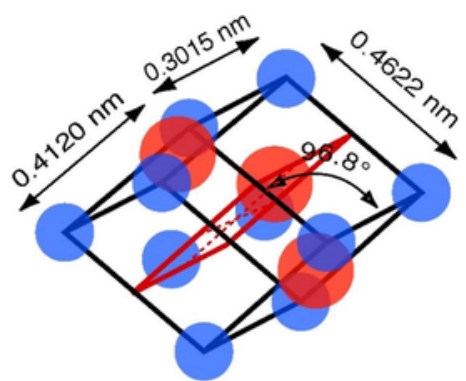

Martensite

Fig. 3. Crystal structures of austenite and martensite. 


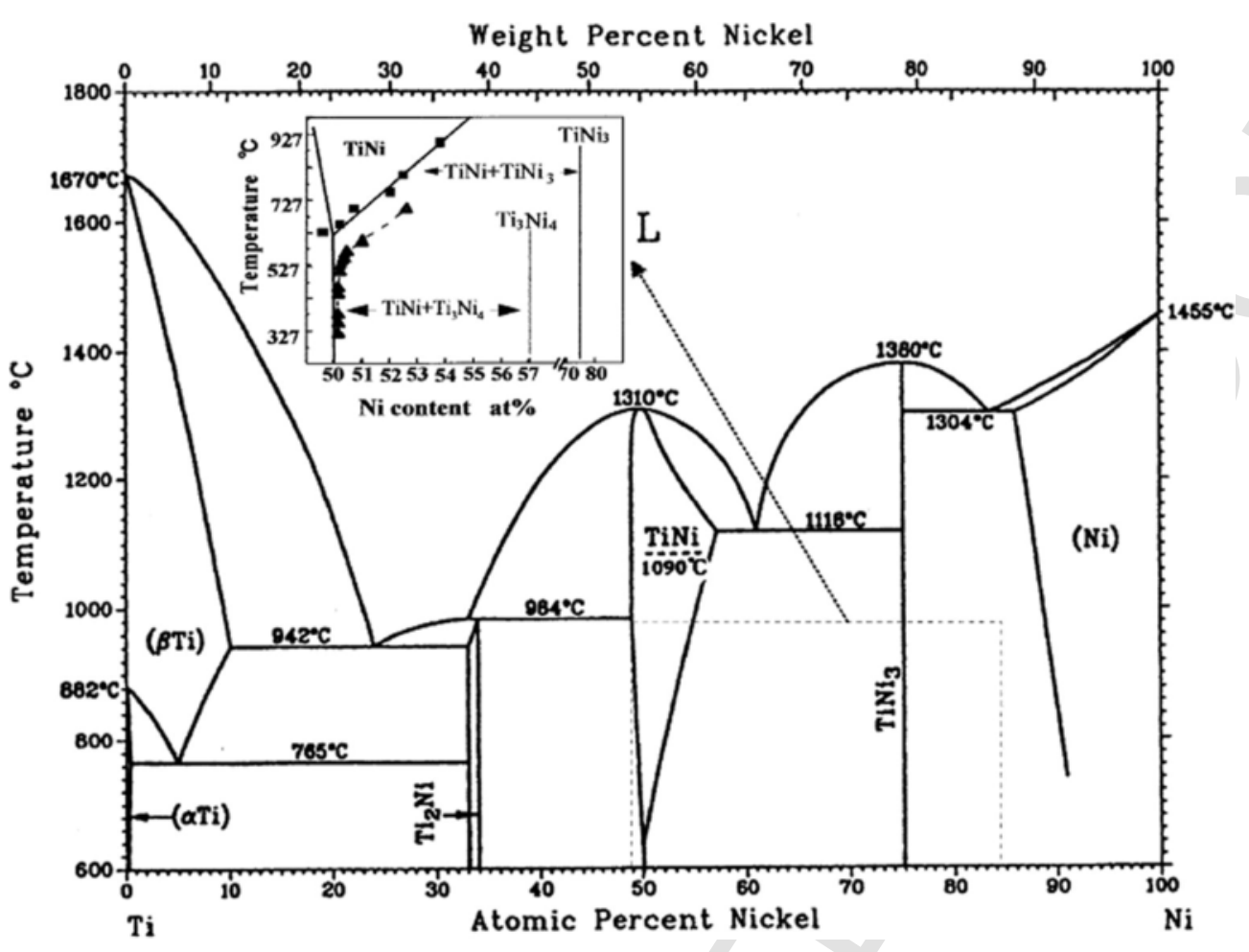

Fig. 4. Phase diagram of Ti-Ni [2].

Extensive studies [2,10-13] have been performed studying the precipitation phenomena for NiTi shape memory alloys. The precipitates $\mathrm{Ni}_{? 4} \mathrm{Ti}_{? 3}, \mathrm{Ni}_{? 3} \mathrm{Ti}_{? 2}, \mathrm{Ni}_{? 3} \mathrm{Ti}$ can form when the NiTi alloy is slightly Ni-rich. In opposition, for Ti-rich NiTi alloys just $\mathrm{Ti}_{{ }_{2}} \mathrm{Ni}$ precipitates may exist.

As a consequence of these precipitation phenomena, namely of $\mathrm{Ni}_{? 4} \mathrm{Ti}_{? 3}$, the intermediary phase of the NiTi system, R-phase, can be formed. When $\mathrm{Ni}_{? 4} \mathrm{Ti}_{? 3}$ is coherent with the matrix, or in the presence of dislocation networks, a thermoelastic transformation, which is a transformation that proceeds by changing the stress or temperature between austenite and R-phase, is observed. Such R-phase transformation, when present, is always an intermediate step for the austenite $\leftrightarrow$ martensite transformation.

The matrix composition of a given NiTi alloy influences its transformation temperatures and, thus, the functional properties at a given temperature. The influence of the alloy composition on the transformation temperature varies significantly if it is a Ni or Ti-rich NiTi. Fig. 5 depicts this variation. It can be observed that, for the Ni-rich NiTi, the transformation temperatures decrease significantly with increasing of $\mathrm{Ni}$ content. On the other hand, increasing the Ti content does not vary significantly the transformation temperatures. Such major difference between Ni and Ti-rich NiTi alloys is probably due to the fact that solubility limit of NiTi on the Ti-rich side is almost vertical. The transformation temperatures of either Ti-rich or equiatomic NiTi are similar. However, for Ni-rich NiTi an increase of 0.1 at.\% Ni may decrease the transformation temperatures by $20 \mathrm{~K}$ [7].

The poor workability of SMAs by conventional machining processes, and their increasing applications demand for suitable joining techniques in order to obtain complex shaped components. This poor workability is related to the high ductility and strong work-hardening of NiTi [14]. In the last two decades, the number of experiments reported in the literature concerning welding and joining techniques for NiTi shape memory alloys has increased significantly, as shown in Fig. 6. Traditional welding processes were tested, but the increasing need to perform highly demanding tasks pushed for the use of state-of-the-art technologies, like laser welding, with promising results. For this, a special section (Section 3 ) is devoted to laser welding of both similar and dissimilar joints.

There is a large number of welding and joining processes, and these can be classified into three major groups:

- Mechanical joining, when the parts are put together with clamps, bolts, rivets, etc.;

- Welding, when the parts are joined by fusion or in the solid state;

- Adhesives, when the parts are bonded by an adhesive applied on the surfaces.

Mechanical joining is a simple and easy to use process, especially when disassembly is envisaged. However, it does not create a continuous joint, so fatigue and corrosion problems can limit its application.

Concerning welding, there are several classifications of the welding processes, but the one in use splits the processes into three main groups: 


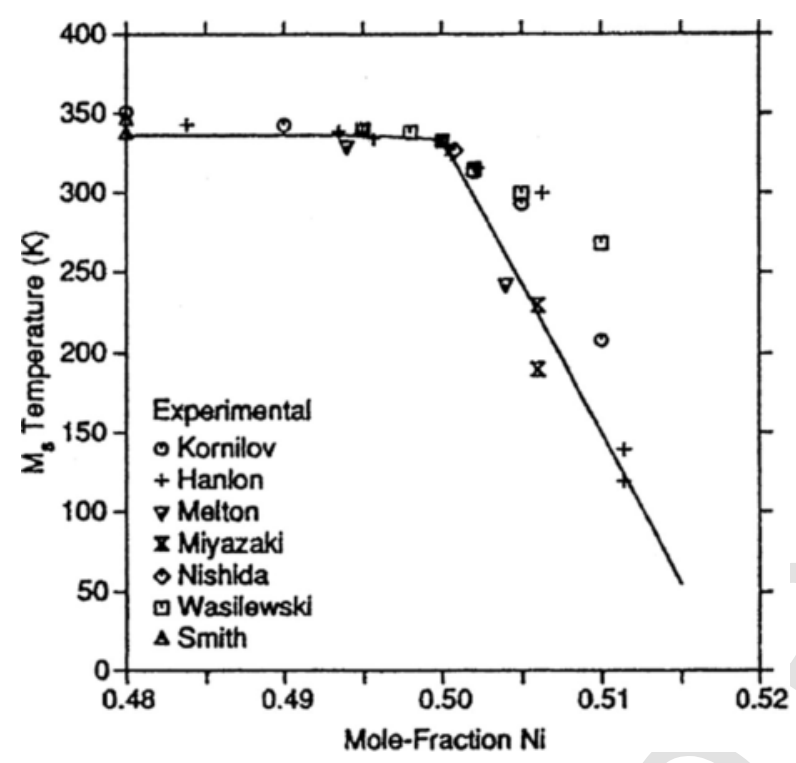

Fig. 5. Variation of the $\mathrm{M}_{2 \mathrm{~s}}$ temperature as a function of the Ni content in several NiTi alloys [2].

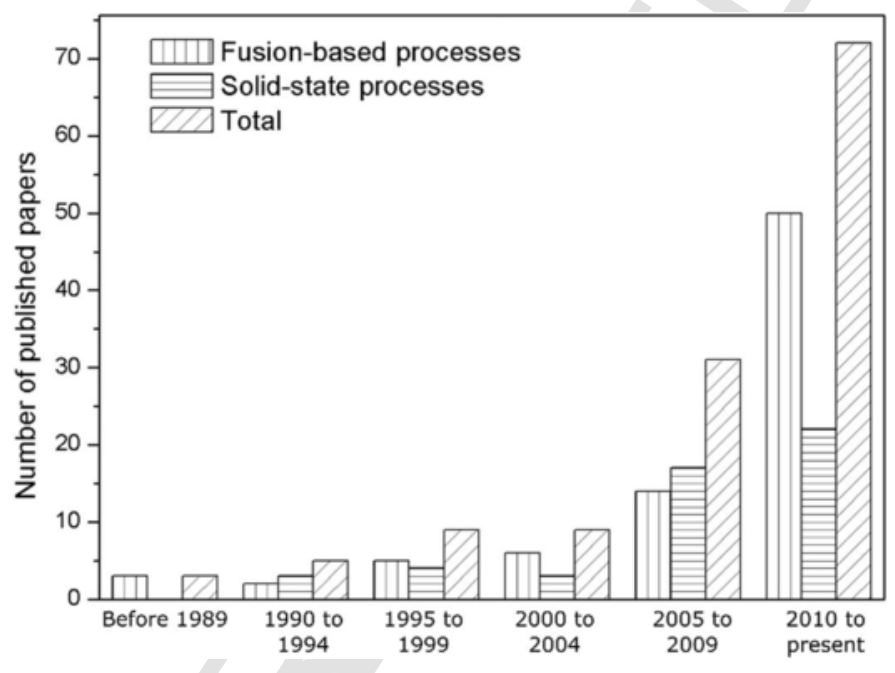

Fig. 6. Number of published papers on joining processes for NiTi shape memory alloys over time.

- Fusion processes, based on melting and solidification of the area to be joined;

- Solid state processes, when there is no melting and joining is accomplished by plastic deformation and solid state diffusion;

- Brazing and soldering when one of the materials or the filler melt and solidify, the parts being thus joined by diffusion. Diffusion reaction-based process can be considered in this group.

Depending on the size of parts and the application, the joining process can be selected.

Fusion welding is the most used process in industry and, thus, a classification exists based on the type of energy source used to melt the materials: electrical arc, thermo-chemical energy, radiant energy and electrical resistance.

Examples of the most studied fusion welding processes for NiTi are: tungsten inert gas (TIG), laser, plasma and electron beam welding. Resistance welding has also been studied for micrometric sized components, as wires, or when mechanical strength of the overall part is not a major request. As far as solid-state processes are concerned, ultrasonic, explosive and friction welding have been investigated. Brazing and reactive diffusion have been studied especially for joining dissimilar materials. Joining by adhesives, diffusion and, more recently, reactive diffusion have also been reported by several research groups. 
Laser welding is, by far, the most investigated and used welding process due to its particular characteristics, such as very low heat input (HI, which is defined as the ratio between the welding power, $\mathrm{P}$ and the welding speed, v: $\mathrm{HI}=\mathrm{P} / \mathrm{v}$ ) and reduced extension of the heat affected zone (HAZ) and fusion zone (FZ), just to mention the most important ones.

Often, there is a need to join different materials taking advantage of the individual properties of each material. In this case, dissimilar welds are envisaged and these are, in many aspects, different from similar welds. Thermo-physical properties of the base materials are different, leading to different heat transfer rates on both sides of the weld. During the process, chemical composition varies across the weld pool, and the interface between solid/liquid phases is not clear. Intermetallic compounds are formed and convection processes occur, like Marangoni effects [15], since base metal densities vary significantly. Some detailed studies on the solidification mechanisms, were conducted on dissimilar welds reporting the microstructural evolution in the FZ of dissimilar NiTi welds, as well as, the main metallurgical problems and strategies to overcome them [16-18]. Embrittlement occurs mainly due to high temperature reaction of NiTi with elements such as oxygen, nitrogen and hydrogen. Brittle intermetallics like $\mathrm{Ti}_{? 2} \mathrm{Ni}$ and $\mathrm{Ni}_{33} \mathrm{Ti}$ can also precipitate during solidification, having adverse effects on the strength and shape memory characteristics. In order to fulfil specific needs of the medical industry, welding experiments on dissimilar joints like NiTi/stainless steel [19] or Hastealloys [20] were performed and reported. In the aerospace industry new parts like gas turbine nozzles are being tested where NiTi is welded to Ti6A14V [21], substituting the previously used mechanical joining by fasteners.

Mechanical and functional behaviours of these alloys are strongly influenced by the thermal effects and modifications of the chemical composition associated with the selected welding process. Nevertheless, welded specimens tend to present lower ultimate tensile strength (UTS) and elongation to fracture. The shape memory effect may prevail depending on whether the strain applied is sufficient (or not) to induce an irreversible deformation of martensite.

This paper presents a critical revision of existing knowledge on welding and joining NiTi, which is the most studied shape memory alloy. The effects of the process on the martensitic transformation, responsible for the shape memory effect and superelastic behaviour are discussed in detail, as well as their effects on the mechanical properties. Due to its industrial relevance, joining of NiTi to other alloys is also addressed.

\section{Welding and joining technologies for NiTi}

\subsection{Major developments in welding technology}

Welding is known since very ancient times (the first evidences date back from 8000 BCE), specially brazing and soldering [22]. In the 18th century there were significant empirical developments that much contributed to the welding development, but it was just in the 20th century, when some major scientific and technological developments took place, that a wide range of welding processes were brought to the industrial market place.

Amongst these developments are: the discovery of the electric arc in 1800 and its later mastering, the widespread use of electricity after the World War I and, more recently, microelectronics and information and communications technology, to quote the most important ones.

These discovery landmarks brought welding into mass production especially after WWI when, finally, welding was considered beneficial for industry.

Oxy-fuel welding was the predominant process till the World War I but the shortage of gases in England by that time pushed for the developments of electric arc based fusion processes, since electricity was already in use [23]. However, the need to protect the welds from atmospheric environments rich in Hydrogen and Oxygen was of major concern to prevent the formation of oxides and the embrittlement and, so, shielded metal arc welding with enrobed electrodes started to be used. Intensive research was performed in those days, aiming to develop new coatings and new metallic rods.

In the following decades advances were seen in welding reactive metals that together with developments in automatic welding and alternate current expanded the use of electric arc based processes.

Tungsten inert gas (TIG) welding was patented in 1942 and in the following years a new development emerged that was the use of a continuous feed wire which very much increased productivity and allowed to weld non-ferrous alloys as Aluminium.

The concepts of metal active/inert gas (MAG/MIG) were eventually set in 1948 and during the World War II construction and repair of both ships and airplanes using welding operations was in place.

Fusion welding processes based on electric arc dominated most of the developments observed till the 50s when the emergence of other concurrent processes started. The scientific community assisted to the revolution of welding processes driven by needs that followed by almost a chronological order:

- the requests of productivity achieved with developments in flux cored or electro-slag welding in the 50s.

- the requirements of joining new soft materials as polymers in the 60 s when solid state processes, as ultrasonic welding, started to be developed.

- the difficulties to weld materials as $\mathrm{Al}$ and Ti alloys that pushed for electron beam welding in the 60s followed by laser in the following decade.

- the need to meet requirements of transport sectors as aeronautics improved adhesives used nowadays in metals, composites or dissimilar welds with medium to low mechanical strength under shear stress solicitations. 
- the increasing need to produce components in parts with specific functionalities and in different materials. This was a driving force for solid state processes to emerge and a wide range exist nowadays.

- the international directives to reduce energy consumption and increase environmental conditions and safety in welding.

In 1991, a new solid state process was patented by The Welding Institute in United Kingdom, and this is Friction Stir Welding (FSW) [24], which is commonly used for materials that are difficult to join by fusion-based processes [25]. In FSW a non-consumable rotating tool consisting of a pin and a shoulder provides mechanical mixing and viscoplastic deformation of the materials in the area to weld. Heat is generated by internal energy dissipation during the viscoplastic material deformation and interfacial friction of the material. The axial load exerted by the tool forges the material in a close forging matrix. Friction Stir Welding prevents most of the problems associated to fusion welding, such as distortions and residual stresses, and can produce high strength joints especially in materials with good viscoplasticity as Al alloys.

Friction welding was known since the 1950s, after the Russians, and this was a process where no fusion or melting was achieved even in low melting temperature alloys.

In 2000, the use of electromagnetic fields, first in forming and later in joining, was another advance in solid state welding, named magnetic pulse welding (MPW).

More recently, after 2008, laser hybrid welding processes were seen an increasing market, as they reduce the disadvantages of both laser and arc welding processes, namely: joint preparation, fit-up and penetration depth. Other hybrid processes are being investigated as friction stir welding assisted by electrical joule effect [26] or by ultrasonic welding [27], to name a few.

As observed in other technologies, there were parallel developments in both materials and manufacturing technologies. NiTi, the most studied shape memory alloy [2], with its peculiar characteristics previously outlined, put weldability problems and, thus, welding this material is a challenge.

In similar joints of NiTi no filler material is needed, while in dissimilar ones, between NiTi and stainless steel or Ti based alloys, interlayers are used to prevent atomic diffusion of the elements and the formation of complex intermetallic compounds.

This overview will focus mostly on autogenous welding processes in similar joints but dissimilar ones will also be included whenever applicable.

The discussion on existing knowledge and the challenges faced with NiTi are presented separating fusion-based processes from solid-state ones. In the first group, TIG, electron beam and laser welding processes are discussed, since the other fusion-based processes are not applicable to NiTi. Solid-state welding has also been investigated and this review presents an analysis of studies performed with explosives, ultrasonic, friction and friction stir, adhesives, diffusion and reactive diffusion bonding, brazing and soldering and resistance.

\subsection{Fusion-based welding processes}

\subsubsection{Tungsten inert gas (TIG)}

Tungsten Inert Gas or Gas Tungsten Arc Welding (GTAW) is an electric arc based welding process, in which the arc is established between a non-consumable electrode in tungsten and the base material under an inert shielding gas atmosphere. The main function of the electric arc is to produce the heat to melt the material, though it also has a cleaning function of both the weld pool and the base materials.

The electrode is made of Tungsten, due to its high melting temperature and thermal emissivity, but additions of rare metals, such as Rhenium or Thorium, are used to improve emissivity enabling arc stability. Continuous current in either direct or reverse polarity are used. The first increases penetration, while the second is used for special materials, such as Aluminium alloys, to break superficial alumina. In reverse polarity, there is a shallow penetration and an overheating of the electrode that has to be cooled in order to prevent its damage. The electrode is typically $1-2 \mathrm{~mm}$ in diameter so the molten pool has small dimensions and the total energy per unit of molten volume is smaller than in other arc-based processes.

TIG is a very controllable and precise process with some particular advantages: (i) it can be applicable to any form of coupling; (ii) the arc is easy to stabilize, even at small electric current intensities; (iii) the heat input can be small enough to limit the extent of the thermal affected zones; (iv) can weld a significant range of material thicknesses, including thin sheets. Welded joints are of high quality with no defects under appropriately selected operating parameters. Limited welding productivity and the need of highly qualified operators are seldom considered the major disadvantages.

TIG was the first welding process tested in similar NiTi joints in 1961 [28]. In this study, though no mechanical analysis was performed, the authors produced defect-free joints. Interstitial phases (based on $\mathrm{H}, \mathrm{N}$ and $\mathrm{O}$ ), however, were observed due to insufficient protection of the molten pool. Ikai et al. [29] several years later resumed this process and observed a decrease in the mechanical properties of the welded joints. In particular, the welded material presented a high irrecoverable strain during cycling tests for a total of 50 cycles at $4 \%$ strain. Just welded wires could withstand the entire cycling routine, while welded plates suffered rupture after 39 cycles. Additionally, wires with different transformation temperatures were successfully joined and the welded joints exhibited the stress-induced martensite transformation in two steps, where each plateau corresponded to the original ones in the base materials. However, as later was studied by [30,31], the presence of contaminants degraded the functional properties of the welded joints.

Recently, Oliveira et al. [32] performed TIG welding of $1.5 \mathrm{~mm}$ NiTi plates in butt joint configuration using dedicated fixing devices to allow inert gas to flow on the face and on the root of the welds to minimize oxidation. The tensile tests of the welds 
showed a total strain to rupture of $20 \%$ and a superelastic plateau $30 \mathrm{MPa}$ below that of the base material. Superelasticity of the welded joints was confirmed by cycling up to $12 \%$ of strain in a total of 600 cycles performed. Shape memory effect was also found to be preserved after welding. An increase in the transformation temperatures of the FZ was observed by differential scanning calorimetry, due to Ti oxidation, despite the good gas shielding.

Considering the significant advantages of the process, a couple of interesting applications were reported using TIG welding of NiTi to stainless steel $[33,34]$. In the first one, actuators were manufactured using tubes of NiTi and AISI304 butt joined. Since the tubes had $1.9 \mathrm{~mm}$ thickness and an outer diameter of $9.3 \mathrm{~mm}$, TIG orbital was performed with an insert of Ni placed between the tubes at the interface prior to welding. The Ni interlayer acted as a filler material preventing the Ti-Fe intermetallic formation. Viable joints could be created with a narrow HAZ, a maximum hardness of about $817 \mathrm{HV}$ and an ultimate torsional strength of $415 \mathrm{MPa}$, which was satisfactory for the construction of a solid state torsional actuator. The high hardness in the partially mixed zone was due to the presence of $\mathrm{Ni}_{? 3} \mathrm{Ti}_{? 2}$ and $\mathrm{Ni}_{? 4} \mathrm{Ti}_{? 3}$ intermetallics. When compared to laser welding, the authors concluded that laser was more suitable for thin walled tubes, while TIG could give full penetration in one single pass at the expense of a larger HAZ due to the higher energy introduced and larger weld bead.

The second interesting application of TIG welding was the manufacture of medical occluders [34], where a cluster of Ti-rich NiTi shape memory alloy wires was welded by TIG and this weld was later welded to a stainless steel AISI $316 \mathrm{~L}$ pipe by laser. Mutual diffusion within a short distance near the fusion boundaries was observed and intermetallics $\mathrm{such}_{\text {as }} \mathrm{Ni}_{33} \mathrm{Ti}$ and (Fe, $\mathrm{Ni}$ ) Ti formed around the fusion boundary.

Another uncommon application was to use TIG to yield a NiTi alloy overlay on AISI 1048 carbon steel substrate aiming to improve erosion behaviour of the steel under solid/liquid (sand/water) mixture [35]. A NiTi rod was welded to steel as a deposited overlay. The hardness of the welded overlay was much higher than the initial hardness of the NiTi rod due to the formation of oxides during welding. However, the austenite phase of the initial rod was maintained, which is the target phase for superelasticity. Lattice distortions caused by residual stresses, induced by the thermal gradient, also contributed to the hardness increase. The oxide particles formed during welding and the small fraction of martensite identified, blocked dislocation movement, so the erosion resistance was improved even at high impact angles of the sand.

\subsubsection{High energy density beams}

Electron beam welding is performed in a vacuum chamber where the electrons are accelerated by a high voltage from the cathode to the anode and focused by electromagnetic field lenses onto the material surface. The kinetic energy of the electrons impacting the material is transferred under the form of heat, rising the material temperature well above its melting point. In the narrow interaction area, a metallic vapour column forms which transmits the heat into depth in a keyhole welding mode. The beam is focused into a very small spot, so that the energy per unit area of beam/material interaction is very high. As a high energy density process, the heat input is very small, thus almost no HAZ is produced and the FZ is very narrow, so this is a precision welding process. If the material is thin, a good control of the focal point position has to be ensured in order to have a good weld bead profile and prevent molten metal to drop. The main advantage is the vacuum environment that prevents oxidation and contamination, but this is also a limitation due to economic reasons, both equipment investment, running and maintenance costs and productivity, that is, the time to make a weld.

Few studies exist on electron beam welding of NiTi, essentially due to the process cost. Yang et al. [36] conducted a study on the weldability of austenitic NiTi with electron beam on $4 \mathrm{~mm}$ thick plates and some interesting results can be retained. The welding mode was a mixed one of keyhole and conduction, with a weld pool constituted by coarse columnar grains with a small quantity of martensite B19'. Both $\mathrm{Ti}_{? 2} \mathrm{Ni}$ and $\mathrm{Ni}_{?_{4}} \mathrm{Ti}_{? 3}$ were formed in the FZ. A decrease of the $\mathrm{M}_{? \mathrm{~s}}$ temperature was measured by differential scanning calorimetry and this means that some Ni was lost during welding, which is in agreement with existing studies, mostly on laser welding as it will be discussed later. An UTS of $85 \%$ of that of the base material was measured and either in the base material or in the FZ a one-step reversible B2 $\leftrightarrow$ B19' transformation was observed. After annealing, grain refinement in the weld metal was observed and grain size decreased with increasing annealing temperature. Ni-rich particles precipitated and both $\mathrm{R}_{? \mathrm{~s}}$ and $\mathrm{M}_{\text {? }}$ temperatures decreased. Additionally, the ultimate tensile stress dropped [37].

As already mentioned, laser was developed a few years after electron beam and replaced this process with significant advantages. A beam of light radiation is produced by a stimulation induced process wherein an energy source excites the active species to a high energetic level which, upon decay to the fundamental level, emits a light radiation where all the photons have the same energy and wavelength. The produced beam is, thus, monochromatic and coherent, that is, all photons are in phase (both in space and in time) and have limited divergence, being possible to focus into a very small spot.

When the laser beam interacts with the work piece the photon energy is transferred to the material and converted into heat, vaporizing and ionizing the molten material creating a plasma above the weld. This plasma absorbs the laser beam and the efficiency of energy transfer is reduced, or can even be suppressed, when a high plasma plume is formed. So a gas is introduced to blow away the plasma facilitating the laser/material continuous interaction.

Depending on the laser power density, two main welding modes may occur, usually referred to as: conduction and keyhole modes [38]. Conduction mode is predominant when the energy density is below a threshold value depending on the material thermal and physical properties and the beam wavelength. The heat transfer is mostly controlled by conduction, as in fusion arc welding processes and the weld aspect ratio is similar to a TIG weld, that is, the face width to height ratio of the FZ is larger than 1. In keyhole welding, the introduced heat is higher than in the previous mode, and a plasma is formed in the interaction 
area and then transferred into depth, forming a cylinder of vapour plasma. A narrow FZ is formed with an aspect ratio below 1. An intermediate mode is often identified that is a mixture of the previous ones.

Under an appropriate gas shielding atmosphere, laser welding is a very precise process, feasible for SMAs. Since this is the most studied process and existing applications mostly uses laser, it is analysed in detail in Section 3.

When compared to arc welding processes, laser welding shows several benefits, including narrow and deep FZ, small HAZ, low residual stresses and a much higher productivity.

In the past ten years lasers have shown improvements and developments mainly to increase energy efficiency and beam quality. Solid state lasers, as Nd/YAG and, most recently, fibre lasers have been developed to accomplish both characteristics, as well as, to improve beam delivery and focusability. When processing materials with a high power laser beam, the ability to focus the beam is critical, because good focusability means a smaller spot size, higher power density and increased welding depth.

Wavelengths also affect the beam quality as, at shorter wavelengths, the more energetic photons can be absorbed by a greater number of bound electrons and, so, the reflectivity falls while the absorption of the beam on a work piece surface increases. Beam divergence and focal spot size needs to be considered in all applications as these play an important role in the quality of laser welding, e.g., small beam divergence and focal spot diameters lead to welds with higher penetration and smaller width for a given welding speed.

While in $\mathrm{Nd} / \mathrm{YAG}$ lasers the active species is $\mathrm{Nd}^{23+}$ dopant in an Yttrium Aluminium Garnet (YAG) disk or rod, fibre lasers are based on ytterbium, erbium or thallium-doped multi-clad silica fibres (or bundles of these). Depending on the dopant, or active species, the emitted wavelength varies in the range of $0.8-1 \mu \mathrm{m}$ that is in the infrared region of the spectrum, where metallic materials highly absorb the beam radiation as shown in Fig. 7.

A high melting efficiency is also observed for low wavelengths lasers compared to $\mathrm{CO}_{? 2}$ ones. The melting efficiency is the energy required to melt a unit volume of material. So the heat input and the power density are determinant when controlling the weld bead profile and the depth of penetration [39].

\subsubsection{Resistance welding}

Resistance welding is a simple process widely used in several industries, especially in automotive. It consists of forcing a high intensity electric current (AC or DC) to pass through the parts to weld, either plates or tubes. According to Joule Law, the quantity of heat generated is proportional to the product of electrical resistance of the interfaces between these, the square of the current intensity and the time.

The resistance between materials is the highest one, so the quantity of heat generated in the interface is higher than in the bulk materials and thus it melts surrounded by solid state material at high temperature, partially deformed due to the volume expansion during melting and the decrease of the yield strength with temperature. Finally, welding is achieved by applying a forging force, so, a weld is produced in a close environment (between parts) with no filler material. The electrical current is driven to the parts through two highly conductive Copper electrodes, which have the additional function of forging the weld till it cools down into air.

The major parameters to control in this process are: the current intensity, the time it passes through the interface, the pressure applied to forge the weld and the electrical resistance which depends on the material resistivity and the surface conditions (e.g. oxides, roughness, etc.).

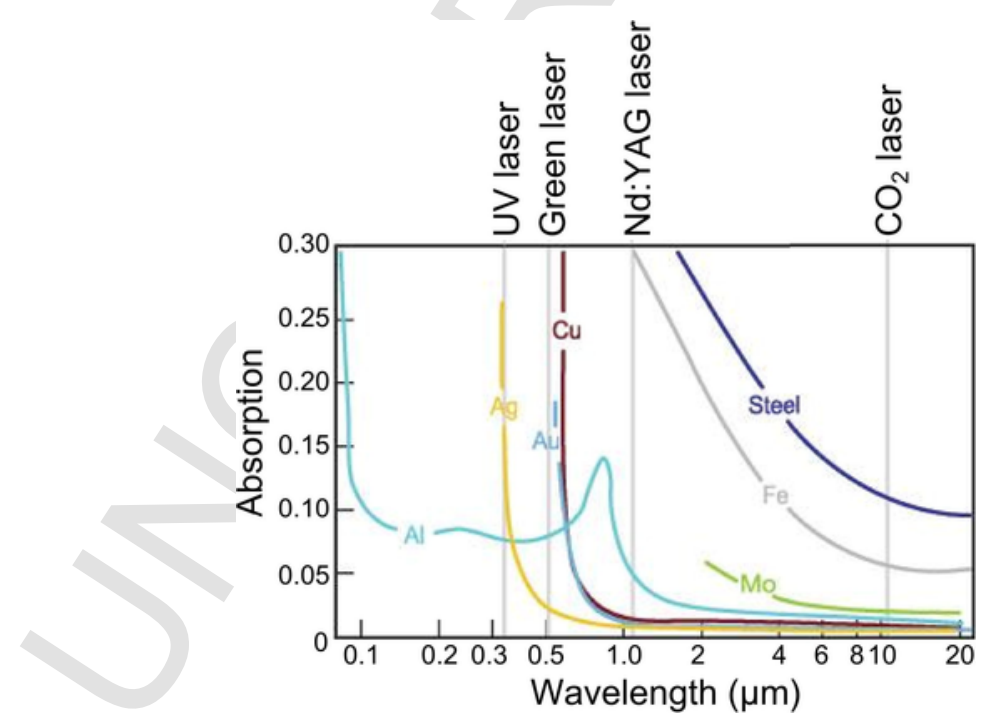

Fig. 7. Absorption of a number of metals as a function of laser beam radiation wavelength (adapted from [38]). 
The process is simple to control and, thus, it was studied for joining NiTi. However, it is a thermomechanical welding process and it is well established the sensitiveness of functional properties of NiTi, so a good heat distribution is a requirement.

Basic research on micro-resistance welding (MRW) was performed by Tam et al. [40] especially in crossed wires of $0.5 \mathrm{~mm}$ diameter. The group studied the bonding mechanisms as well as the mechanical properties, the microstructural features and phase transformations. Heat generated during welding locally annealed the strain hardened material, altering the transformation temperatures of the weld metal, as expected, which were similar to solution treated material. The bonding mechanisms involved are described to be mostly in solid state bonding involving interfacial melting and dynamic recrystallization, amongst other.

Besides the applications of MRW, an interesting study was performed by [41] in resistance welding when joining thin walled NiTi tubes to create ordered architectural cellular structures as an alternative to other manufacturing technologies to produce porous structures in NiTi for biomedical and other applications. Two tubes were joined along their generatrix, using superelastic NiTi with $7 \mathrm{~mm}$ outer diameter and a wall thickness of $0.2 \mathrm{~mm}$. The welding process was seen to highly affect the transformation behaviour, microstructure and mechanical properties of the joint, so annealing treatments in different conditions of maximum temperature and time were conducted in a post weld heat treatment. The authors demonstrated that RW was a feasible technique for joining NiTi in complex structures with low density and reversible elasticity.

\subsection{Solid-state processes}

Independently of the welding process, melting always involves solid-liquid-solid transformations, and these are accompanied by dimensional variations, distortions and residual stresses. So, solid-state welding processes can prevent these, as well as, the formation of undesired phases formed during solidification and in solid state upon cooling. For this, several solid-state processes have been studied to join NiTi.

\subsubsection{Explosive welding}

Explosive welding is, eventually, the first solid-state process studied to weld NiTi. In this process, detonation of explosives is used to bring the weld surfaces of the materials to be joined in a very high velocity oblique collision [42]. As a consequence of the impact, a severe, but localized plastic flow at the interacting surfaces is created. Due to the dynamics of the process high temperatures may occur at the weld interface. The major advantage of such techniques is for joining dissimilar metal combinations that are impossible by other methods. Nevertheless, similar joining using explosive welding is also possible.

First studies reported on using explosive welding to join NiTi were for dissimilar welding with steel [43-45]. In these studies a common objective was aimed: take advantage of the high resistance of NiTi to cavitation erosion, when compared to the alloys used to build pumps and hydroturbines, and join it with low-carbon steel which provided the structural strength for such application.

Zimmerly et al. [43] welded austenitic NiTi to low carbon steel. After welding, the NiTi interface was observed by X-ray diffraction and low-intensity martensite peaks were identified due to the formation of shock-induced martensite during welding. One of the largest challenges for such type of works is, mainly, to maintain an austenitic interface after joining, as this phase shows a better resistance to cavitation erosion than martensite. As a consequence of the plastic deformation and defect production during the shock loading, an increase of NiTi hardness was observed. As far as the cavitation erosion properties of the as-welded material are concerned, a slight decrease was observed when compared to the NiTi base material. However, post-weld heat treatments restore most of the lost resistance. The effect of the welding parameters on the interface resistance could not be assessed, as failure during tensile lap shear tests occurred, either in the NiTi or in the low-carbon steel, but never at the bond interface. Richman et al. [44] added new results on joining martensitic NiTi to the same steel by explosives. Those results agreed with Zimmerly et al. [43], as the welded austenitic NiTi required a post-weld heat treatment in order to recover most of the erosion resistance lost due to the welding technique. On the other hand, the effect of post-weld heat treatments on the as-welded martensitic NiTi was not evident to be beneficial to the cavitation-erosion resistance of the welded joint.

More recently, and after the preliminary work of Prummer et al. [46], Belyaev et al. [47-49] produced NiTi/stainless steel composites by explosive welding. In $[47,48]$ it was shown that the plastic deformation induced during welding lead to a partial depression of the martensitic transformation, but with a post-weld heat treatment, the kinetics of this transformation could be recovered. No brittle intermetallics between NiTi and stainless steel were found after explosive welding. Later, in [49] NiTi/ stainless steel composites were studied under repeated thermal cycling, showing the shape memory effect. The recoverable strain exceeded the value for the two-way shape memory effect of the NiTi base material, due to the action of the elastic steel layer. It was concluded that, such a bimetal composite produced via explosive welding, could be used as an actuator due to its functional properties.

Explosive welding for joining NiTi to itself was also studied by several authors [50-55]. In these studies, two different NiTi alloys, with different compositions and transformation temperatures, were used. The objective was to obtain a NiTi/NiTi composite with macroscopic heterogeneities in chemical composition. In [50-52,54,55], after explosive welding of NiTi to itself a controlled thickness reduction was performed and the effect of heat treatments on the transformation temperatures to the welded joints was analysed. As expected, by a proper selection of the heat treatment temperature, the martensitic transformation could be adjusted so that the hysteresis of the transformation varied depending on the foreseen application. Xing et al. [54] studied the damping behaviour of NiTi/NiTi explosive joints and found that the internal friction peaks, which are related to the phase fractions ratio austenite/martensite, of the two base materials had a different role on the damping behaviour, depending on the test- 
ing temperature. This was due to the different transformation temperatures that are known to influence the damping behaviour of NiTi shape memory alloys [56].

Although, explosive welding for joining NiTi to itself and to steel, both stainless and low-carbon, were already successfully performed, some issues still need to be addressed. In applications where very high strain rates are applied, such as in explosive welding, material models are necessary to describe the dependence of the flow stress on temperature, strain rate and pressure during the process [57]. For shape memory alloys, their unique mechanical properties of these materials pose additional theoretical and computational challenges.

\subsubsection{Friction welding}

Friction welding is achieved due to the frictional heat generated on the surface between two work pieces under rapid rotation while being pressured together [58]. Due to the increasing heat generated during this process, the surfaces soften, plasticize and can mix together. As such, it is required that at least one of the materials to be joined can withstand significant torque [59]. The strength of friction welded joints can overcome that of the base materials to be joined.

Friction welding has several variants which are dependent on the processes and equipment involved: linear friction welding [60]; rotary friction welding [61]; spin welding [62]; inertia friction welding [63]; and friction stir welding [25]. From these, friction stir welding is the most recent and, as such, special attention has been devoted to this technique.

In FSW, a non-consumable rotating tool consisting of a pin and a shoulder moves along the joint, rigidly clamped [64] under an axial forging force. Due to the friction between the moving tool and the work piece, as well as, to internal friction during plastic deformation, heat is developed which increases the viscoplasticity of the materials and allows mixing of both materials in order to form a weld in the solid state, that is, without any melting. During stirring, the temperature increases due to plastic deformation and originates dynamic recrystallization producing an equiaxial refined grain structure in the stirred zone. One of the important advantages of friction stir welding is the low energy consumption, compared to other fusion welding processes [65], and is environmental friendly since no gas, fumes or particles are emitted.

Shinoda et al. $[66,67]$ joined NiTi rods and observed a grain refinement due to dynamic recrystallization in the stirred zone, as expected. Increasing the applied pressure, the grain size in the dynamically recrystallized zone decreased. The UTS of the welded joints was similar to that of the base material, but with a lower elongation to fracture $[66,68]$. Post-weld heat treatments were seen to improve the functional properties of the welds, which were then similar to those of the base material.

Friction stir processing is a variant of friction stir welding with the objective to modify the in-volume or surface properties of a material, though it can also be used for joining thin sheets in overlap configuration. Friction stir processing was studied to assess its feasibility for joining NiTi [69] and confirmed that superelasticity and shape memory effect were preserved [70]. Additionally, NiTi particles were added to an Al matrix creating a NiTi/Al composite [71,72]. Good bonding between the NiTi particles and the Al was observed under SEM and no harmful interfacial products were observed. With appropriate processing parameters and suitable size of the introduced NiTi particles, the tensile strength of the NiTi/Al composite could surpass that of the Al base material [72]. More recently, NiTi/Al composites were successfully obtained by FSW assisted by electrical current [73]. With this hybrid variant of FSW it was possible to improve bonding between NiTi and Al.

Dissimilar joints of NiTi to stainless steel were produced by rotary friction welding with and without a Ni interlayer [74]. Optical microscopy of the joints produced with the Ni interlayer (Fig. 8) revealed a planar interface without intermetallic phases. In

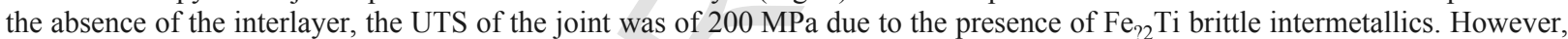
this phase was avoided and the UTS increased to $510 \mathrm{MPa}$ when the Ni interlayer was used. Although the welding time was short, a $\mathrm{NiTi}+\mathrm{Ni}_{\text {?3 }} \mathrm{Ti}$ eutectic layer was observed at the $\mathrm{NiTi} / \mathrm{Ni}$ interface.

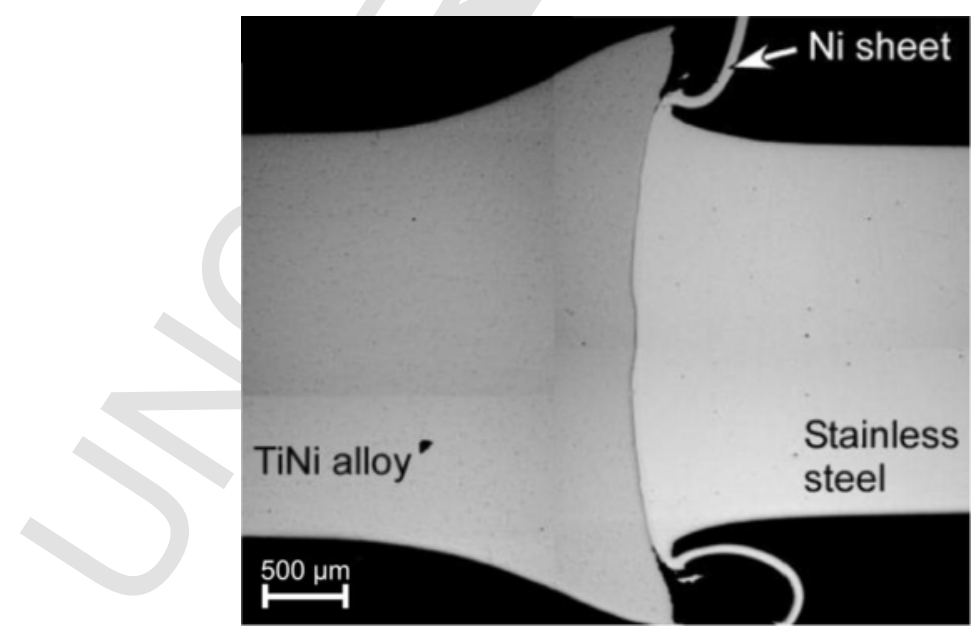

Fig. 8. Optical micrograph of the NiTi/stainless steel joint produced by friction welding using a Ni interlayer (adapted from [74]). 
Significant research work still needs to be performed on friction based processes to weld NiTi, in particular with friction stir welding in order to assess the effect of this process on the mechanical and functional properties of welded NiTi.

\subsubsection{Ultrasonic welding}

In ultrasonic welding, the parts to weld are pressed by a static compressive load while a high frequency mechanical vibration is induced by a piezoelectric transducer. The piezoelectric transforms electric current into high frequency mechanical vibration. Ultrasonic transducers drive the transversely vibrating tip of the sonotrode which is pressed against the top work piece. The high frequency vibration applied locally generates friction between the surfaces, increasing the temperature in the interface well below the material recrystallization temperature and causes plastic deformation of the faying surfaces in contact. The combination of the static compressive load and the shear forces due to vibration, originates a dynamic stress field and an elastoplastic deformation.

This relative interface movement cause shear deformation of contacting surface asperities, dispersing interface oxides and ultimately bringing clean metal-to-metal contact and adhesion between the surfaces. Atomic diffusion along the interface assists bonding and the final weld has a fine isotropic grain structure. The energy required is directly proportional to the material hardness and thickness. Other process parameters are: the contact force, the ultrasonic wave amplitude and the time to weld. However, ultrasonic welding is limited to small parts and thin materials.

Some authors have attempted to use ultrasonic additive manufacturing for metallic matrix composites reinforced with micrometric wires of NiTi. The composites envisaged find applications in adaptive or smart structures that can monitor their condition, control, or even, heal damage and adapt to environments [75,76].

These applications aimed at consolidating embedded NiTi SMAs in an Al matrix around the reinforcing fibres to improve bonding quality without affecting the functional properties of the alloys. Using low pressure and oscillation amplitude no material degradation was observed, but it was seen that bonding was stronger when the temperature increased to about $300{ }^{\circ} \mathrm{C}$, that is $25 \%$ the melting point of NiTi. However, when the applied pressure was high, transformation of austenite occurred with detrimental effect on the overall properties of the composite. When the NiTi wires undergo martensite to austenite transformation, an increase in composite stiffness of $6 \%$ was measured, as well as, a reduction in resistivity of $3 \%$ [77].

\subsubsection{Adhesives joining}

Adhesive bonding is another joining technique that can be tailored according to the requirements of the materials to be joined. Bonding by adhesives is of particular importance for the manufacturing of lightweight constructions. Compared to mechanical joints, it allows for a homogenous stress-distribution when the joint is loaded [78], which is rather beneficial when fatigue is an issue.

In order to have successful joints by adhesive bonding, the quality of the materials surfaces is of major importance which implies, very often, a previous surface treatment to maximize the degree of molecular interaction between the substrate and the adhesive [79]. Additionally, surface treatments can be used to obtain a more suitable microstructure on the substrates in order to improve adhesion.

Adhesive bonding can be easily integrated into most industrial sequences allowing great flexibility in terms of design and production [80]. Also, with such technique, large surface areas can be joined together. However, an important disadvantage of the use of adhesives for material's joining is its limited heat resistance, which may prevent the use of adhesive joints in aggressive environments.

Several parameters have a key role in order to promote a sound bond between the adhesive and the substrates to be joined. Some of the most relevant to be addressed are: adhesive chemistry; type of adhesive cure; substrate compatibility; joint design and its function [81].

In this review on the adhesive bonding of NiTi shape memory alloys, attention is only given to the cases where conventional joining by adhesives (using overlap joint configuration) was performed.

The first experimental work analysing adhesive bonding between two NiTi plates was done by Man et al. [82] to modify the superficial texture of NiTi in order to enhance the adhesion properties of the surfaces. Bonding between two NiTi plates was achieved by irradiating the joint with a laser, while high purity nitrogen gas was discharged onto the molten pool. Later, etching was performed in order to promote a three-dimensional TiN dendritic structure protruding from the NiTi substrate. These three-dimensional structures can be generated due to the different etching rates of pure TiN and NiTi. Since TiN possesses a better corrosion resistance, NiTi is preferentially removed during etching leaving behind the TiN dendrites. The TiN phase is created due to the reaction of the Ti atoms with the $\mathrm{N}$ atoms when the NiTi surface melts. Due to the Marangoni effect [15], TiN is transferred towards the bottom of the weld pool, allowing the formation of a dendritic structure as observed in Fig. 9. With an appropriate etching time, the adhesive strength could increase up to $150 \%$ when compared to sandblast etched samples used for control. The reason for such an improvement was related to more protruding dendrites obtained after longer etching times. As such, more locking sites were available resulting in a higher adhesion and strength.

The mechanical and functional properties of single lap adhesive bonded NiTi joints were assessed also by Niccoli et al. [83]. Different surface treatments were analysed. Chemical etching was disregarded due to significant material loss. Sandblasting and degreasing were also considered as surface treatments. Degreasing did not modify the surface roughness, in opposition to sandblasting which was able to increase it. Tensile tests performed on the bonded joints in the martensitic state revealed higher UTS when these were produced after sandblasting (up to $330 \mathrm{MPa}$ and $9 \%$ strain vs $210 \mathrm{MPa}$ and $5.8 \%$ strain for degreased joints as 


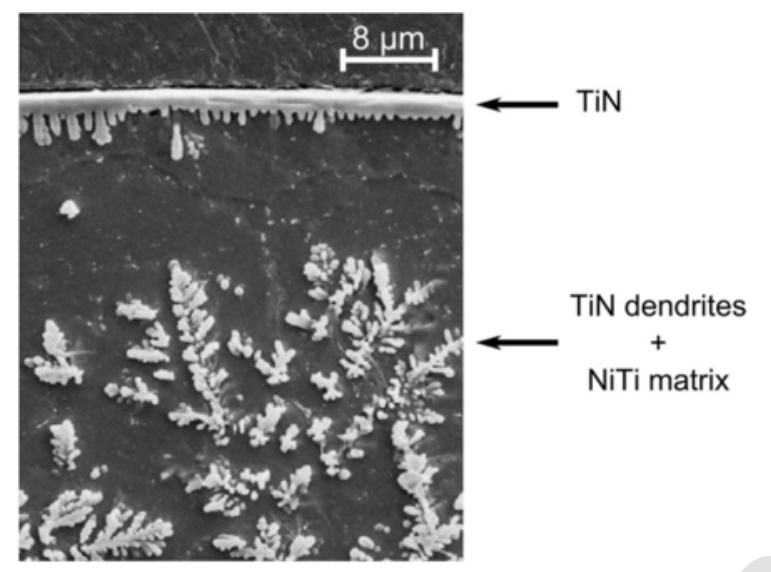

Fig. 9. Optical micrograph of the cross section of the laser gas nitride NiTi joint (adapted from [82]).

depicted in Fig. 10). After training, the bonded joints were able to exhibit complete shape memory recovery, indicating that the functional properties were preserved after adhesive bonding.

Although several studies have addressed the adhesion interaction in composites using polymers with embedded NiTi, there is a significant lack of research on the study and production of NiTi joints (either similar or dissimilar) by adhesive bonding. Considering that this technique is widely used in the automotive and aerospace industries, understanding the feasibility of its application to NiTi shape memory alloys might boost the use of these joints.

\subsubsection{Brazing and soldering}

In brazing and soldering, joining is achieved by a low melting temperature filler material [84], lower than $450{ }^{\circ} \mathrm{C}$ in brazing, or above this in soldering [85], while the base materials are in the solid state. When the filler is melted by arc or a chemical energetic process, it wets the materials surfaces creating a bond by short distance diffusion mechanisms to the surrounding solid base materials.

The right choice of the braze alloy is of great importance: its mechanical properties, wettability and possible formation of brittle intermetallics with the materials to be joined must be considered when selecting the filler.

The time to melt the filler depends on its melting temperature [86] and heating method [87,88], which can be performed on furnace, by microwave or infrared radiation to have fast thermal cycles [89].

Both similar and dissimilar NiTi brazed joints were investigated. For the similar brazed joints, mainly two distinct filler materials were used: $\mathrm{Nb}$ and Ag-based alloys. Dissimilar brazing involving NiTi mostly involve NiTi/stainless steel joints, despite $\mathrm{NiTi} / \mathrm{Ti} 6 \mathrm{Al} 4 \mathrm{~V}, \mathrm{NiTi} / \mathrm{NiAl}$ and others have also been studied.

The first work reported on similar joining of NiTi by brazing techniques was presented by Yang et al. [90] using $\mathrm{Cu}$ and $\mathrm{Ti}-15 \mathrm{Cu}-15 \mathrm{Ni}$ as filler materials heated by infrared laser. The influence of the filler material on the functional properties of the brazed joint was evident: when using $\mathrm{Cu}$ as filler, full recovery by shape memory effect was observed, while with $\mathrm{Ti}-15 \mathrm{Cu}-15 \mathrm{Ni}$ filler no bending tests could be performed due to the brittleness exhibited by the joint, resulting from the presence of $\mathrm{Ti}_{? 2}(\mathrm{Ni}, \mathrm{Cu})$.

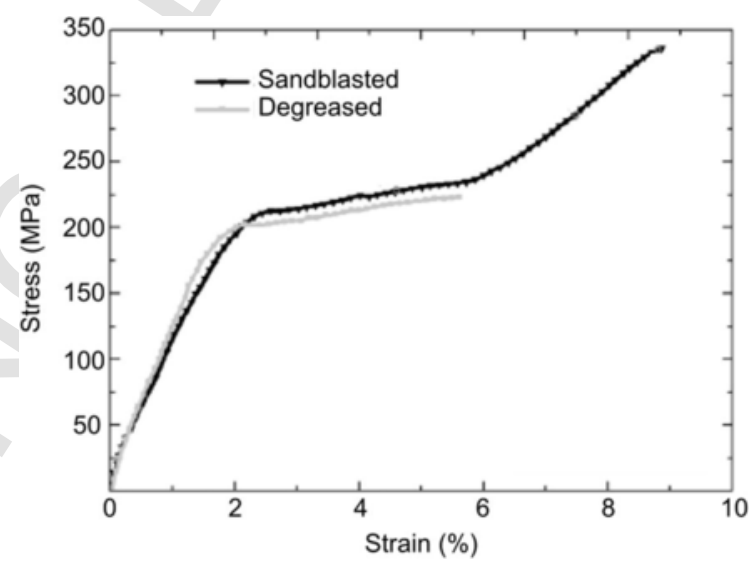

Fig. 10. Stress-strain curves for sandblasted and degreased adhesive bonded NiTi joints (adapted from [83]). 
Later, Grummon et al. [91-94] used $\mathrm{Nb}$ as a filler material and performed brazing in a vacuum furnace. Cellular NiTi structures formed and since $\mathrm{Nb}$ was placed in close contact to $\mathrm{NiTi}$, an eutectic reaction occurred around $1180{ }^{\circ} \mathrm{C}$. Time-resolved microstructural observations of the brazed joint are presented in Fig. 11. It can be seen that after just $1 \mathrm{~s}$ significant progression of the melting had already occurred. Increasing the brazing time, $\mathrm{Nb}$ is consumed and the amount of pro-eutectic NiTi decreases.

Mechanical properties of these cellular honeycomb structures, which had a relative density of only $5 \%$, revealed very interesting mechanical properties: superelasticity was observed, with up to 50\% compressive strains recovered upon unloading [93].

Wang et al. [95] also took advantage of the eutectic reaction created between $\mathrm{NiTi}$ and $\mathrm{Nb}$ to braze NiTi wires with $\mathrm{Nb}$ powders deposited on the contact areas of the wires, in a furnace. The advantage of using $\mathrm{Nb}$ to promote joining by brazing, aside from creating an eutectic reaction with $\mathrm{NiTi}$, is its biocompatibility [96] and its influence to widen the hysteresis of the transformation temperatures of $\mathrm{NiTi}[97,98]$.

$\mathrm{Ag}$ and Ag-based fillers are also widely used in brazing due to their low melting temperatures. Several works have addressed the influence of Ag-based filler materials on the joint characteristics of NiTi/NiTi brazed joints [99-101]. Different fillers and heating methods were tested. Shiue et al. [99] used an infrared laser to melt Ag-Cu-Ti braze alloys (two different compositions) and join equiatomic NiTi. The joints with either of the brazing alloys had Ag-rich, Cu-rich and Ti-rich phases, but the shear properties were not affected by the braze alloys. However, the exact composition of the braze alloy was found to have significant influence on the shape memory recovery: higher Ti content created joints with superior shape memory recovery $(92 \%$ vs $64 \%$ of the applied deformation). This significant difference was attributed to the different microstructures originated by each brazing alloy. The presence of CuNiTi had a detrimental effect on the shape memory recovery.

Eijk et al. [100], brazed NiTi with Ag-Ti and Ag-Cu-Ti braze alloys in a microwave. With both of these alloys joining was achieved with a significant difference of the existing phases after the brazing process. Ag-Cu alloy was used for vacuum furnace brazing of NiTi by Zhao et al. [101]. Lap joints were prepared and it was observed that after a given lap length the strength of the brazed joint was higher than that of the base material. However, when the lap length was below 3 mm, the diffusion layer created between $\mathrm{NiTi}$ and the $\mathrm{Ag}-\mathrm{Cu}$ braze was found to be the weakest region of the joint. The brazed joints were found to exhibit full recovery by shape memory effect when the applied strain was below $4 \%$. Above this deformation, even after triggering the shape memory effect, some irrecoverable strain was observed.

Similar brazing of NiTi assisted by infrared laser was also accomplished using pure $\mathrm{Cu}$ and Ti-Cu-Ni alloy as filler materials [90]. It was observed that the brazing parameters had significant influence on the shape memory recover of the joints: longer brazing times originated decreasing amounts of CuNiTi phase, which was detrimental for the shape memory recovery. Significant formation of $\mathrm{Ti}_{? 2}(\mathrm{Ni}, \mathrm{Cu})$ resulted in high brittleness of the brazed joints.

Significant research work has been devoted to cope with dissimilar joining of NiTi to other engineering materials. Gale et al. [102] investigated martensitic NiTi and NiAl furnace brazed using $\mathrm{Cu}$ as a filler material. Likewise to NiTi, NiAl alloys also exhibit shape memory effect [103]. Although no significant microstructural changes were detected in the NiAl substrate, Ti migration from NiTi lowered the transformation temperatures of the NiTi substrate and thus, austenite was present at room temperature. In the bond-line between the two base materials, $\mathrm{Ni}_{? 3} \mathrm{Ti}$ with a $\mathrm{D}_{? 24}$ structure was observed. Interestingly, some of these precipitates adopted a metastable L12 structure due to the high Ni content in this region.

From the available literature on dissimilar brazed joints, the NiTi/stainless steel combination using Ag-based braze alloys is the most studied [100,104-106]. Li and his co-workers [104,106] analysed the effect of brazing parameters on the microstructure and mechanical properties of NiTi/stainless steels joints brazed by laser using Ag-based (Ag-Cu-Zn-Sn) filler material. Good wettability of the braze alloy with both base materials was observed, as shown in Fig. 12. Within the brazing joint, $\alpha-A g, A g Z n$, $\mathrm{Ag}_{? 3} \mathrm{Sn}$ and $\mathrm{Cu}_{25} \mathrm{Zn}_{? 8}$ were detected by X-ray diffraction analysis. Diffusion of $\mathrm{Ag}, \mathrm{Cu}$, Sn and $\mathrm{Zn}$ into the two base materials was observed due to the formation of a diffusion reaction layer. Similarly, Ni and Ti from NiTi, and Fe, Cr and Ni from the stainless steel diffused to the braze alloy during the joining process. Hardness measurements revealed that a significant decrease, com-
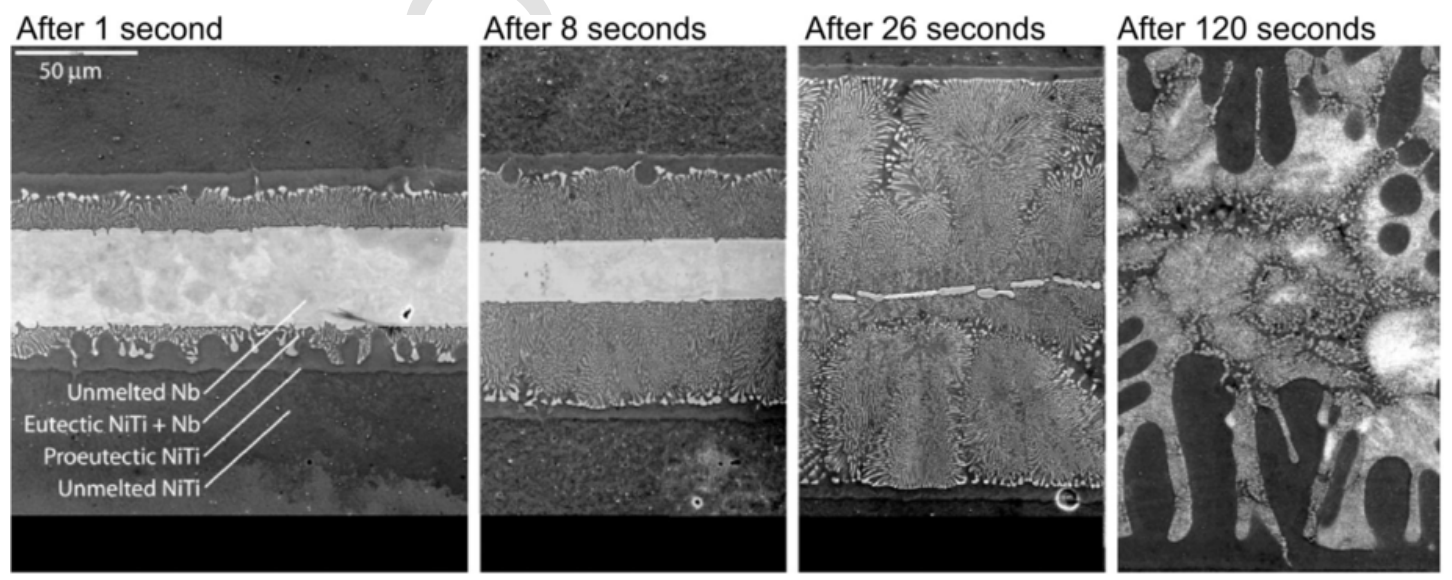

Fig. 11. Time-resolved development of the brazed microstructure (adapted from [91]). 


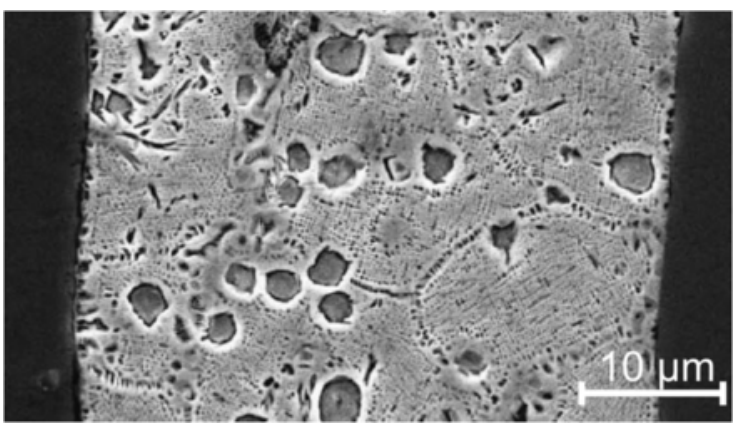

Fig. 12. SEM imaging of the microstructure in a dissimilar stainless steel-NiTi laser-brazed joint. Stainless steel is positioned on the left side, while NiTi on the right side (adapted from [104]).

pared to both base materials, occurred in the joint centreline due to the formation of soft phases. By adjusting the brazing parameters, a maximum strength of $360 \mathrm{MPa}$ was achieved [106]. Although the superelastic behaviour of the brazed joint was not studied, local analysis of the NiTi HAZ shown a decrease in its superelastic properties due to a coarse grain structure. Similarly, deterioration of shape memory effect in the thermal affected NiTi region was observed ( $91 \%$ recovery vs $100 \%$ of the base material).

The same authors have also studied the corrosion behaviour of their laser brazed NiTi/stainless steel joints in artificial saliva [105]. Although the brazed joint had lower corrosion resistance than the stainless steel, it was higher than the filler material and similar to NiTi. However, the $\mathrm{pH}$ value of the artificial saliva influenced the corrosion behaviour: in more acidic environments (lower $\mathrm{pH}$ ) the corrosion resistance decreased. No significant change in the mechanical properties, in terms of the tensile strength and shape memory recovery after bending, of the NiTi HAZ was observed after the corrosion tests. In the former, a $25 \mathrm{MPa}$ decrease was observed, while in the latter only a 3\% change was measured. It must be noticed that the mechanical properties of the dissimilar brazed joints using Ag-based filler can meet requirements for orthodontic applications, as the maximum load during orthodontic clinic is significantly below the maximum load sustained by the joints [107]. Changing the filler material from Ag-based to $\mathrm{Cu}$ did not revealed any significant modification of the mechanical properties of the brazed dissimilar joints.

Successful joining between NiTi and stainless steel was reported by Satoh et al. [108,109] in "laser autogenous brazing". In this process there is no filler material and the laser parameters have to be carefully controlled so that the base material irradiated by the laser beam does not exceed its melting point. In the NiTi/stainless steel dissimilar joints, the laser was positioned either on the stainless steel side or on the NiTi side and moved towards the interface between both materials. Thermal resistance of the interface causes an increase of temperature up to its melting point. When the laser beam reached the interface, it was turned off and the liquid layer quickly quenched due to the contact with adjacent cold base material. Advantages of this method are the high quench rate, the minimization of mixing between the two materials and localized melting in just one material. Appropriate brazing parameters decreased the mixed layer formed and maximized the strength up to $500 \mathrm{MPa}$, which is higher than the onset for the stress induced transformation. Nevertheless, during the tensile tests, no evidence of the superelastic plateau was observed.

NiTi was also brazed to Ni-based superalloy (Hastelloy C-276) by microwave using AgTi filler [100]. Excessive porosity was observed which is detrimental for the mechanical properties of the joints. Multi-diffusion occurs throughout the brazed joints leading to a complex microstructure. It is apparent that the AgTi filler is not a suitable choice for joining both NiTi and Hastelloy.

Brazing NiTi to NiTiNb was successfully obtained by Zhao et al. [110] using an Ag-Cu filler in a vacuum furnace. The most interesting remark from this study was the wide recovery temperature range from -60 to $+45^{\circ} \mathrm{C}$. Laser brazing NiTi to Ti6Al4V using Ag nanoparticles was attempted by Quintino et al. [111]. However, poor adherence of the nanoparticles to the base materials was observed, indicating that joining between NiTi and Ti6Al4V was not efficiently promoted.

NiTi and low carbon steel rod were brazed assisted by oxyacetylene flame, using Ag-based filler material [112]. Sound joints were obtained and these were mechanically cycled, without fracture, up to $60 \mathrm{load} /$ unload cycles within the superelastic plateau and very close to their UTS. As such, this process can be promising for structural applications in civil engineering where a not expensive process is required.

NiTi was also used as a braze alloy by Munez et al. [113] for joining W to ferritic-martensitic steel for a divertor application $[114]$ in fusion reactors. Good wettability between NiTi and the base materials, due to the existence of Ti, ensured sound joining. Also, as the thermal expansion of NiTi was between those of the base materials, the thermal stresses originated upon cooling decreased, and so did the risk of cracking in the brazed joint.

\subsubsection{Diffusion and reactive diffusion bonding}

In diffusion bonding, the joining mechanism is dependent on the interdiffusion of atoms across the interface between the surfaces to be joined [115]. For interatomic bonds to be established, the materials must be in close contact, that is, within the atomic 
spacing. However, virtually, there is no effective way to ensure such close contact and several factors prevent this intimate proximity, the most important ones being related to the surface conditions, namely the surface geometry and roughness and the presence of impurities and oxides. In diffusion bonding, the parts to join are placed under pressure to eliminate the surface asperities and below the yield strength of the materials to avoid macroscopy deformation. The temperature can range between 0.5 and 0.8 of the absolute melting temperature of involved materials to improve diffusion [116]. The time necessary for diffusion bonding can range between few minutes up to several hours [117].

Although this is a solid-state technique, it is possible to have some liquid material in the joint interface, if a low melting temperature interlayer is used that may form a low melting eutectic phase (usually Copper) [115]. In this case, joining is produced by a transient liquid phase diffusion bonding [118].

Some of the advantages of diffusion bonding are: low deformation of the joints; ability to join large areas; the thermal gradient tends to be smaller than those in fusion based processes [119]. However, specimen preparation and joint fit-up require extreme caution has they significantly influence the ability to obtain a sound joint.

Diffusion bonding involving NiTi is recent and the available literature is scarce. Senkevich et al. [120] studied the effect of bonding temperature and holding times on the mechanical properties of the similar joints: increasing the temperature (ranging from 800 to $1100{ }^{\circ} \mathrm{C}$ ) and/or the holding time (from 5 to $60 \mathrm{~min}$ ) improved the mechanical properties. High temperatures and prolonged times were required to obtain high quality diffusion bonded joints. However, it was observed the formation of brittle intermetallics such as $\mathrm{Ti}_{? 2} \mathrm{Ni}$ and $\mathrm{Ti}_{?_{4}} \mathrm{Ni}_{{ }_{2}} \mathrm{O}$, created by the interaction of the bonded surfaces with residual oxygen. The affinity of $\mathrm{Ti}$ to $\mathrm{O}$ at high temperatures required high vacuum environments. NiTi base material microstructure was also of great importance

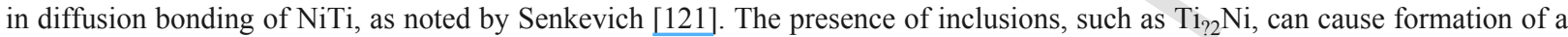
liquid phase by an inverse peritectic reaction: $\mathrm{Ti}_{{ }_{2}} \mathrm{Ni} \rightarrow \mathrm{L}+\mathrm{NiTi}$, after holding times above $2 \mathrm{~h}$. By decreasing, or avoiding, the presence of such intermetallics, melting during the bonding process decreases, and so does the degradation of the bonded joints.

Senkevich et al. [122] and Cavaleiro et al. [123] produced NiTi/Ti6Al4V joints by diffusion bonding. In [122] the optimum temperature ranged between 900 and $950{ }^{\circ} \mathrm{C}$, with a welding time between 30 and 60 min, using a contact pressure of $5 \mathrm{MPa}$. For these parameters range, the tensile strength of the joints reached a maximum of $170 \mathrm{MPa}$, which was higher than the $107 \mathrm{MPa}$ reported for laser welding of the same dissimilar combination [21].

Cavaleiro et al. [123] deposited Ni/Ti nanometric multilayers by sputtering onto the two base materials. The use of such layers provides extra energy at the interface, in a reaction-assisted diffusion bonding process, thus reducing the bonding temperature [124]. In-situ X-ray diffraction analysis, using synchrotron radiation, allowed to observe the formation of brittle intermetallics, such as $\mathrm{Ti}_{? 2} \mathrm{Ni}$ at $750{ }^{\circ} \mathrm{C}[123] . \mathrm{Ti}_{? 2} \mathrm{Ni}$ intermetallics were also observed in [122] giving raise to significant hardness increase when compared to the base materials. Optical microscopy of the reaction-assisted diffusion joints revealed a high quality joint, with an almost non-detectable bond-line between the two materials (Fig. 13). The influence of the Ni/Ti multilayers was proven very effective in decreasing the temperature required for joining $\mathrm{NiTi}$ to Ti6Al4V: sound joints were produced above $900{ }^{\circ} \mathrm{C}$ [122], but also at $750{ }^{\circ} \mathrm{C}$ [123]. Thus, for industrial applications, this temperature drop may be an economic advantage.

Despite the fact that just recently diffusion bonding, started to be applied to NiTi, it is clear that this processing is an interesting one either for similar or dissimilar material combinations especially in microjoining or when joining small parts. Additionally, it is expected that other dissimilar material combinations, relevant for industrial applications, may be studied.

To summarise, Table 1 presents a comparison of the most relevant advantages and disadvantages of each welding process discussed within this review.

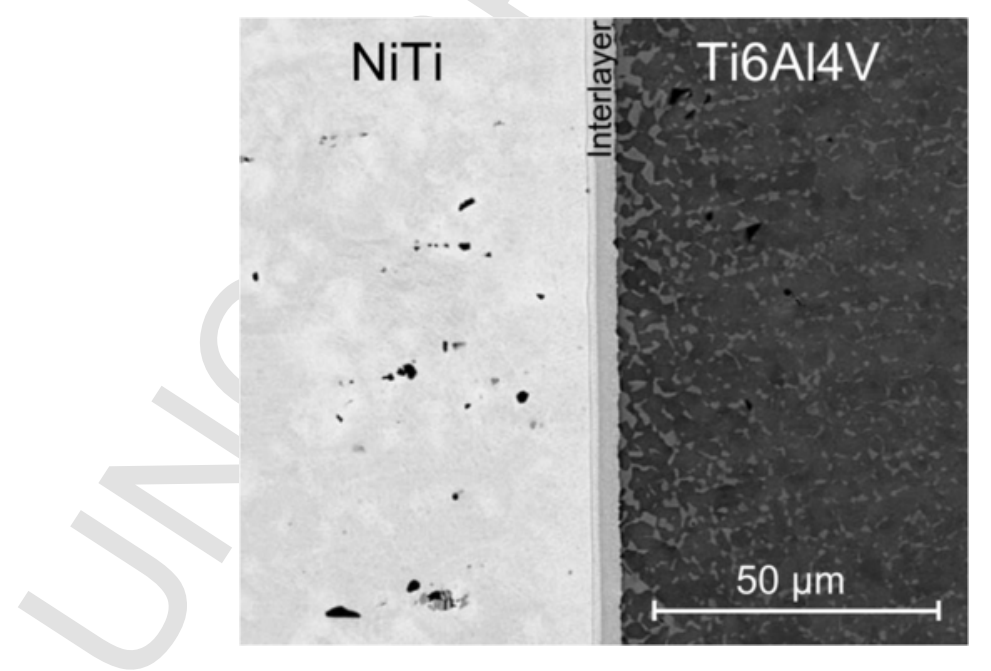

Fig. 13. SEM imaging of the NiTi/Ti6Al4V joint using Ni/Ti multilayers (adapted from [123]). 
Table 1

Comparison of the different joining techniques for NiTi shape memory alloys: main characteristics, benefits, limitations and existing works.

\begin{tabular}{|c|c|c|c|c|}
\hline Process & $\begin{array}{l}\text { Main } \\
\text { characteristics }\end{array}$ & Benefits & Limitations & Existing works \\
\hline TIG & $\begin{array}{l}\text { - Fusion weld- } \\
\text { ing by electric } \\
\text { arc } \\
\text { - Inert shield- } \\
\text { ing gas }\end{array}$ & $\begin{array}{l}\text { - Low heat input } \\
\text { - Simple welding } \\
\text { source } \\
\text { - Flexible and } \\
\text { easy to use } \\
\text { - Wide range of } \\
\text { material thick- } \\
\text { ness above } \\
1 \mathrm{~mm}\end{array}$ & $\begin{array}{l}\text { - Manual process } \\
\text { - Low productivity } \\
\text { - Possibility of tungsten inclu- } \\
\text { sions } \\
\text { - Possibility of element } \\
\text { volatilization and material oxi- } \\
\text { dation } \\
\text { - Environmental problems }\end{array}$ & {$[29,32-35]$} \\
\hline Laser beam & $\begin{array}{l}\text { - Fusion weld- } \\
\text { ing } \\
\text { - Monochro- } \\
\text { matic light } \\
\text { beam radia- } \\
\text { tion }\end{array}$ & $\begin{array}{l}\text { - No contact with } \\
\text { heat source } \\
\text { - Small interac- } \\
\text { tion area } \\
\text { - High energy } \\
\text { density } \\
\text { - Minimal heat } \\
\text { input } \\
\text { - Narrow HAZ } \\
\text { and FZ } \\
\text { - Low thermal } \\
\text { damage and } \\
\text { distortions } \\
\text { - High precision } \\
\text { - Automatic or } \\
\text { robotised } \\
\text { - High welding } \\
\text { speed }\end{array}$ & $\begin{array}{l}\text { - Complex to use } \\
\text { - Fixing devices and dimensional } \\
\text { tolerances } \\
\text { - Equipment and running costs } \\
\text { - Preferential volatilization of } \mathrm{Ni} \\
\text { giving rise to local changes of } \\
\text { functional characteristics } \\
\text { - Expensive process }\end{array}$ & {$[17-19,125-171,172-191]$} \\
\hline
\end{tabular}


Table 1 (Continued)

\begin{tabular}{|c|c|c|c|c|}
\hline Process & $\begin{array}{l}\text { Main } \\
\text { characteristics }\end{array}$ & Benefits & Limitations & Existing works \\
\hline $\begin{array}{l}\text { Electron } \\
\text { beam }\end{array}$ & $\begin{array}{l}\text { - Fusion weld- } \\
\text { ing } \\
\text { - Electron } \\
\text { beam radia- } \\
\text { tion }\end{array}$ & $\begin{array}{l}\text { - No contact with } \\
\text { heat source } \\
\text { - Small interac- } \\
\text { tion area } \\
\text { - High precision } \\
\text { - High energy } \\
\text { density } \\
\text { - Minimal heat } \\
\text { input } \\
\text { - Narrow HAZ } \\
\text { and FZ thermal } \\
\text { - Low tam and } \\
\text { damage } \\
\text { distortions } \\
\text { - No oxidation or } \\
\text { contamination } \\
\text { - Automatic or } \\
\text { robotised }\end{array}$ & $\begin{array}{l}\text { - Complex to use } \\
\text { - Fixing devices and dimensional } \\
\text { tolerances } \\
\text { - Time of preparation } \\
\text { - Vacuum chamber } \\
\text { - Equipment and running costs } \\
\text { - Expensive process }\end{array}$ & {$[36,37]$} \\
\hline Resistance & $\begin{array}{l}\text { - Fusion weld- } \\
\text { ing } \\
\text { - Joule effect } \\
\text { - Pressure }\end{array}$ & $\begin{array}{l}\text { - Simple to apply } \\
\text { and control } \\
\text { - Simple equip- } \\
\text { ment }\end{array}$ & $\begin{array}{l}\text { - Joint configuration limited to } \\
\text { overlap } \\
\text { - Size of components } \\
\text { - Non continuous joining }\end{array}$ & {$[40,41]$} \\
\hline $\begin{array}{l}\text { Explosion } \\
\text { welding }\end{array}$ & $\begin{array}{l}\text { - Solid state } \\
\text { process } \\
\text { - Plastic defor- } \\
\text { mation }\end{array}$ & $\begin{array}{l}\text { - Dissimilar join- } \\
\text { ing } \\
\text { - Simple process } \\
\text { - Not expensive } \\
\text { - Minimal resid- } \\
\text { ual stresses }\end{array}$ & $\begin{array}{l}\text { - Environmental problems } \\
\text { - Joint configuration limited to } \\
\text { overlap }\end{array}$ & {$[43-45,47-55]$} \\
\hline Friction & $\begin{array}{l}\text { - Solid state } \\
\text { process } \\
\text { - Plastic defor- } \\
\text { mation }\end{array}$ & $\begin{array}{l}\text { - Dissimilar join- } \\
\text { ing } \\
\text { - No oxidation or } \\
\text { volatilization } \\
\text { - No heat af- } \\
\text { fected zone } \\
\text { - Minimal distor- } \\
\text { tion and resid- } \\
\text { ual stresses } \\
\text { - Environmental } \\
\text { friendly }\end{array}$ & $\begin{array}{l}\text { Equipment costs } \\
\text { - Risk of functional properties } \\
\text { degradation due to high strain } \\
\text { hardening }\end{array}$ & {$[66-72,74]$} \\
\hline
\end{tabular}


Table 1 (Continued)

\begin{tabular}{|c|c|c|c|c|}
\hline Process & $\begin{array}{l}\text { Main } \\
\text { characteristics }\end{array}$ & Benefits & Limitations & Existing works \\
\hline Ultrasonic & $\begin{array}{l}\text { - Solid state } \\
\text { process } \\
\text { - Plastic defor- } \\
\text { mation }\end{array}$ & $\begin{array}{l}\text { - Dissimilar join- } \\
\text { ing } \\
\text { - No liquid/solid } \\
\text { transformations } \\
\text { - No heat af- } \\
\text { fected zones } \\
\text { - Minimal distor- } \\
\text { tion } \\
\text { - Low residual } \\
\text { stresses } \\
\text { - No risk of inter- } \\
\text { metallics for- } \\
\text { mation } \\
\text { - Environmental } \\
\text { friendly }\end{array}$ & $\begin{array}{l}\text { - Small thicknesses and part size } \\
\text { - Joint configuration limited to } \\
\text { overlap }\end{array}$ & {$[75-77]$} \\
\hline Adhesives & $\begin{array}{l}\text { - Solid state } \\
\text { process } \\
\text { - Adhesive } \\
\text { bonding }\end{array}$ & $\begin{array}{l}\text { - Dissimilar join- } \\
\text { ing } \\
\text { - Simple process } \\
\text { - Flexibility } \\
\text { - Not expensive }\end{array}$ & $\begin{array}{l}\text { - Joint configuration limited to } \\
\text { overlap } \\
\text { - Reduced tensile strength and } \\
\text { fatigue strength }\end{array}$ & {$[82,83]$} \\
\hline Brazing & $\begin{array}{l}\text { - Diffusion } \\
\text { joining }\end{array}$ & $\begin{array}{l}\text { - Dissimilar join- } \\
\text { ing } \\
\text { - No oxidation or } \\
\text { volatilization } \\
\text { - No heat af- } \\
\text { fected zones } \\
\text { - Minimal distor- } \\
\text { tion and resid- } \\
\text { ual stresses } \\
\text { - Environmental } \\
\text { friendly }\end{array}$ & $\begin{array}{l}\text { - Poor mechanical strength of the } \\
\text { joints } \\
\text { - Joint configuration limited to } \\
\text { overlap }\end{array}$ & {$[90,91,93-95,99-102,104-106,108-113]$} \\
\hline $\begin{array}{l}\text { Diffusion and } \\
\text { reactive } \\
\text { diffusion }\end{array}$ & $\begin{array}{l}\text { - Diffusion } \\
\text { joining }\end{array}$ & $\begin{array}{l}\text { - Dissimilar join- } \\
\text { ing } \\
\text { - No heat af- } \\
\text { fected zones } \\
\text { - No oxidation or } \\
\text { volatilization } \\
\text { - Minimal distor- } \\
\text { tion and resid- } \\
\text { ual stresses } \\
\text { - Environmental } \\
\text { friendly }\end{array}$ & $\begin{array}{l}\text { - Mechanical strength } \\
\text { - Size of the parts }\end{array}$ & [120-123] \\
\hline
\end{tabular}

\section{Laser welding of NiTi}

Laser welding is, by far, the most used joining technique for NiTi shape memory alloys owing to its intrinsic characteristics, namely: low heat input, high energy density, and monochromaticity, narrow HAZ and reproducibility as described previously.

As a consequence of the wide variety of situations of NiTi base material to be welded (initial composition and thermo-mechanical history prior to welding, for example), a comparison to understand the effects of laser welding and its implications on the mechanical behaviour and microstructure is not obvious. Also, the use of $\mathrm{CO}_{? 2}, \mathrm{Nd}: \mathrm{YAG}$ or fibre lasers in either pulsed or continuous wave mode are known to produce different effects on the welded joints. For this, a systematic review of the most relevant studies is presented, focusing on the effects of laser welding on the microstructure, mechanical behaviour (both tensile, cycling tests, one-way and two-way shape memory effect), transformation temperatures, corrosion behaviour and the effect of post-weld heat treatments as well as, on the addition of filler materials if appropriate.

As in any manufacturing process, the operating conditions largely affect the efficiency of the joints. As far as laser welding is concerned, laser wavelength, power and mode, welding speed, focus size and position and shielding gas type and flow rate are the most relevant. The interaction of the power and welding speed were found to be statistically important in the Taguchi analysis performed by Chan et al. [133], while shielding gas flow rate was considered a weak factor. However, the shielding gas, both type and flow rate, are of extreme importance to prevent or minimize oxidation and contamination during welding. So, the gas type is of concern. For example, Argon is an effective shielding gas when welding NiTi [133], but when Helium is used it facilitates the formation of narrow welds due to its capacity to rapidly extract heat and it also helps to control the plasma [192]. Additionally, the effect of the shielding gas flow rate on the microstructural and mechanical behaviour must not be neglected. 
Considering the types of lasers, $\mathrm{Nd}$ :YAG and fibre lasers are now the main choice when compared to $\mathrm{CO}_{? 2}$ lasers. The lower wavelengths of $\mathrm{Nd}$ :YAG and fibre lasers enhance the beam absorption thus requiring less energy for welding. From published results, it is perceived that laser in pulse wave mode is preferred for joining wires or thin foils, while for higher thickness sheets laser welding operating in continuous wave mode produces joints with better mechanical properties.

Based on their previous work, Chan et al. 1132] used Taguchi experiments to determine the best welding conditions, which are dependent not only on the base material, but also on the laser system, for improving the mechanical properties of the welded joints. In fact, one of the tested samples was able to reach a strength of about $95 \%$ that of the base material, with just a slightly decrease on the stress onset for martensite detwinning of the welded joint.

More recently, Otibar et al. [152] used design of experiments to evaluate the quality of laser welded NiTi joints. Factors such as alloy composition, laser power and pulse duration were studied, amongst others. Based on this study the authors proposed an optimum combination of different factors to ensure the best response in terms of both tensile strength and strain. This is an interesting approach, especially for industrial environment, providing that all stages of the process can be monitored accordingly (i. e. have a good control of the initial condition of the base material and on the laser welding parameters to have the highest reproducibility possible).

\subsection{Similar laser welding}

Laser welding of NiTi shape memory alloys dates back to 1989 when Araki et al. [125] welded 3 mm thick Ni-rich NiTi plates, using a $\mathrm{CO}_{? 2}$ laser. Due to the high sensitivity of NiTi to high temperatures, laser welding was considered to be an adequate process to minimize the thermal affected regions and to preserve its functional properties: shape memory effect and superelasticity.

Early laser welding studies on NiTi shape memory alloys were performed using $\mathrm{CO}_{? 2}$ lasers [31,125-127] while, nowadays, the primary choice for these studies are the infrared lasers, such as Nd:YAG $[128-131,145,165,166]$ and fibre lasers $[132-134]$ due to their low wavelength and increased material absorptivity and, thus, narrow welds $[38,135]$.

\subsubsection{Microstructure}

The microstructure in the FZ of the NiTi laser welds can present either a dendrite-like, planar or cellular microstructure or a combination of these. The solidification structure observed can be explained based on rapid solidification theory [193], which establishes four parameters to govern the microstructure found in the FZ: temperature gradient $(\mathrm{T})$, undercooling $(\Delta \mathrm{T})$, crystal growth rate $(\mathrm{R})$ and alloy composition. The growth rate to temperature gradient ratio, $G / T$, governs the solidification mode, while the product G.R represents the cooling rate and controls the crystal growth. As the constitutional supercooling increases, the solidification structure changes from planar to cellular and from cellular to dendritic. As such, it is possible to observe only one, two or even all three structures in the FZ of a laser weld. An example of the coexistence of the three types of microstructures is presented in Fig. 14.

In the heat affected zone solid state transformations occur, such as: grain growth, formation of intermetallics and recrystallization. Fig. 15 depicts the microstructures observed under optical microscopy of a laser welded NiTi thin plate. In this case, it is clear a refined equiaxed structure close to the fusion zone, while going into the base material, an anisotropic structure is clearly revealed since the maximum temperature in this zone was not sufficient to induce microstructural modifications observable at this scale [146].

The effect of the weld thermal cycle on the hardness of the different regions is not straightforward, as it also depends on the initial condition of the base material, that is, on the thermo-mechanical history of the material [194,195]. This dependence was studied by Tuissi et al. [137], where two heat treatments were performed on the NiTi base material prior to welding. One of the heat treatments consisted of a full solution at $900^{\circ} \mathrm{C}$ for $60 \mathrm{~min}$ and the other one was ageing at $400{ }^{\circ} \mathrm{C} \mathrm{during} 20 \mathrm{~min}$. In the

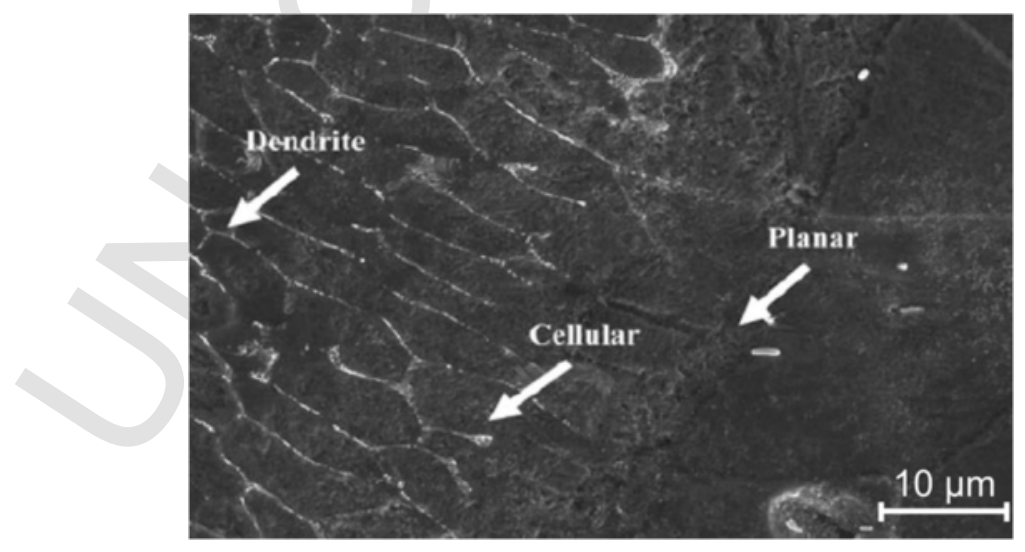

Fig. 14. Different solidification microstructures observed in the fusion zone of laser welded NiTi (adapted from [132]). 


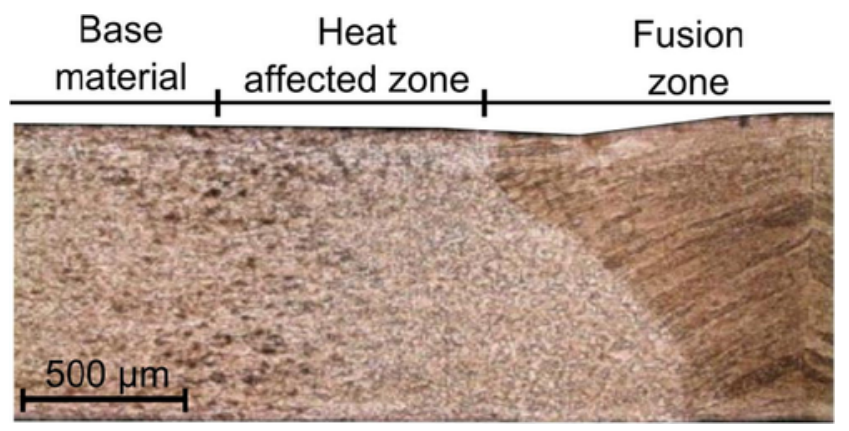

Fig. 15. Microstructural differences between the base material and the heat affected and fusion zones (adapted from [167]).

former, the hardness in the FZ increased compared to the base material, while in the latter, the opposite behaviour was registered: lower hardness of the FZ. Nevertheless, $[31,138]$ did not observe a significant change when measuring the hardness across the different regions of the weld.

In the HAZ there is usually a decrease of hardness values, due to recrystallization and grain size effects [132,139], being these effects more notorious when the base material is cold-worked. In the FZ the hardness tends to decrease, which can be explained by a full annealing effect promoted by the laser [140].

Several research groups have been performing structural characterization of existing phases in the different zones of laser welds, especially by X-ray diffraction [196], due to the microstructural features size and the narrow dimension of the different heat affected zones [133,141-143,166,168]. Fernandes et al. [142] and Oliveira et al. [166,168-170] used synchrotron X-ray radiation to probe laser welds from the base material into the FZ, in transmission mode, with a reduced spot size of $200 \times 200 \mu \mathrm{m}$ and good spatial resolution. Fig. 16 depicts measured data [168] and a significant microstructural change is observed: both the fusion and the heat affected zones show martensite and austenite to coexist, while the base material was fully austenitic at room temperature. Similar observations were presented by Iijima et al. [141], using conventional $\mathrm{Cu}$ K $\alpha$ radiation, although not discussed.

The structural characterization is of great importance, as the identification of these phases in the welded region is crucial to understand the mechanical behaviour of the welded joints.

One of the reasons for the deterioration of the mechanical properties lays on the formation of brittle intermetallics in the FZ, such as $\mathrm{Ti}_{? 2} \mathrm{Ni}[127,144,146,147]$. Schloßmacher et al. [144] proposed that $\mathrm{Ti}_{?_{2}} \mathrm{Ni}$ precipitation and the presence of oxygen in the FZ lead to a premature failure of the joints. This assumption reinforces the need to have the NiTi base material as free of impurities as possible and required good gas protection during welding so that no contaminants (such as hydrogen or oxygen) can be picked-up by the liquid bath. The presence of $\mathrm{Ti}_{?} \mathrm{Ni}$ is also detrimental for the corrosion behaviour of the laser joints, as these, when finely dispersed, are known to be preferential sites for pit initiation in both equiatomic and Ni-rich NiTi [197].

Aside from $\mathrm{Ti}_{? 2} \mathrm{Ni}$, other intermetallics were also found to exist in the $\mathrm{FZ}$ of the laser joints, namely: $\mathrm{Ni}_{33} \mathrm{Ti}^{[132,133,148,149]}$, and $\mathrm{Ni}_{? 4} \mathrm{Ti}_{? 3}$ precipitates $[150,167]$. The presence of Ni-rich precipitates in the HAZ due to laser welding must be more carefully analysed as the thermo-mechanical history of the base material has a significant role on the onset for the precipitation to occur. For example, if the base material was cold-rolled, the temperature raise in the HAZ may be sufficient for precipitation and/or recrystallization phenomena to occur, even though the time available for such processes is quite short. On the other hand, an annealed base material may not experience any microstructural change in the region adjacent to the FZ by the sole reason that the

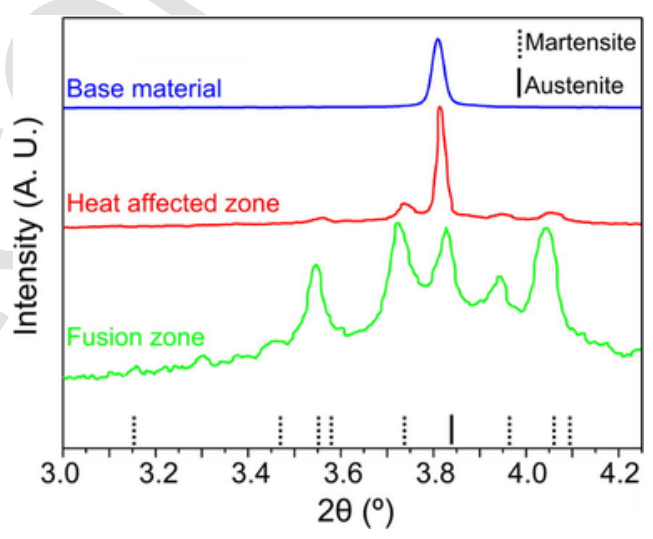

Fig. 16. X-ray diffraction measurements on different regions of the welded NiTi joint (adapted from [168]). 
heat treatment performed on the base material has already promoted the microstructural changes. This is the reason why, sometimes, it is reported that no HAZ is observed in NiTi laser welds $[31,146]$.

The presence of precipitates in the thermal affected regions must be considered as they decrease the Ni or Ti content of the surrounding matrix, depending on the precipitation of $\mathrm{Ni}$ or Ti-rich compounds, respectively. For Ni-rich alloys, the dependence of the transformation temperatures on the composition is more significant than for Ti-rich NiTi, which is related with the solubility range on the Ti-rich side of the Ni-Ti phase diagram [2]. As such, for laser welded Ni-rich NiTi alloys, the composition dependence of the transformation temperatures may bring significant differences in terms of transformation characteristics, when comparing the FZ and the HAZ with the base material. For example, a 0.1 at.\% shift may change the transformation temperatures by $20 \mathrm{~K} \mathrm{[7].} \mathrm{As} \mathrm{it} \mathrm{will} \mathrm{be} \mathrm{discussed} \mathrm{later,} \mathrm{the} \mathrm{most} \mathrm{striking} \mathrm{aspect} \mathrm{arising} \mathrm{from} \mathrm{compositional} \mathrm{shifts} \mathrm{in} \mathrm{the} \mathrm{different} \mathrm{regions} \mathrm{of} \mathrm{the}$ weld is related to the transformation temperatures within each zone, which may cause, for example, the base material to show one stable phase, while the HAZ and/or FZ have another, at a given fixed temperature.

Another possible effect of such precipitation phenomena is the appearance of the R-phase transformation on the HAZ and/ or FZ. R-phase transformation may occur when $\mathrm{Ni}_{?_{4}} \mathrm{Ti}_{? 3}$ coherent precipitates are formed due to the formation of stress fields $[198,199]$. Due to the low extension of the thermal affected regions, after laser welding, conventional analytical techniques such as conventional X-ray diffraction using laboratorial sources, differential scanning calorimetry or electrical resistivity, cannot be used with high accuracy for determining the phase transformations in each region. For such analysis, special dedicated techniques, such as synchrotron or micro X-ray diffraction and/or transmission electron microscopy, must be applied.

\subsubsection{Mechanical behaviour}

\subsubsection{Tensile properties}

Most of existing work on laser welding of NiTi is devoted to Ni-rich alloys, probably because they can exhibit superelastic properties at room temperature. Ti-rich alloys, on the other hand, tend to be martensitic at the same temperature.

For Ti-rich NiTi a significant decrease of the UTS (more than 30\% that of the base material [127,138]) in the joints is justified by the grain boundary precipitation of $\mathrm{Ti}_{? 2} \mathrm{Ni}$ in the $\mathrm{HAZ}$ and the presence of micro-cracks in the FZ [127]. An embrittlement of the welded material, when compared to the base material, justified the lower ductility and tensile strength.

It was already reported that, in pulsed wave mode, dislocations can be introduced in the material, leading to work-hardening, due to the high thermal impact of multiple laser individual spots $[136,146]$. These dislocations decrease the ductility of the joint when compared to the base material.

The plateau for the martensite detwinning in martensitic NiTi can reach up to 6\% strain [200]. Falvo et al. [138] reported a decrease in the martensitic plateau after welding, as shown in Fig. 17. It was proposed that this detwinning deformation was reduced due to dislocation slip in the HAZ. It is apparent that, after the detwinning plateau of martensite, elastic deformation of the detwinned structure occurs prior to fracture. Although no structural analysis was performed in Falvo's work, it is reasonable to conclude that the large microstructural difference, observed by optical microscopy, between FZ (coarse grain size) and base material (fine grain size) may cause the observed decrease in mechanical properties of the as-welded joint.

The UTS of the welded joints is mostly below that of the base material, though it depends on the initial condition of the base material. Analysing the stress-strain curve of the base material in Chan et al. work [132], it can be observed that the tensile stress of NiTi base material and its elongation at fracture are considerably lower than most studies reported in the literature such as $[5,201,202]$, where NiTi was tested in more demanding conditions, in terms of strain or stress applied, without fracture. Gugel et al. [128] reported that similar laser welds presented a stress-strain behaviour similar to the base material, but the UTS of the welded joints was $25 \%$ below that of the base material. However, the NiTi joints exhibited the superelastic plateau up to $7 \%$ and fracture occurred at about $1 \mathrm{GPa}$. Comparing these values with the ones presented by Chan et al. [132] also for laser welds, a superior mechanical behaviour is reported by Gugel [128], despite the UTS of the joints being $75 \%$ that of the base material. It seems evident that the ultimate tensile strength of a welded joint is not the adequate parameter to compare the effect of laser welding amongst different works, as for the base material it is strongly depending on its initial condition.

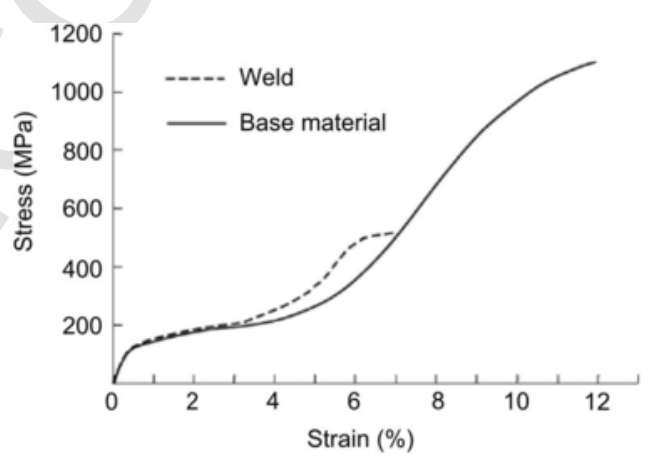

Fig. 17. Stress-strain curve for martensitic NiTi and its laser welded joint (adapted from [138]). 
As such, to assess the possible detrimental effects in NiTi joints, other parameters must be considered to be compared to the base material, namely: transformation strain, start and finishing stresses of the plateau, superelastic recovery upon loading/unloading cycling and shape memory effect recovery.

The effect of the rolling direction when welding NiTi plates must also be considered as it is a factor that may alter the mechanical properties of the welded joint. Vieira et al. [140] reported that a higher UTS was measured when the welding direction was perpendicular to the base material rolling direction. So, this should be taken in consideration for designing purposes.

The Clausius-Clapeyron relationship expresses the rate of change of the critical stress for the stress-induced transformation of temperature for the effect of the lattice distortion of martensite on the transformation [203]. The relationship can be expressed generally as:

$\frac{d \sigma}{d T}=-\frac{\Delta S}{\varepsilon_{t r}}$

where $\sigma$ is the critical stress, $\mathrm{T}$ is the testing temperature, $\Delta \mathrm{S}$ is the entropy variation and $\varepsilon_{\text {?t }}$ is the transformation strain. For NiTi the $d \sigma / d T$ ratio varies between 5 and $8 \mathrm{MPa} \mathrm{K}^{?-1}[204]$. Schloßmacher et al. [136] presented the only study to analyse the effect of laser welding on the $d \sigma / d T$ ratio. Samples from the base material, welded joint and a so called "remolten" specimen were tested by load/unload up to $6 \%$, at different temperatures, and the stress at $3 \%$ strain in the superelastic plateau was measured, while recording the irrecoverable strain after each unload to 0 stress. The "remolten" specimen consisted on an array of laser-welds covering the entire gauge length of the specimen under test. Although the mechanical behaviour of such specimen is not entirely correspondent with the FZ, it is still a good estimation. It was also observed, that the laser welded specimen followed the Clausius-Clapeyron relation with a gradient of about $7 \mathrm{MPa} \mathrm{K}^{\text {?-1}}$, very close to the value of the base material, within the expected range for NiTi [204]. The irrecoverable strain, from both base and laser welded materials, are depicted in Fig. 18. At $10{ }^{\circ} \mathrm{C}$ the irrecoverable strain is significantly high due to presence of martensite at that temperature. At $50{ }^{\circ} \mathrm{C}$, above the $\mathrm{M}_{\text {?d }}$ temperature (where the stress for inducing dislocation slip is lower than for the stress induced transformation), plastic deformation was observed in both samples. Thus, a working temperature range between 20 and $40{ }^{\circ} \mathrm{C}$, was suggested for applications based on superelasticity, where the irrecoverable strain of the welded material is just slightly higher than the base material. However, it must be noticed that this working range depends of the base material transformation temperatures and on the laser welding parameters, namely the heat input and the energy density. The "remolten specimen" presented significantly higher values of irrecoverable strain (up to $4.4 \%$ ), which can be partially attributed to the high density of glissile dislocations observed in these samples by transmission electron microscopy.

The stress-induced martensite transformation in NiTi proceeds with the propagation of deformation in macroscopic shear bands [205]. Experimental results suggest that the end of the superelastic plateau (also called Lüders-type plateau) may not be necessarily coincident with completion of the austenite to martensite phase transformation [206]. Micro or macro-mechanical modelling of laser welded NiTi is scarce. Chan et al. $[151]$ presented the only study on this topic, where they proposed a constitutive model to describe the mechanical behaviour of the welded joint under cyclic solicitation. The constitutive model was adapted and modified from [207] and the main modifications performed were based on the fact that, after laser welding, residual stresses exist in the HAZ and FZ of laser welded NiTi joints [169]. As such, the critical stress for the stress-induced transformation should occur at a different stress level of the base material. This argument was sustained by the fact that, during cyclic tests, stress kinks were observed prior to the superelastic plateau [151] or within the plateau [128]. Fig. 19 shows the described stress kinks on both base material and welded joint reported by [151]. It must be noticed that, in austenitic NiTi, prior to the superelastic plateau, an overshoot of stress is observed as reported by Tobushi et al. [208]. This overshoot can be explained by the fact that an extra force is required to create the martensite nucleus. Then, the interface between austenite and martensite moves under constant stress, as typical for the superelastic plateau. If the strain rate during such tests is low, the interface can move freely af-

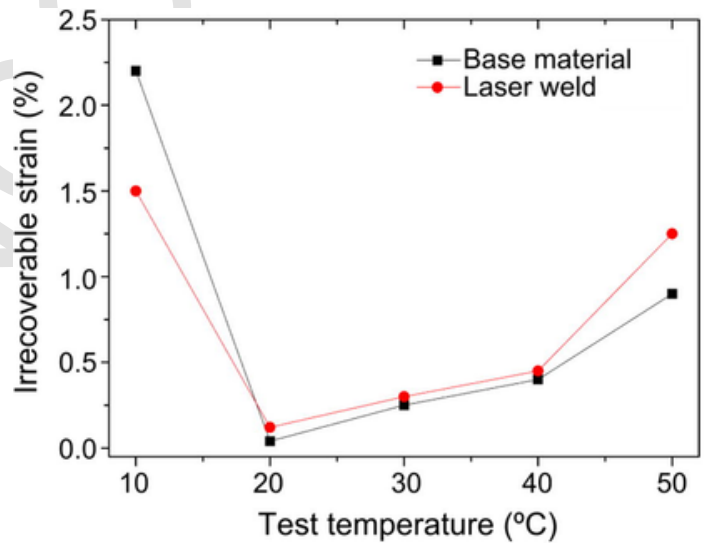

Fig. 18. Temperature dependence of the irrecoverable strain after loading up to $6 \%$ and subsequent unloading (adapted from [136]). 

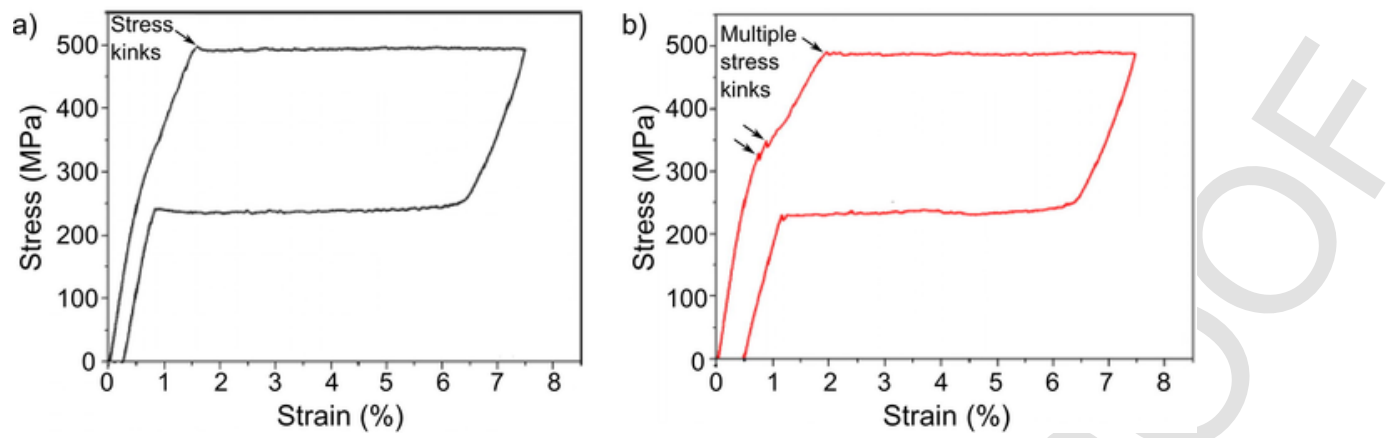

Fig. 19. Observation of stress kinks: (a) base material; (b) welded material (adapted from [151]).

ter the creation of the martensite nucleus, allowing for the relaxation of the high stress required. But, if the strain rate is high, the interface will move quickly after the creation of the martensite nucleus and will not have time to relax the stresses in the interface. If the test speed is very low, these stress kinks are observed [128,151].

Other adaptation of Chan's model relied on considering that the HAZ and FZ, after the stress induced transformation of austenite to martensite, will undergo plastic deformation. This assumption was made considering that the irrecoverable strain after the load/unload cycle, presented a higher value of deformation in the welded joint than in the base material (Fig. 19). So, a component was introduced in the mathematical formulation that considered the plastic strain of the thermal affected regions. Such higher irrecoverable strain, after the stress-induced transformation, may be due to martensite stabilization which can be of thermal (due to the local chemical composition changes induced by the welding procedure [171]) or mechanical origin (when, during superelastic cycling, the accumulation of defects allows for an increase of the volume fraction of non-transforming austenite [209]).

A fairly good agreement between experimental tests and the developed constitutive model was observed (Fig. 20). Although in this experimental work Chan et al. [151], assumed that the thermal affected regions were still austenite, as the base material, other authors have reported the presence of martensite in those regions, while the base material was austenitic [142,166,168,170]. As such, other significant modifications (mainly considering the role of martensite on the stress relaxation and irrecoverable strain after each load/unload cycle) must be incorporated in the proposed constitutive model.

Tensile curves of laser welds usually comprise the full weld including the HAZ and FZ. A more in depth study of the tensile behaviour of the thermal affected regions of Ni-rich laser welded NiTi, was performed by Hsu et al. [31]. Within the gauge length of tensile specimens, two-thirds of the volume fraction of the analysed weld corresponded to the FZ, while the remaining was the HAZ. Assuming that the tensile specimens resembled a lamellar composite (HAZ/FZ/HAZ) an expected ultimate tensile strength of the FZ was computed and was close to $740 \mathrm{MPa}$. Tensile tests revealed that the composite had a higher UTS than the base material, despite the elongation at fracture being considerably lower, as observed in Fig. 21. This value was in good agreement with the tensile curve of the laser weld. However, the specimen presented a brittle fracture, while the base material had ductile-like features. As such, the mechanical behaviour of the laser joint was limited by ductility on the FZ, which was found to be lower than the base material.

An example of a more complex welded NiTi joint was studied by Tam et al. [139], where Ni-rich wires were welded as depicted in Fig. 22. SEM images revealed full penetration welds with no apparent defects (Fig. 23). Of particular interest was the smooth surfaces presented by the welded joint. This condition was considered very good for biomedical implants as it should increase the biocompatibility with the human body [210].
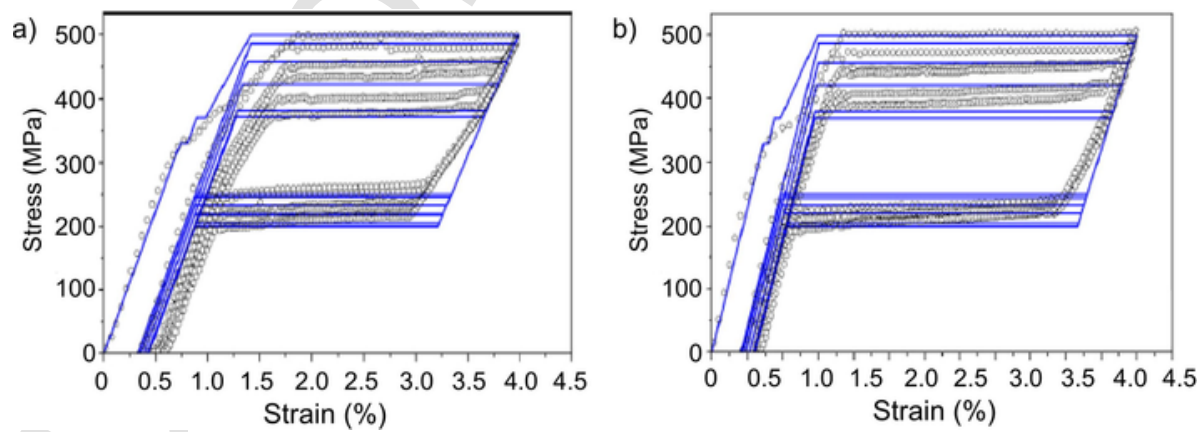

Fig. 20. Experimental and simulated stress-strain curves of NiTi joint up to: (a) 4\%; (b) 6\%. 1st, 2nd, 5th, 10th, 25th and 50th cycles are shown. Experimental and simulated data are represented by dots and blue line, respectively (adapted from [151]). 


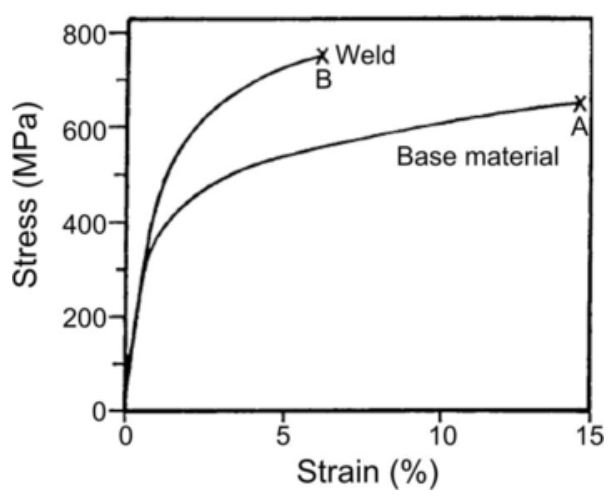

Fig. 21. Stress-strain curves for base material and laser welded joint, which is assumed to be a composite of heat affected zone/fusion zone/heat affected zone (adapted from [31]). Points A and B were used to compute the expected tensile strength of the fusion zone ( $\sigma_{\text {?FZ}}$ ) according to the equation: $\sigma_{\text {com }}=0.34 \sigma_{B M}+0.66 \sigma_{F Z}$, where $\sigma_{\text {?BM }}$ and $\sigma_{\text {?com }}$ correspond to points A and $\mathrm{B}$, respectively.

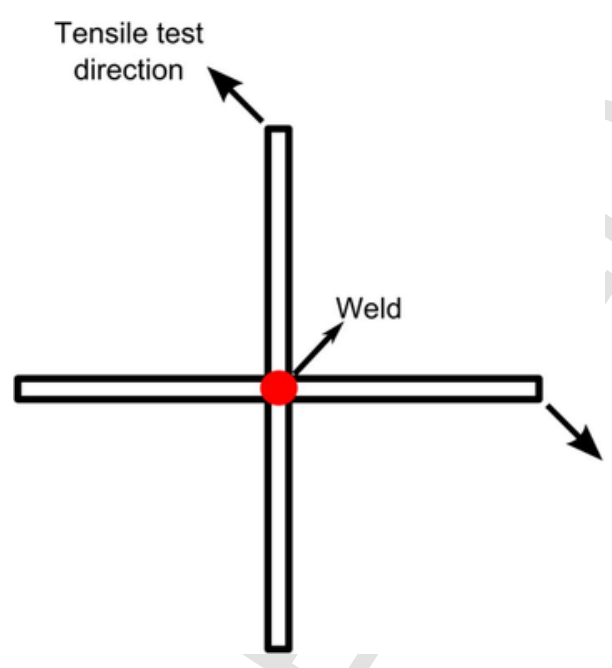

Fig. 22. Schematics of the welded joint (adapted from [139]).

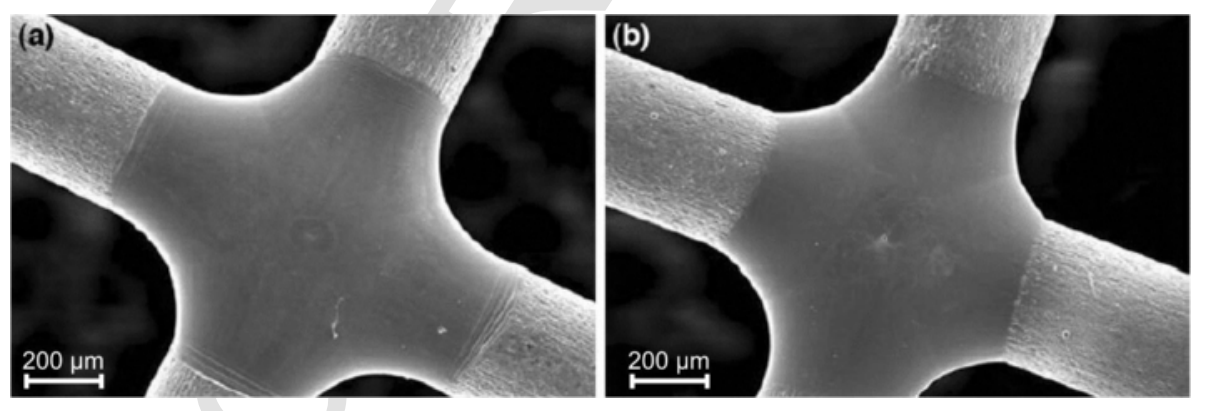

Fig. 23. SEM images of: (a) top of welded joint; (b) bottom of welded joint (adapted from [139]).

The superelastic behaviour of any shape memory alloy can only be assessed after at least one load/unload cycle. When the material is mechanically tested in the austenitic or martensitic phase a constant-stress plateau is expected. In the former case, upon unloading, the irrecoverable strain at zero stress should be significantly lower than in the latter. For that reason, although a constant-stress plateau can be observed in tensile tests of NiTi welds, it is not assured that superelasticity is preserved.

Several factors are known to influence the superelastic response of NiTi, namely: the testing temperature [208], the effect of previous thermo-mechanical treatments [211], the maximum applied strain [212] and the grain size [213]. As it can be easily understood, all these factors play a significant role on the mechanical cycling behaviour of the welds. Thus, the interpretation and discussion of the observed behaviour can be highly complex. Also, the large variety of conditions regarding similar laser weld- 
ing of NiTi requires paying close attention to the experimental details of each study so that a clear comparison between results can be performed. Different lasers and welding parameters affect the superelastic behaviour of the NiTi welds, as these significantly alter the microstructure in the thermally affected regions.

As a rule of thumb, laser welds present lower superelastic behaviour (higher irrecoverable strain after unloading) when compared to the base material. Chan et al. [132] subjected laser welds to a load/unload cycle at different strains (4, 6 and $8 \%)$. It was observed that, with increased applied strain, the irrecoverable strain upon unloading increased. Also, these values were greater than those of the base material, this being attributed to the microstructural modifications occurred in the FZ. It was also observed that the critical stress, for the stress-induced transformation, in the welded joint decreased, when compared to the base material. Similar findings, regarding the decrease of the critical stress for the occurrence of the superelastic plateau, were also reported in $[137,140]$. It is suggested that this stress reduction occurs due to the microstructural modifications introduced in both HAZ and FZ, which allows for these regions to reach the constant stress plateau, after the initial elastic deformation, at lower stress values than those of the original base materials.

\subsubsection{Mechanical cycling behaviour}

In NiTi SMAs fatigue can occur by two distinct modes: functional and structural fatigue [214]. In the former the functional properties of the material suffer a degradation during cyclic solicitation, while the latter the material fails, during high cyclic loads like any other engineering material. Several studies report the cycling behaviour of NiTi welds $[31,125,126,132,137,140,144,166]$. However, a significant disparity in the reported experiments is observed. Cycling tests reported are in a range from 1 to 600 cycles and in a strain range between 3 and $10 \%$. The test speeds, also tend to be very different. As such, a comparison between different results is not straightforward.

Hsu et al. [31] cycled laser welds under 3\% imposed strain during 50 mechanical load/unload cycles and observed a permanent strain of $0.19 \%$ which was higher than that of the base material $(0.09 \%$ of irrecoverable strain). However, this small permanent deformation was attributed to the low total strain imposed during the tests. Similar results were reported by Gugel et al. [128], when cycling both base material and welded specimens for a total of 10 cycles up to $2.5 \%$ strain. Nonetheless, for applications where conventional materials are not able to present such elastic behaviour, NiTi laser welds can definitely be used.

The effect of maximum strain imposed during cycling on accumulated irrecoverable strain was studied by Vieira et al. [140]. When testing both the base material and the welded joint up to 4 and $8 \%$ strain for a total of 30 cycles, significant differences were found. While after the cycling tests at $4 \%$ the welded material presented an accumulated irrecoverable strain of nearly $0.7 \%$ and this value increased up to about $4.4 \%$ for $8 \%$ imposed strain tests. In both cases, the welded material always had a higher accumulated irrecoverable strain than the base material. Interestingly, it was pointed out that the superelastic behaviour of the joints was observed up to applied stresses that were just $50 \mathrm{MPa}$ below their UTS, which may be of significant importance for industrial applications.

Chan et al. [153] analysed the cycling behaviour of NiTi welds up to 100 cycles, with a maximum imposed strain of $4 \%$. The aforementioned stress kinks (Fig. 19 from [151]) which were attributed to a local stress induced transformation of the thermal affected region were only observed in the first loading cycle. The absence of those features in the following cycles suggests that local plastic deformation of those regions has occurred, thus, not contributing for the superelastic effect and leading to an increase in the irrecoverable strain.

Another experimental condition that may influence the analysis of the results, concerning the effect of laser welding on the superelastic behaviour, is related to the ratio between the volumes of the heat affected regions to the base material during these cycling tests. It is expected that, for the tests performed in the same conditions, when this ratio is higher (the relative importance of the thermal affected region is, thus, more significant), a decrease in the superelastic properties should occur. This effect may be related to the already reported microstructural heterogeneities observed in those thermal affected regions when compared to the base material.

The functional fatigue by superelasticity of NiTi laser welded plates was assessed by Oliveira et al. [166] by subjecting the welded samples to a total of 600 load/unload cycles at maximum imposed strains of 8 and $10 \%$. Although martensite was observed in the HAZ and FZ, while the base material was fully austenitic, the welded joints still exhibited superelasticity (Fig. 24). The superelastic recovery was found to be correlated with heat input introduced during welding: higher heat input led to higher extension of the thermal affected regions and, as a consequence, the superelastic recovery decreased. Aside from the evidence of thermal stabilization of martensite in the HAZ and FZ of the welds, mechanical stabilization of the stress-induced martensite during superelastic cycling was also observed under synchrotron radiation [171]. Thermal stabilization of martensite occurred due to a local variation of the chemical composition of both HAZ and FZ due to welding, which raised the transformation temperatures of those regions. Mechanical stabilization of martensite occurred due to the introduction of dislocations during cycling of the welded joints. The microstructural differences of the as-welded, after 4 and 600 cycles at 10\% strain are depicted in Fig. 25 .

Typical applications that take advantage of superelasticity in cyclic solicitations are displayed in Table 2 . It is, thus, evident that understanding the fatigue behaviour and the underlying microstructural processes is of great importance, in order to safely design NiTi components [214]. Microstructural features, such as grain size, are known to influence the fatigue strength of NiTi [215]. For example, the presence of coarse grain size in the thermal affected areas after welding, can be responsible for the decrease on the fatigue life of polycrystalline materials $\underline{\underline{2216]} .}$. 

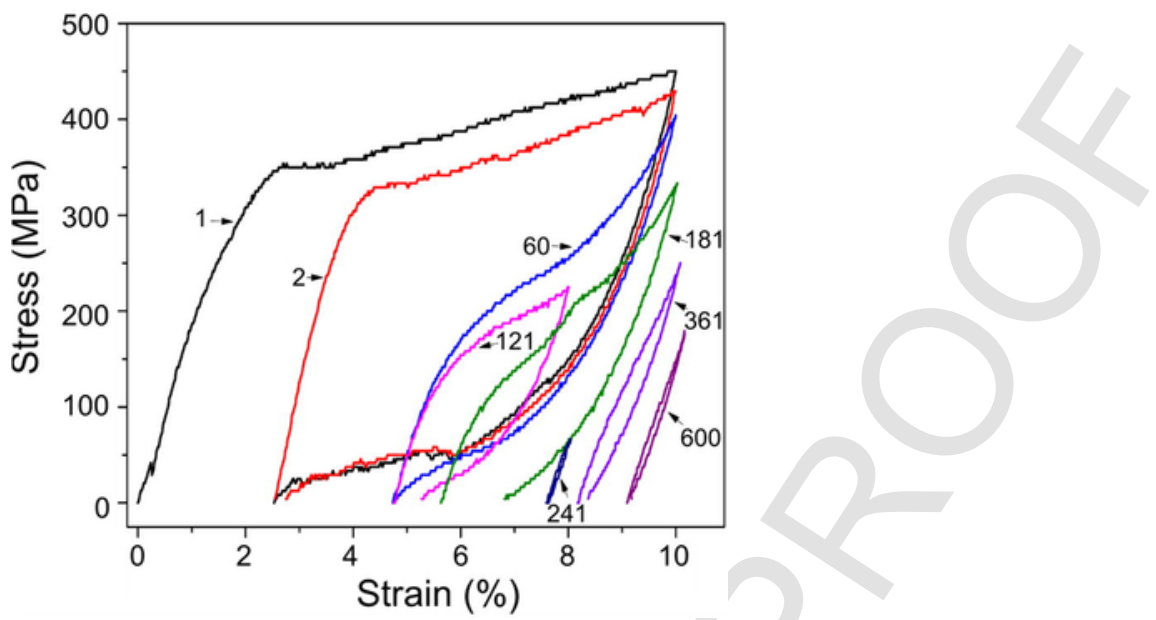

Fig. 24. Example of superelastic behaviour presented by the laser welded NiTi joints after a given pre-defined number of cycles (adapted from [166])

Conventional fatigue of laser welded NiTi was studied using rotating-bending specimens [154,155] analysing the effect of the imposed strain amplitude on the number of cycles to failure [154] and the influence of the bending frequency on the fatigue strength [155]. As expected, it was observed a decrease on the fatigue properties of NiTi after laser welding, which was attributed to the segregation of solute and impurities upon solidification of the weld metal and to the existence of coarse grain dendritic structures in this region.

It was observed that the differences between the base material and welded material increased when increasing the strain amplitude. When the imposed strain amplitude was below $0.4 \%$, the welded joints were able to withstand up to $10^{? 6}$ cycles without rupture. However, when the strain amplitude increased to $1.0 \%$, the fatigue life of the NiTi joint was reduced to about $10^{? 3}$ cycles, while the base material was able to sustain a total of $10^{? 4}$ cycles.

Considering the influence of the bending frequency, it was seen a decrease of the fatigue strength when increasing the bending frequency. During the stress induced transformation of austenite to martensite, the temperature of the sample increases [217]. As such, when the frequency increased, the generated heat also increased. With increasing temperature, the plateau for stress induced transformation increases requiring a higher stress to occur. It is even possible to overcome the $\mathrm{M}_{\mathrm{Pd}_{\mathrm{d}}}$ temperature, at which the stress for dislocation slip is lower than that required for the starting of the stress induced transformation. Thus, these factors explain the lower fatigue strength of the NiTi base material and laser welds with increasing frequency.

Fracture analysis of the welded samples after fatigue tests, revealed that cracks were originated in the FZ due to higher roughness, when compared to the base material, coming from solidification after laser melting. In NiTi, it was reported that increasing surface roughness, as usually found in the FZ, may decrease the fatigue-crack growth resistance [218], justifying the decrease in the fatigue strength of the welded material. Brittle-like features in the fracture surface were reported in [154], while in [155] the welded material fractured in a ductile mode.

Nevertheless, laser welded NiTi joints revealed a lower fatigue strength when compared to the base material, though these joints were still able to withstand a significant number of cycles, which is of significant importance for applications in micro-electro-mechanical systems [219], for example.

\subsubsection{Shape memory effect}

Shape memory effect is, eventually, the most important functional property attributed to NiTi and, thus, preserving the shape memory effect after welding is of major concern, for example, in applications such as in actuators.

The shape memory effect on laser welded NiTi was reported in early studies $[125,126]$. Full recovery of the imposed strain was achieved when the samples were heated to the austenitic phase. That is, from the functional properties presented by NiTi, the shape memory effect appears to be the less affected by laser welding.

Several authors reported that at least $90 \%$ of the imposed deformation is recovered when the shape memory effect is triggered $[31,127,137,144,168]$. Evidence of the shape memory effect in laser welded NiTi was investigated by either tensile $[31,125,127,137,144]$ or bending tests [168]. In the former, the samples are pulled, in the martensitic phase, up to a certain strain and unloaded to a 0 stress condition, presenting a significant deformation. Then, the welded specimens were heated above the $\mathrm{A}_{? \mathrm{f}}$ temperature and the shape memory effect occurred, allowing for a significant strain recovery of the imposed deformation. In bending tests, the procedure was similar but the samples were bent over a given curvature radius.

However, the shape memory recovery is dependent on the applied strain. Schloßmacher et al. [144] tested NiTi joints up to $6 \%$ strain with subsequent unloading to 0 stress and heating above $\mathrm{A}_{? \mathrm{f}}$. They reported that the irrecoverable strain after martensite $\rightarrow$ austenite transformation increased with the applied strain, as it was expected. Although the irrecoverable strain of the welded joints was small (bellow 0.1 and $0.3 \%$ for strains of 4 and $6 \%$, respectively), these were less performant than the base material. The effect of imposed strain on the shape memory recovery for Ti-rich laser welded NiTi was also evidenced by Falvo et al. 

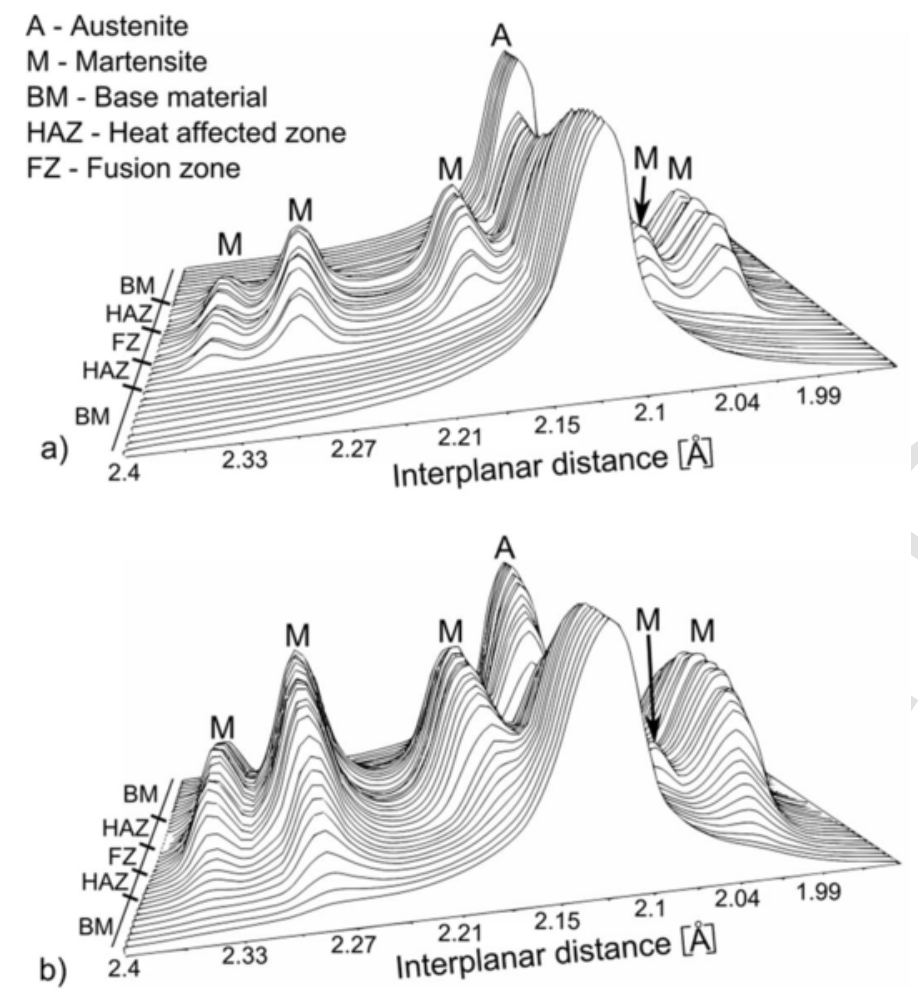

b)

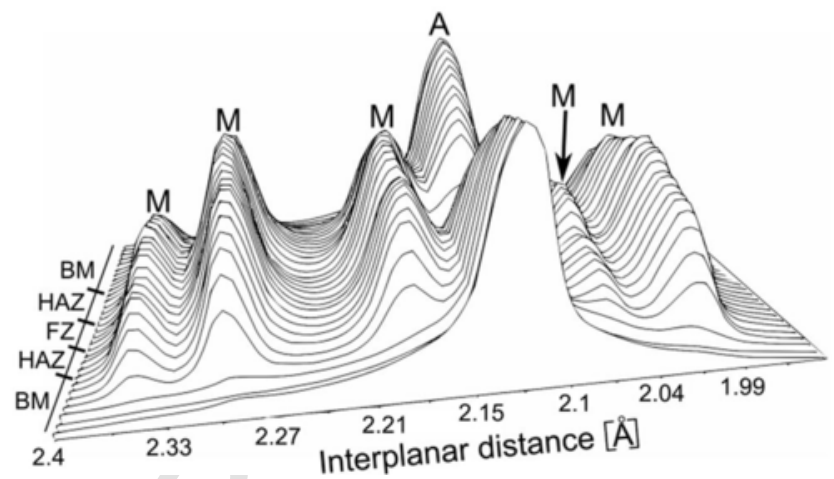

Fig. 25. Superimposition of the X-ray diffractograms for laser welded NiTi samples: (a) as-welded; (b) after 4 cycles at $10 \%$ strain; (c) after 600 cycles up to $10 \%$. Intensity in log scale (from [171]).

Table 2

Typical applications of NiTi shape memory alloys that require superelastic behaviour and expected fatigue life [214].

\begin{tabular}{ll}
\hline Application & Fatigue life [number of cycles] \\
\hline Stents & $10^{98}$ \\
Damping, internal friction & $10^{? 8}$ \\
Orthodontic wires & $10^{? 5}$ \\
\hline
\end{tabular}

[138]. Fig. 26 depicts the experimental results of Falvo et al. It was observed that the maximum strain recovery of the welded joint was $4 \%$ for an imposed strain of 5\%, while, for the base material, the maximum strain recovery achieved $5.2 \%$ for a total strain of $7.3 \%$. It can be noticed that the curve correspondent to the evolution of the strain recovery, $\varepsilon_{\text {?m }}$, increases up to a certain point and then starts to decrease, being this feature observed earlier in the welded sample. This was seen to be related to the development of dislocation slip, leading to plastic deformation. This early development of slip in the welded material can be due to the lower strength of the joint when compared to that of the base material. 


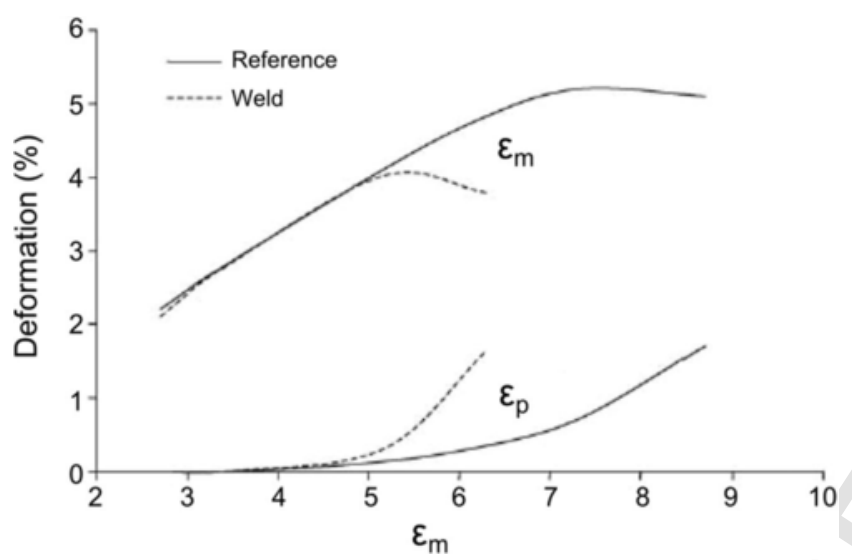

Fig. 26. Influence of the imposed strain, $\varepsilon_{? \mathrm{p}}$, on the strain recovery by shape memory effect, $\varepsilon_{? \mathrm{~m}}$, and permanent strain, $\varepsilon_{? \text { t, }}$, for both base material and laser welded joint (adapted from [138]).

When reporting the shape memory effect of NiTi welds, researchers are often concerned with the overall behaviour of the welded joint. However, recently, Oliveira et al. [168], observed the presence of distinct shape memory effects in the base material and in the region comprising the HAZ and FZ. The evolution of the recovery angle with time measured (Fig. 27), shows that the thermal affected regions return to their original shape earlier than the base material, which is an interesting observation. Though both the heat affected zone and the fusion zones were constituted of austenite and martensite at room temperature (while the base material was fully austenitic), heating the samples to this temperature after bending, the shape memory effect was clearly evidenced.

The problem of the two-way shape memory effect after welding was also addressed [130]. Ti-rich NiTi, $1.2 \mathrm{~mm}$ thick plates, martensitic at room temperature, were butt welded using a Nd:YAG laser. After welding, the residual stresses resulting from previous cold working of the base material and laser welding were reduced by post-weld heat treatment. A load/unload cycle, up to $3.5 \%$ strain was performed to compare the mechanical response of the base material and the welded joint; the main difference observed was on the stress for the onset of martensite detwinning, which was found to be higher in the welded specimen. This effect was attributed to the grain growth and formed precipitates due to the weld thermal cycle. Previous research performed on NiTi showed that increasing the recrystallization temperature of Ti-rich NiTi give rise to increasing transformation temperatures [220]. So, for the same mechanical testing temperature, the critical stress for the stress induced transformation should be lower.

Similar load/unload curves for laser welds were recorded by $[138,144]$, which did not showed significant difference on the stress values for the onset of martensite detwinning, when compared to the base material, in opposition to others observations [130]. This highlighted that the thermo-mechanical history of the base material prior to welding plays a significant role on the features presented by the joints after welding. Experimentally, this was confirmed by heat treating cold worked Ti-rich NiTi laser welded samples after at $400{ }^{\circ} \mathrm{C}$ for $45 \mathrm{~min}[138]$ and at $700{ }^{\circ} \mathrm{C}$ for $20 \mathrm{~min}[130]$.

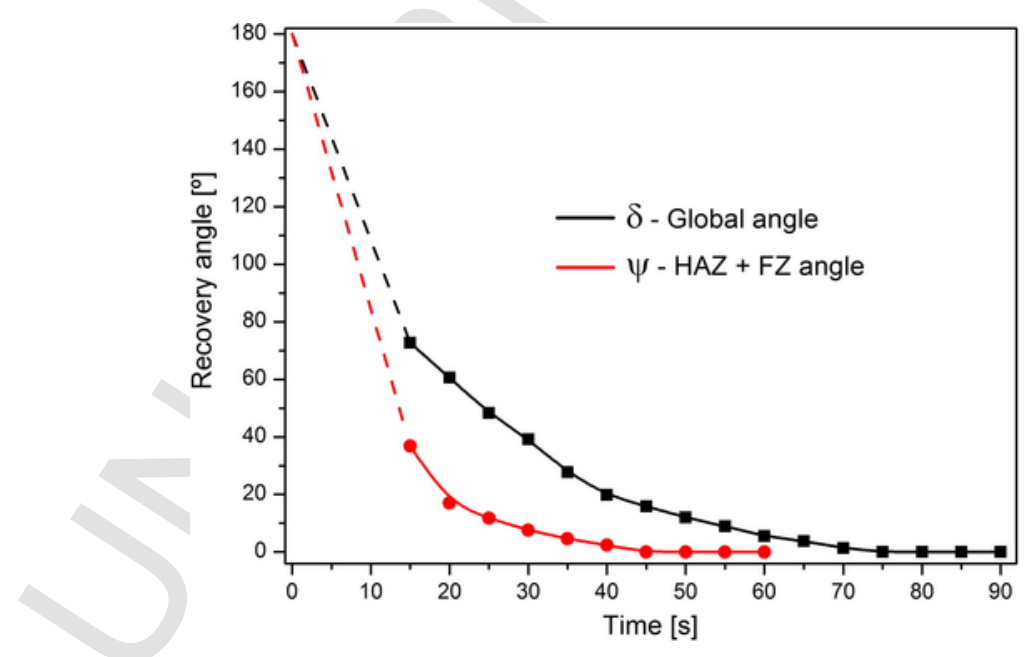

Fig. 27. Evolution of the recovery angle over time for a NiTi weld (from [168]). The "Global angle" and "HAZ + FZ angle" corresponds to the shape memory effect observed in the base material of the welded joint, and in the heat affected and fusion zones, respectively. 
Training of the samples was also performed for a total of 8 cycles up to a strain of $3.5 \%$ to obtain the two-way shape memory effect [130]. Fig. 28 depicts the stress-strain curves correspondent to a selected number of training cycles of both base material and welded samples. It can be observed that, increasing the number of training cycles, hardening occurs and, thus, a large stress level is measured together with a decrease of the stress required for the onset of the martensite detwinning.

As a requirement for the two-way shape memory effect, after each load/unload cycle the material must be heated above the $\mathrm{A}_{\text {?f }}$ temperature so that martensite transforms into austenite [4]. Thus, Falvo et al. [130] recorded (i) the residual strain, $\varepsilon_{\text {? }}$, corresponding to the strain at 0 stress after each load/unload cycle, (ii) the recovery deformation, $\varepsilon_{\text {?re, }}$, which corresponded to the strain at 0 stress after transformation into austenite and (iii) the two-way shape memory strain $\varepsilon_{\text {?tw }}$, after subsequent cooling to the martensitic phase. In the base material, the two-way shape memory strain recovery increased continuously with the number of cycles; despite this behaviour was also observed in the welded joint for the early training cycles, the two-way shape memory recovery started to decrease with a correspondent increase on the residual strain, as observed in Fig. 29. This effect may be explained by the development of dislocations slip in the welded region leading to plastic deformation.

These results show that smart actuators based on laser welded NiTi joints can be produced. However, it must be pointed out that the performance of these actuators may be reduced when compared to the base material, due to the lower values of two-way shape memory strain.

A two-stage shape memory effect, which is different from the two-way shape memory effect, was observed [126] in welds of two NiTi sheets with different compositions, with full recovery of the imposed deformation on the joint. As the base materials had different transformation temperatures, it was expected that the FZ had a transformation temperature in between them. Thus, the shape memory effect could be triggered at different times: after deformation in the martensitic phase by heating to the lower $\mathrm{A}_{? \mathrm{f}}$ temperature of both base materials causing the first-stage shape memory effect; subsequent heating up to the higher $\mathrm{A}_{\text {?f }}$ temperature of the other base material promoted the second-stage shape memory effect.

Similarly, analysing butt welds of an equiatomic alloy and a Ni-rich NiTi by differential scanning calorimetry, the base materials showed just one transformation peak upon cooling/heating corresponding to the austenite $\leftrightarrow$ martensite transformation [156]. After welding, two peaks were identified due to mixing of the two materials. However, it is interesting to note that, upon
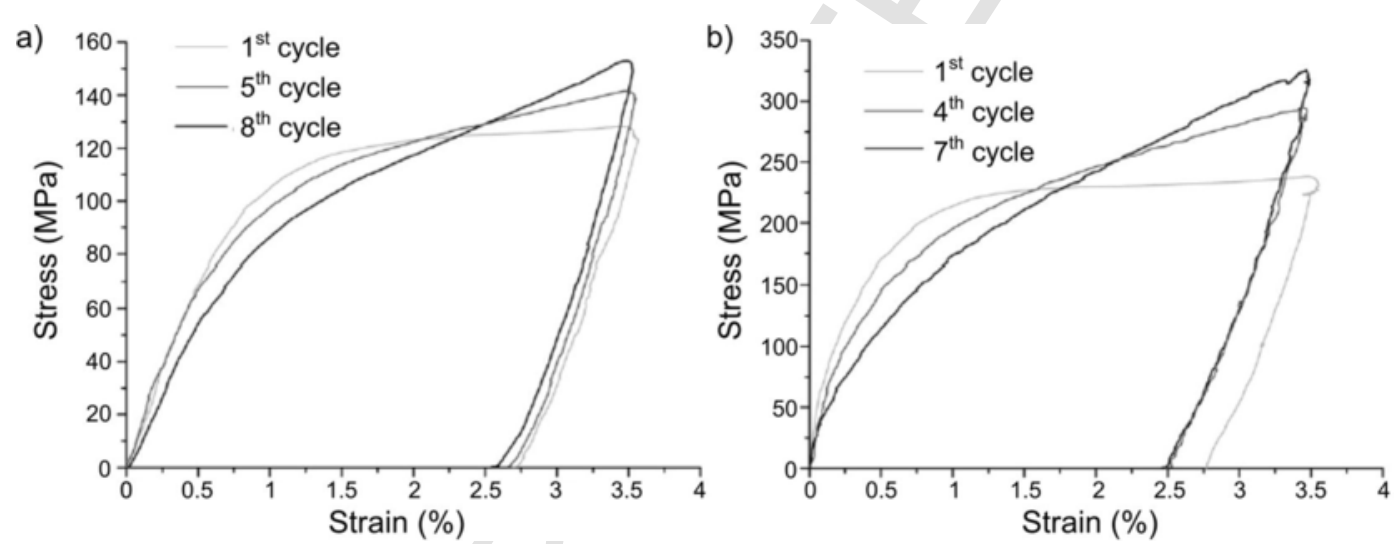

Fig. 28. Training cycles of: (a) base material; (b) welded joint (adapted from [130]).
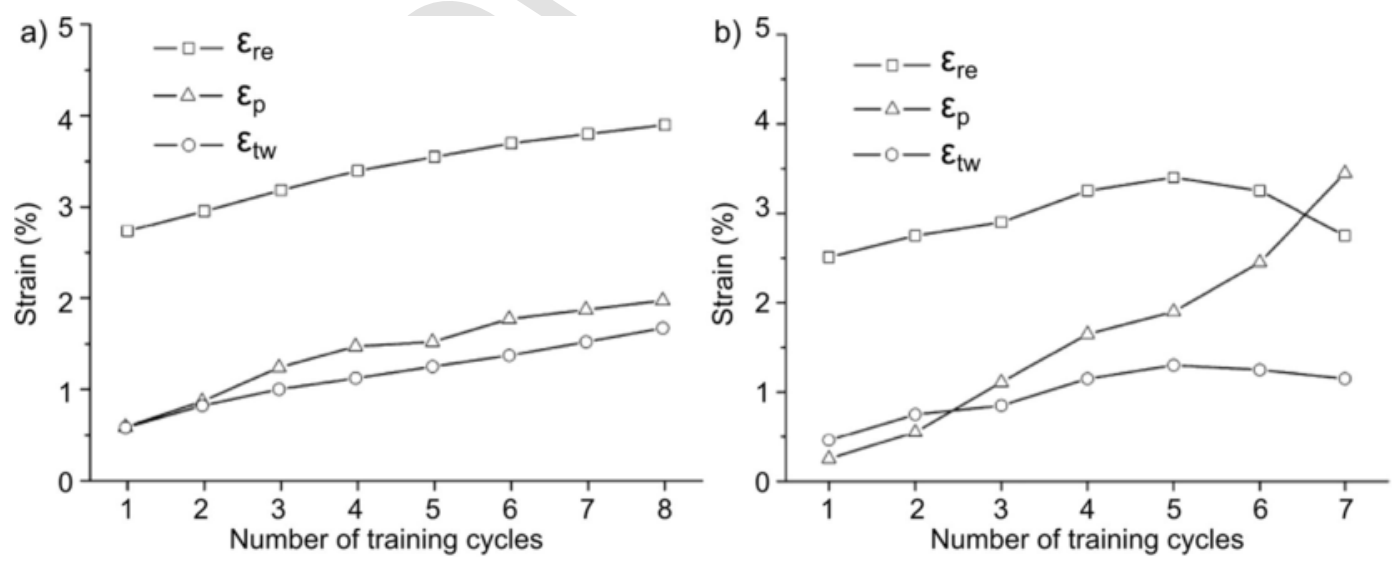

Fig. 29. Evolution of the shape memory behaviour and plastic strain with the number of cycles in: (a) base material; (b) welded joint (adapted from $[130]$. $\varepsilon_{\text {? }}-$ residual strain; $\varepsilon_{\text {?r }}-$ recovery deformation; $\varepsilon_{\text {?tw }}-$ two-way shape memory strain. 
cooling, a first transformation peak was observed which matched the transformation peak of the equiatomic base material, while the second peak identified was shifted to lower temperatures, when compared to the Ni-rich base material. Upon heating, the second transformation peak of the weld matched that of the Ni-rich base material. That is an increase of the Ni content on the Ni-rich NiTi alloy occurred since laser welding can be comparable to a solution treatment, and as such, a decrease in the transformation temperature on the thermal affected regions of the Ni-rich alloy happened which is in good agreement with existing knowledge [2].

\subsubsection{Phase transformation temperatures}

As known, transformations temperatures can be determined by differential scanning calorimetry [221,222], dilatometry [223] or electrical resistivity $[224,225]$. However, transformation temperatures of the thermal affected regions in NiTi welds have been mostly determined by differential scanning calorimetry, despite their small dimensions.

This problem was reported by [144] and, to overcome it, the minimum required dimension of the sample to be tested was remolten by the laser to simulate the FZ. However, it is very difficult to ensure that a given sample for thermal analysis has only one of the thermal affected regions [156].

A clear example of the effect of the base material initial condition, and its influence on the transformation temperatures of the FZ, was presented by Tuissi et al. [137] and is depicted in Fig. 30. The "type 1 material", was heat treated at $900{ }^{\circ} \mathrm{C}$ for $1 \mathrm{~h}$ prior to welding, and the welded region only had a slight increase in the transformation temperatures. The smooth increase of the heat flow signal prior to the $\mathrm{M}_{\text {?s }}$ temperature (upon cooling), observed in the laser welded joint can be related to a higher density of nucleation sites for martensite formation. For the "type 2 material", which, prior to welding, had a heat treatment at $400{ }^{\circ} \mathrm{C}$ for $20 \mathrm{~min}$, it was possible to detect a spreading of the transformation temperatures over a range higher than $80{ }^{\circ} \mathrm{C}$. This particular feature shows that a strong modification was introduced by the laser and individual contributions to a given transformation cannot be recognized properly.

Some of the changes in the transformation temperatures on the welded region were attributed to oxygen pick-up during welding by Hsu et al. [31] in equiatomic NiTi/NiTi joints, where a shift of $\mathrm{M}_{\text {?s }}$ to lower temperatures was observed, when compared to the base material (32 vs $38^{\circ} \mathrm{C}$, respectively). The oxygen content was measured and it was found to be significantly higher in the FZ. For NiTi, the increase in oxygen content is known to decrease the transformation temperatures by favouring the formation of Ti-rich secondary phases [226], and this reinforces the need for a good shielding protection, so that the contamination in the FZ is not detrimental to the joints properties.

Falvo et al. [138] stated that laser welding has the potential to reset the effect of cold-working and heat treatments on the welded joint. Comparing the differential scanning calorimetry curves of the base material and thermal affected regions (HAZ and FZ) in the same sample, depicted in Fig. 31, it was observed that the two-stage transformation, corresponding to austenite $\rightarrow$ R-phase $\rightarrow$ martensite gives place to a one-stage transformation from austenite to martensite. Cold-worked NiTi subjected to annealing heat treatments may show two-step transformation [227,228]. This thermal behaviour may be completely destroyed by the welding procedure.

Tuissi et al. [127] performed differential scanning calorimetry measurements in both base material, HAZ and FZ. Their findings show that in the base material and in the HAZ only one transformation peak is identified in both cooling and heating. However, in the FZ a partially overlapped two-step transformation was observed and was attributed to the presence of R-phase due to the imposed residual stresses after welding.

The effect of laser welding on the modification the transformation temperatures does not have always the same trend. For example, the $\mathrm{M}_{? \mathrm{~s}}$ temperature of the welded region can be lower than that of the base material $\left(-40.5\right.$ vs $2.2^{\circ} \mathrm{C}$, respectively [153]), or higher ( -10 vs below $-60^{\circ} \mathrm{C}[154]$, respectively). It is thus clear that, other microstructural features in the thermally affected
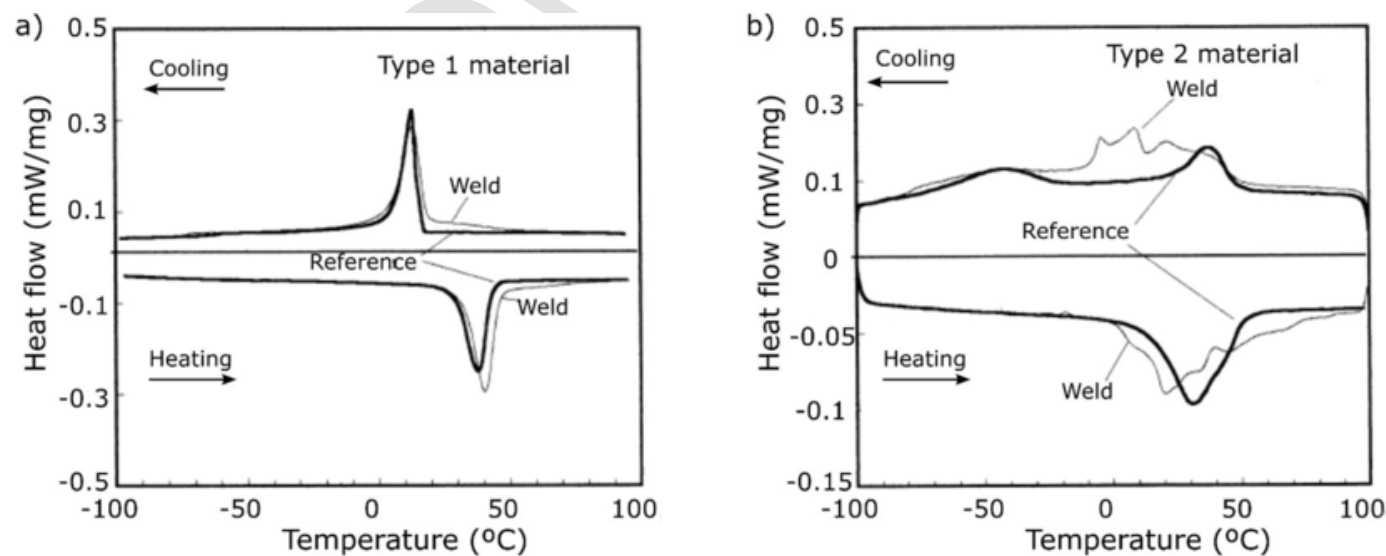

Fig. 30. Differential scanning calorimetry curves for base material and welded region where the base material had a heat treatment of: (a) $900{ }^{\circ} \mathrm{C}$ for $1 \mathrm{~h}$; (b) $400{ }^{\circ} \mathrm{C}$ for $20 \mathrm{~min}$ (adapted from [137]). 

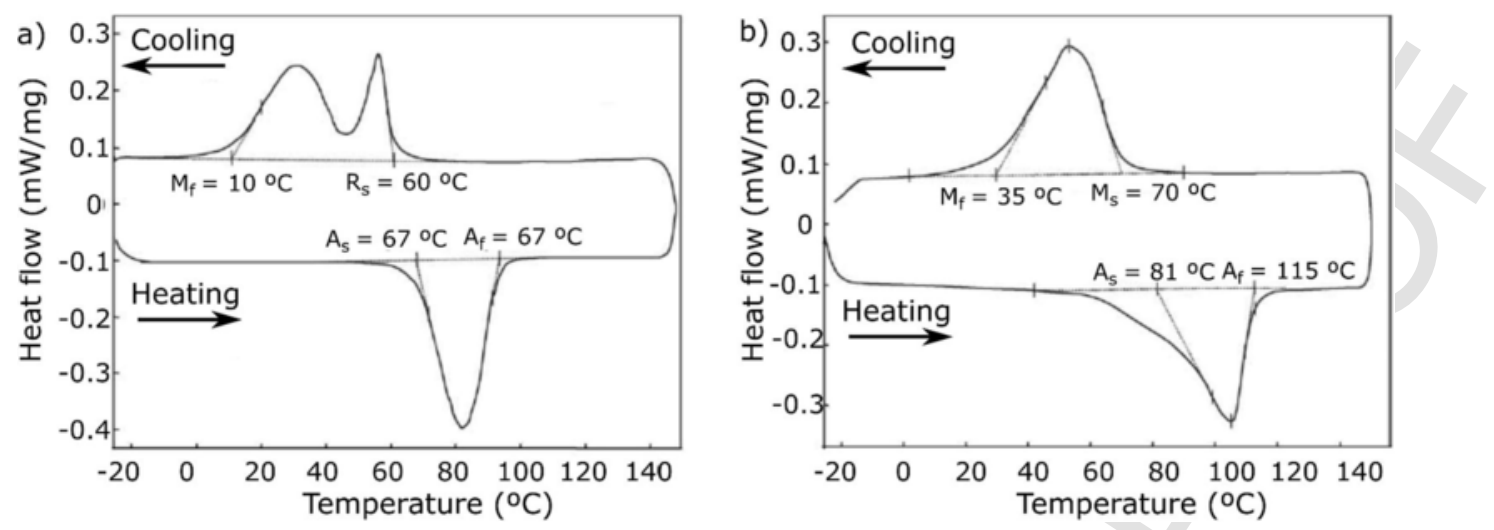

Fig. 31. Differential scanning calorimetry curves of: (a) base material; (b) thermal affected regions (heat affected zone and fusion zone) (adapted from [138]).

regions may have a role on these modifications. Namely, the possibility of laser-induced defects (as reported in [136]) or the observed grain size differences, when comparing the FZ to the base material [128,140,153], without excluding the possibility of precipitation phenomena as noticed in [132,148], or the incorporation of external elements during welding [31]. All these factors affect the transformation temperatures of NiTi.

Increased defect density is known to cause a broadening of the transformation peaks [229]. This broadening can be overturned by annealing. As such, when welding cold-worked NiTi, it was referred that laser welding acts as a solution treatment [156] and can reset the effects of cold-work and previous heat treatments [138], as stated previously. The dependence of the transformation temperatures with the grain size is related with the grain boundary area [230]. With a higher grain boundary area per unit of volume, corresponding to smaller grain size, nucleation sites also increase, leading to a narrower transformation peak. In opposition, for large grain sizes broadening of transformation peaks is expected to occur. As a general rule of thumb, increasing the grain size decreases the transformation temperatures.

Precipitation in NiTi modifies the local composition of the matrix. A Ni or Ti depletion occurs when either Ni or Ti-rich precipitates form. Chan et al. work [132], observed $\mathrm{Ni}_{33} \mathrm{Ti}$ in the welded region and so, it was expected a raise in the transformation temperatures due to the Ni depletion in the surrounding matrix. However, a decrease in the transformation temperatures was observed and attributed to thermally induced defects in the weld. In fact this is a complex issue and further research is still needed for a deeper understanding of the phenomena involved. The addition of alloying elements is also known to change the transformation temperatures of $\mathrm{NiTi}[2]$.

Laser processing of NiTi was performed by Khan et al. [231]. Although this is not a laser welding research, some interesting findings can still be applicable. In the laser processed material, full penetration of NiTi with a pulse overlap of $80 \%$ was attained. This can be then compared to bead on plate welding, which is normally used for determining the best range of parameters for butt welding. Differential scanning calorimetry of the processed region, where fusion occurred, revealed the presence of extra peaks at high temperatures when compared to the one-stage transformation observed, both in cooling and heating, in the base material. These extra peaks were due to a variation in the microstructure of the material after laser processing: while the base material was fully austenitic, the processed region had both austenite and martensite (observed by X-ray diffraction). As such, a good agreement between the thermal analysis and the microstructural characterization by X-ray diffraction was obtained. The existence of martensite in the processed region was explained based on preferential volatilization of Ni in the FZ [232]. In fact, Ni depletion increases the transformation temperatures [2]. So, the austenitic base material at room temperature prior to laser processing, experienced an increase in its transformation temperatures that allowed for martensite to be stable at room temperature, replacing austenite as the equilibrium phase. From [232] significant contributions can then be retrieved for understanding the implications of similar laser welding of NiTi joints. Namely, on how a material that is fully austenitic at room temperature can present, at room temperature, martensite in the FZ after welding; this may also justify the increase of transformation temperatures observed in this region when compared to the base material. Detailed structural characterization using synchrotron X-ray diffraction, performed by other authors, also showed, at room temperature, the presence of martensite in the fusion after welding, while the base material was austenitic [142,166,168,170]. In fact, it was observed in [170] that, after welding, in the HAZ and FZ of an originally fully austenitic NiTi SMA there is a variation of the phase fraction of martensite and austenite, with the martensite content increasing towards the weld centreline (Fig. 32).

It must be also noticed that for NiTi, differential scanning calorimetry is often used to index the transformation steps [206]. However, the transformation peaks observed with this technique do not provide direct information on the crystallographic phases that were formed [233]. As such, multi-step transformations, as reported in the literature for laser welding of NiTi [127,137], may then be misinterpreted. So, complementary analysis of both X-ray diffraction and differential scanning calorimetry can provide a solid basis to clearly identify the transformation characteristics in the welded material. 


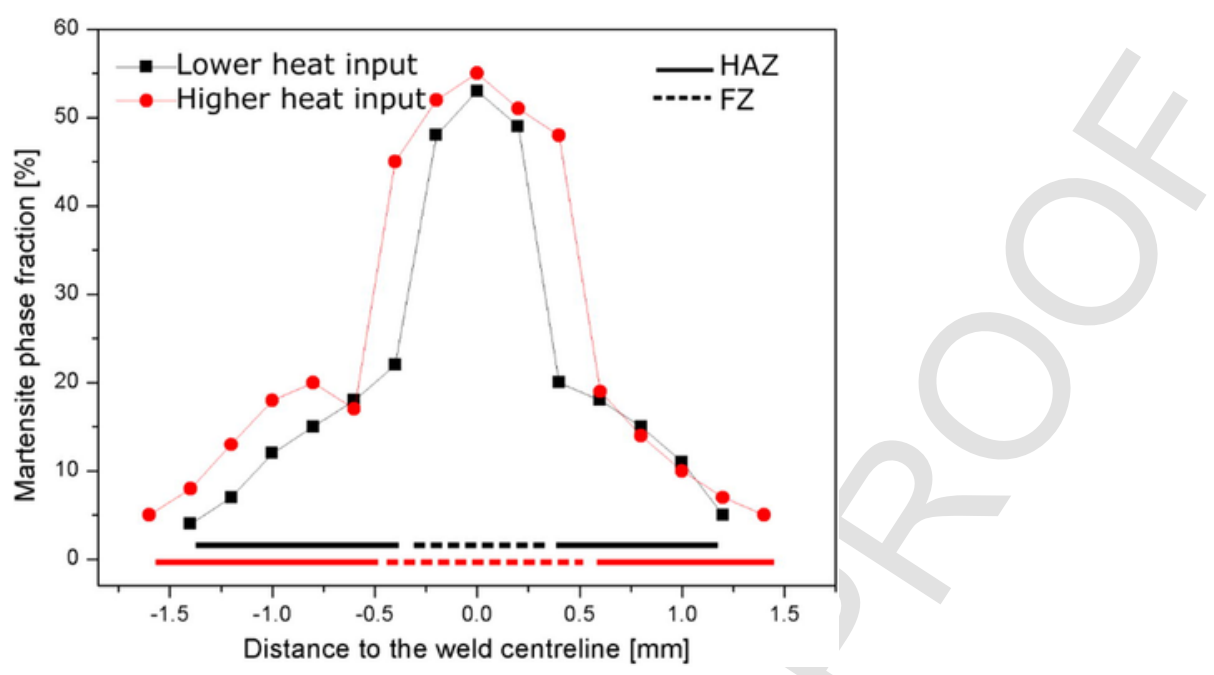

Fig. 32. Evolution of the martensite and austenite phase fraction in a laser welding NiTi joint with a fully austenitic base material (from [170]).

\subsubsection{Corrosion resistance}

Combining the shape memory effect and superelasticity to a good corrosion resistance turns NiTi into an ideal candidate for the biomedical industry, where devices such as stents [234] or archwires [235] are manufactured. It is reported that the corrosion resistance of NiTi is between that of stainless steel and Ti6Al4V alloy [236].

Due to its use in the biomedical field, corrosion resistance of NiTi is usually tested in fluids that simulate human body ones [237]. As the welded NiTi joints are intended for being used in such industry, it is, thus, important to understand how laser welding influences the corrosion resistance of NiTi and to assess this property for the long-term stability and biocompatibility of implants and devices [147]. Nickel release may occur when NiTi is in contact with body fluids [238] and can cause allergic, toxic or carcinogenic effects [239]. Thus, NiTi may require the use of barrier layers to prevent Ni into the human body [240].

Several works have studied the corrosion behaviour of laser welded NiTi [133,147,157-160,165]. The presence of heterogeneous microstructures can be detrimental to the corrosion resistance of NiTi [241]. As such, it would be expected that NiTi laser welded joints would present a lower corrosion resistance than the base material, due to the significant microstructural differences that can be found in the thermal affected regions. However, Yan et al. [165] showed that the welded joint had a superior corrosion resistance than the base material. Tests were performed in both $\mathrm{NaCl}$ and Hank's solutions with different concentrations and the breakdown potential measured in the welded joints increased. When analysing the base material, it was observed the presence of carbides. These were completely removed from the FZ due to the weld thermal cycle, resulting on an improvement of the corrosion properties of the joints. Aside from removing such carbides, an increasing Ti/Ni ratio was measured in the FZ [165], which is known to be beneficial for the improvement of the corrosion properties, of NiTi [242]. The welded specimens did not present a decrease in its corrosion properties, when compared to the base material, which was justified by the homogenization of the microstructure and the non-existence of weld defects in the FZ [133]. Similar findings were also reported by Yan et al. [157].

In another study, Yan et al. [147] showed that, aside from a raise of $700 \mathrm{mV}$ in the breakdown potential of the welded joint when compared to the base material, the former has a wider passive region, as shown in Fig. 33. Ruhlig et al. [158] also studied the local electrochemical activity of NiTi welds compared to the base material and did not find any significant differences between them.

In opposition to the aforementioned works on corrosion behaviour of laser welded NiTi, Hsu et al. [31] reported a significant decrease of those properties when tested in artificial saliva where the corrosion rate of the FZ was significantly higher $(274 \mu \mathrm{m} /$ year) than for the base material $(17 \mu \mathrm{m} / \mathrm{year})$. This decrease was attributed to the formation of intermetallic particles in the welded region, which were not reported by other authors. So, a good control of the laser welding procedure must be used to avoid the formation of undesirable intermetallic phases in the FZ.

The combination of both mechanical solicitations and the surrounding medium may significantly change the corrosion behaviour of NiTi [243]. As such, is of great importance to understand the corrosion performance of NiTi welds upon mechanical solicitation. Chan et al. performed two distinct works reporting the susceptibility to stress corrosion in Hank's solution of laser welded NiTi $[159,160]$. The corrosion resistance of NiTi comes from the formation of Titanium oxide [234], which forms spontaneously. However, during mechanical solicitation this passivating film may be damaged and not promptly restored. Localized corrosion in superelastic NiTi is strongly affected by the cracking of the surface oxide, crack opening/closing and passivation, mutually competing during cyclic mechanical loading in fluids [244]. Also, in chloride based mediums, such as the Hank's solution, the poor-self healing of the oxide films is intensified. Moreover, embrittlement of NiTi is more likely to occur due to hy- 


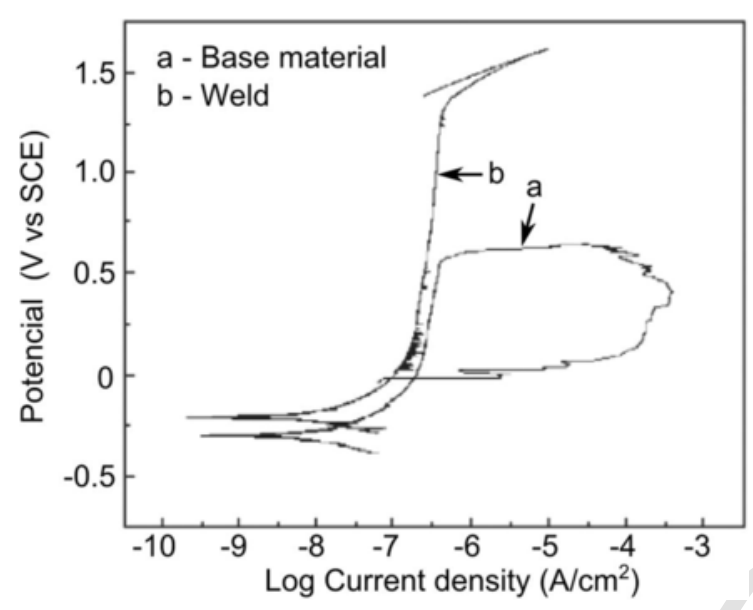

Fig. 33. Cyclic potentiodynamic polarization curves in $0.9 \% \mathrm{NaCl}$ solution of: (a) base material; (b) welded joint (adapted from [147]).

drogen absorption [245]. Stress-induced martensite was found to be more prone to oxidation than austenite [246], which must be considered when investigating the viability of using NiTi in possible corrosive environments where superelasticity is required.

In both $[159,160]$ studies, slow strain-rate tests were performed to analyse the mechanical properties of NiTi welds in Hank's solution. Chan et al. [159] found out that the HAZ was the weakest zone due to its coarse grain size. Stress corrosion cracking of the welded material occurred at a potential close to $E_{\text {?pit }}$ of that region, while the base material was immune at this potential. A small reduction on the UTS of the welds was reported at open circuit potential, as it can be observed in Fig. 34. Also, there is a clear change in the slopes of the regions II and III.

The analysis of the evolution of the open potential during the slow strain rate test, shown in Fig. 34, gives substantial information on the cracking and posterior re-formation of the oxide in the welded region. When the open circuit potential decreases, the oxide film is damaged, while, when it increases, growth of the oxide film occurs. At small strains (region I in Fig. 34), the oxide film is not damaged, so the open circuit potential remains almost constant. In region II, stress-induced martensite of the thermal affected regions occurs, as explained previously [151]. For this, the open circuit potential of the welded sample exhibited a mixed potential of both the base material and the thermal affected regions. Further increase of the applied strain leads to an almost constant decrease of the open circuit potential (region III). Two mechanisms take place in this region: (i) competition between film damage and its formation and (ii) increasing amount of stress-induced martensite. Region IV shows a sharp decrease of the open circuit potential due to necking. The occurrence of necking rapidly increases oxide damage, promoting the fracture of the welded material.

In [160], Chan et al. studied the cycling behaviour (10 cycles up to 4\% strain) of the welded material in the Hank's solution or in an inert environment. The more significant difference between the cyclic behaviour was a higher accumulated irrecoverable strain presented in Hank's solution (Fig. 35). This decrease in the superelastic properties of the welded material in the Hank's

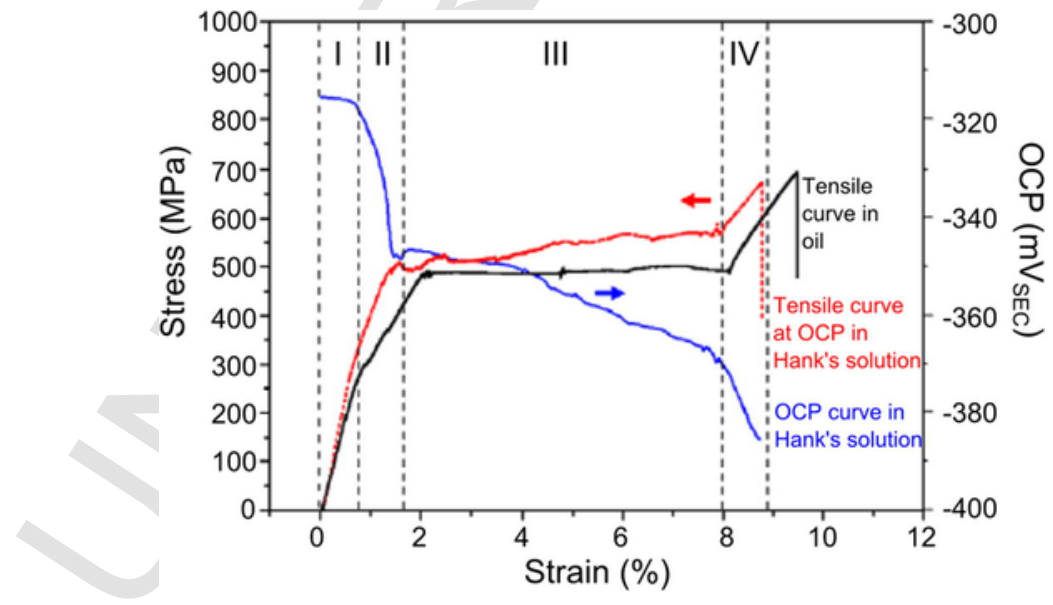

Fig. 34. Stress-strain behaviour of the welded material in oil (black curve) and in Hank's solution (red curve). The open circuit potential (OCP) of the weld in the Hank's solutions is represented by the blue curve (adapted from [159]). 


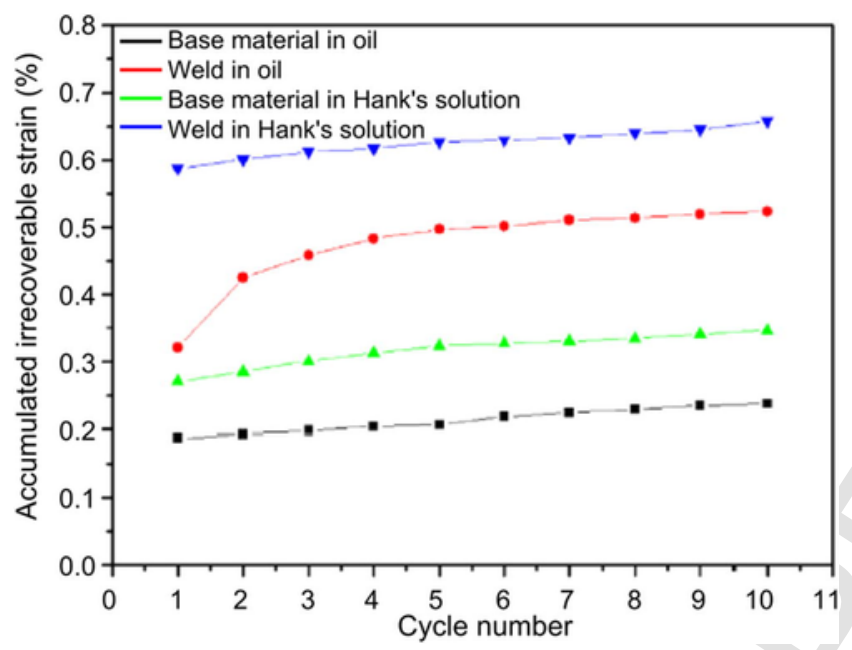

Fig. 35. Evolution of the accumulated irrecoverable strain with the number of cycles ( $4 \%$ strain) for: base material on oil (black); weld in oil (red); base material in Hank's solution (green); weld in Hank's solution (blue) (adapted from [160]).

solution was caused by presence of hydrogen in the repassivation of the oxide film. This welded sample showed the presence of hydrogen induced cracking and a brittle fracture.

An in vitro study of the biocompatibility after laser welding of NiTi was reported by Chan et al. [161]. In this study, the response of mesenchymal stem cells [247] on the effects induced by laser welding on the material (surface roughness, topography and $\mathrm{Ti} / \mathrm{Ni}$ ratio) were evaluated. A good biocompatibility of the welded material was reported based on the successful cell adhesion and spreading. Usually, cell spreading is a good indicator of the non-toxicity of a given material/medium [248]. Interestingly, it was pointed out that the morphology of those stem cells were modified by the topography of the FZ, namely its dendritic structure.

It is apparent that the corrosion performance of NiTi welds presents interesting behaviour that should allow their use in aggressive environments, where such type of joints may be of great use like in biomedical devices.

\subsubsection{Post-weld heat treatments}

Post-weld heat treatments are usually used for: stress relief of residual stress due to the weld thermal cycle [249] or optimization of the tensile properties of the welded material by obtaining a more suitable microstructure [250,251]. Accordingly, by choosing appropriate heat treatment parameters (temperature and time) the mechanical properties of the welds can be improved.

For Ni-rich NiTi shape memory alloys, precipitation of $\mathrm{Ni}_{? 4} \mathrm{Ti}_{? 3}, \mathrm{Ni}_{? 3} \mathrm{Ti}_{? 2}$ and $\mathrm{Ni}_{\text {?3 }} \mathrm{Ti}$ was seen to occur. $\mathrm{Ni}_{\text {? }} \mathrm{Ti}_{? 3}$ and $\mathrm{Ni}_{? 3} \mathrm{Ti}_{? 2}$ are metastable precipitates $[252,253]$ while $\mathrm{Ni}_{33} \mathrm{Ti}$ is the equilibrium precipitate $[2]$. For Ti-rich NiTi appropriate heat treatments can originate $\mathrm{Ti}_{?_{2}} \mathrm{Ni}[254]$.

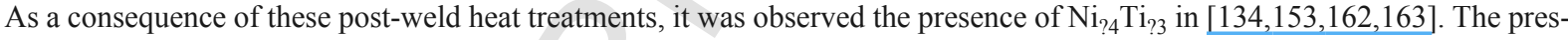
ence of $\mathrm{Ni}_{? 4} \mathrm{Ti}_{33}$ may improve the mechanical properties of NiTi as it can resist the plastic flow by acting as effective barriers to dislocation motion [153].

For Ni-rich NiTi, the heat treatments promote a raise in the transformation temperatures, due to Ni depletion of the matrix surrounding the Ni-rich precipitates [2]. This was also observed by Chan et al. [153] and is shown in Fig. 36. As such, it appears that the modification of the transformation temperatures of the welded region, after a post-weld heat treatment, is enhanced by the removal of structural defects (such as dislocations) and Ni depletion. In opposition, for Ti-rich welded NiTi, precipitates formed during heat treatments can promote a decrease in the transformation temperatures.

Fig. 36 shows that a two-step transformation took place after two different post-weld heat treatments performed in [153]. This is an indication that R-phase should exist as an intermediate phase during austenite $\leftrightarrow$ martensite transformation. Similar results were observed by Yan et al. [163]. R-phase formation is justified by the presence of $\mathrm{Ni}_{\text {? }} \mathrm{Ti}_{\text {? }}$ precipitates, which are known to promote the existence of coherency stress fields favouring the formation of this phase [255].

In Chan et al. work [153], the elongation at fracture could increase by $1 \%$, when compared to the non-treated weld, providing that the time and temperature chosen for the heat treatment were adequate. The onset for the stress-induced martensite can also be modified as shown in Fig. 37 [163].

The effect of post-weld heat treatments on the cycling behaviour of NiTi joints has been studied (Fig. 38) by Chan et al. [153]. While after the heat treatment, performed at $350{ }^{\circ} \mathrm{C}$ for $60 \mathrm{~min}$, superelastic behaviour is observed (Fig. 38a), after the heat treatment performed at $450{ }^{\circ} \mathrm{C}$ for the same time, a typical martensitic curve is identified (Fig. 38b). The absence of stress kinks, as reported by the same authors in [151] (shown in Fig. 19), is pointed out in Fig. 38. This gives an indication that the heat treatments have promoted a homogenization of the existing phases along the welded material. 


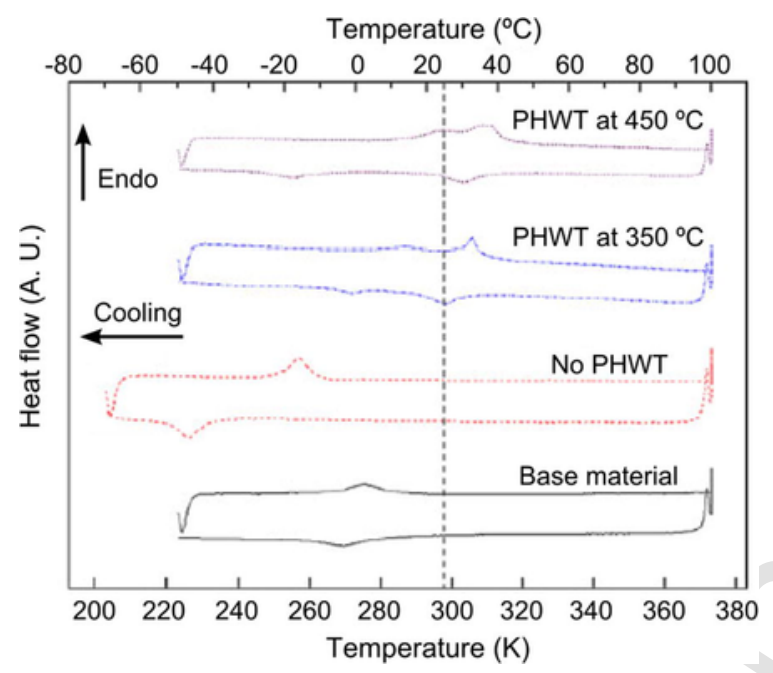

Fig. 36. Differential scanning calorimetry curves for the base material and fusion zone of NiTi welds with and without post-weld heat treatments (PHWHT). The dashed line represents room temperature (adapted from [153]).

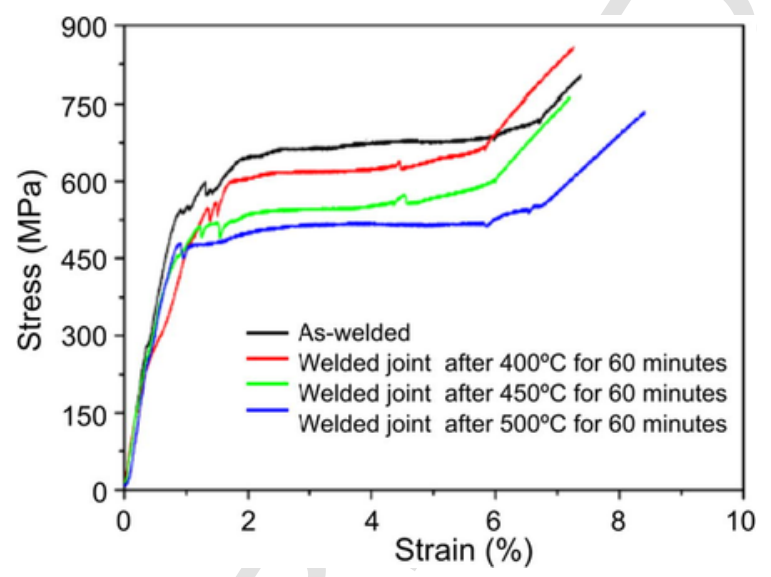

Fig. 37. Effect of post-weld heat treatments on the mechanical properties of laser welded NiTi joints (adapted from [163]).
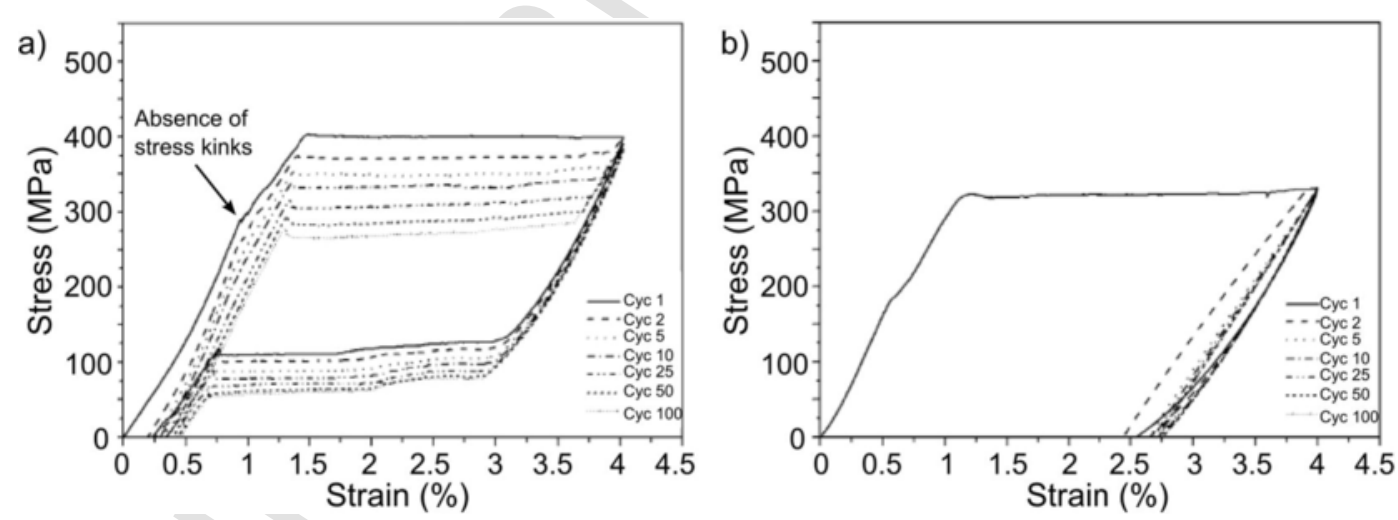

Fig. 38. Cycling behaviour of welded joints after heat treatment performed at: (a) $350{ }^{\circ} \mathrm{C}$ for $60 \mathrm{~min}$; (b) $450{ }^{\circ} \mathrm{C}$ for $60 \mathrm{~min}$ (adapted from [153]).

The irrecoverable strain observed in Fig. 38a is mainly due to martensite detwinning, as this phase is stable at the test temperature alongside with austenite. When compared to the weld without any post-weld heat treatment, an improvement, in terms of the irrecoverable strain, was observed. This behaviour was attributed to the fine precipitation of $\mathrm{Ni}_{24} \mathrm{Ti}_{23}$. For Fig. $38 \mathrm{~b}$ the irrecov- 
erable strain is more significant after the performed post-weld heat treatment, which changed significantly the transformation temperatures, allowing for martensite to be stable at the test temperature (room temperature), together with some austenite. An adequate choice of the post-weld heat treatment parameters is then required in order to preserve the functional properties of the welded joints.

Regarding the effects of post-weld heat treatments on the rotating-bending fatigue strength of the NiTi welds, Yan et al. [162] showed that with the appropriate heat treatment a significant improvement can be obtained (Fig. 39). While for both heat treatments $\mathrm{Ni}_{? 4} \mathrm{Ti}_{? 3}$ precipitation has occurred, a significant decrease in the fatigue strength was observed for the heat treatment performed at a higher temperature $\left(500^{\circ} \mathrm{C}\right.$ vs $400{ }^{\circ} \mathrm{C}$, for $\left.60 \mathrm{~min}\right)$. The reason for this behaviour, lays on the coarse grain size of such precipitates. When coarse $\mathrm{Ni}_{? 4} \mathrm{Ti}_{? 3}$ precipitates $(300 \mathrm{~nm}$ vs $10 \mathrm{~nm})$ are found in the material, the stress fields are attenuated with the introduction of dislocations to relax this misfit.

The corrosion behaviour of the welded joints can also be improved by choosing a suitable post-weld heat treatment, which depends on the initial condition of the base material. For example, Chan et al. $[133,134]$ reported that a post-weld heat treatment at $350^{\circ} \mathrm{C}$ for 60 min could greatly improve the corrosion resistance of the welded joints. In opposition, for a post-weld heat treatment at $450{ }^{\circ} \mathrm{C}$ for $60 \mathrm{~min}$, although an improvement was also reported, it was not as significant. This increase in the corrosion resistance behaviour, after the post-weld heat treatments, was attributed to $\mathrm{Ni}_{? 4} \mathrm{Ti}_{? 3}$ precipitation, which altered the surface composition. Moreover, aside from the raise in the $\mathrm{Ti} / \mathrm{Ni}$ ratio, due to Ni-rich precipitation, the $\mathrm{TiO}_{? 2} / \mathrm{TiO}$ ratio also increases, explaining, thus, the better corrosion resistance after the post-weld heat treatment.

During slow strain-rate tests in Hank's solution, Chan et al. 164$\rceil$ tested the cycling behaviour up to $4 \%$ strain for 10 cycles, of a NiTi weld with a post-weld heat treatment at $350{ }^{\circ} \mathrm{C}$ for $60 \mathrm{~min}$. A comparison was performed with the base material and with the weld with no post-weld heat treatment. In Fig. 40a the open circuit potential of the welded sample after heat treatment reveals a more stable pattern than the as-welded sample. The better corrosion resistance after the heat treatment is ensured by the higher value of the open circuit potential. Nonetheless, the corrosion behaviour of the heat treated welded sample is still lower than that of the base material in the Hank's solution. For the slow strain-rate cycling tests in the Hank's solution, the accumu-

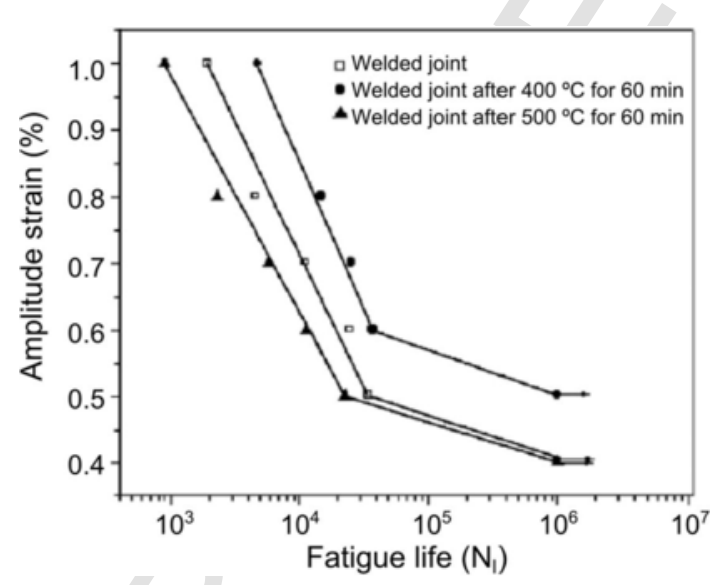

Fig. 39. Amplitude strain and number of cycles to failure for laser welded NiTi with and without post-weld heat treatments (from [162]).
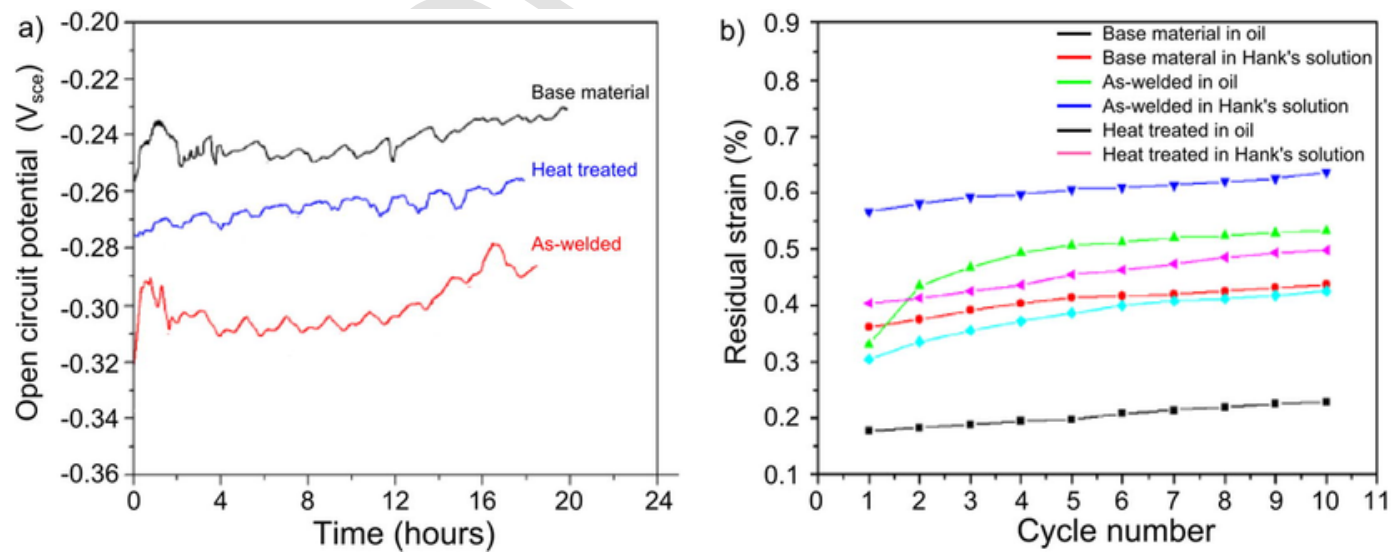

Fig. 40. Effect on the post-weld heat treatments on laser welded NiTi: (a) variation of the open circuit potential during slow strain-rate cycling test (10 cycles up to $4 \%$ strain) in Hank's solution; (b) evolution of the accumulated irrecoverable strain during the cycling tests in different environments (adapted from [164]). 
lated irrecoverable strain of the welded sample after heat treatment significantly decreases, when compared to the as-welded sample (Fig. 40b). As such, superior superelastic behaviour was obtained. If the welds are to be subjected to stress corrosion conditions, the lower residual stresses achieved after adequate post weld heat treatment have a beneficial effect on the weld performance.

It is, thus, apparent that post-weld heat treatments, can in fact optimize the mechanical and functional properties of the welded NiTi joints. For this, it is necessary to choose the optimum conditions for the heat treatment.

\subsubsection{Filler materials}

Though laser welding is usually performed under autogenous conditions, in particular cases a filler material can be used to improve mechanical properties by suppressing undesired phases or by promoting a more appropriate microstructure [256]. Since laser welding of NiTi can be easily performed, provided that the welding parameters are carefully selected, few studies exist on the use of filler materials in similar NiTi joints. However, since the transformation temperatures of NiTi are also dependent on the alloying elements [2], the use of a filler material can be interesting to tune the transformation temperatures of the welded joints and their mechanical response.

Zhao et al. [148,149] reported the use of Cerium as a filler in laser welding of Ni-rich NiTi sheets. In [148], the microstructural differences between Cerium-filler and non-filler laser welds were analysed. Optical microscopy did not reveal any significant difference between both joints. By energy-dispersive X-ray spectroscopy only a small variation of the chemical composition was observed in the fusion boundary that could have resulted from the complex mixtures of different structures. The effect of the Cerium addition was clear by X-ray diffraction, which showed the presence of $\mathrm{CeO}_{? 2}$ particles uniformly dispersed in the FZ.

Concerning the mechanical response of the welded NiTi joint, with and without Cerium, a two-stage superelasticity was reported in the latter [149], as depicted in Fig. 41.

This peculiar behaviour was attributed to co-existence martensite. The microstructure of Cerium-added welds resembled a heat treatment microstructure with $\mathrm{CeO}_{? 2}$ and Ni-rich precipitates uniformly dispersed in the surrounding matrix. As such, when compared to the base material, the Cerium-added weld shows a two-stage superelasticity with a first plateau at the same critical stress of the base material and a second plateau at a significantly higher stress level. This feature conveys to the welded joint a higher apparent rigidity.

$\mathrm{Ce}$ and $\mathrm{Nb}$-additives were introduced in NiTi joints by Zhao et al. [257]. For Cerium addition a thin foil of (50.9Ni-49.1Ti)-2Ce (at.\%) was placed between the $50.9 \mathrm{Ni}-\mathrm{Ti}$ (at.\%) base material. Niobium addition into the FZ was achieved by laser welding the same base material with $47 \mathrm{Ni}-44 \mathrm{Ti}-9 \mathrm{Nb}$ (at.\%). The mechanical properties of the additive-welded joints were superior to those of the similar joints, as shown in Fig. 42. The improvement of the mechanical properties of the additive joints is explained through the fine solidification structures with a good grain-linking in the weld centre, in opposition to a coarse grain structure in the non-additive joints. So, the main effect of the Cerium or Niobium addition was to refine the microstructure of the weld. Second phases were found to exist in both $\mathrm{Ce}$ and $\mathrm{Nb}$-additive joints: $\mathrm{Ce}$-oxides and $\beta$ - $\mathrm{Nb}$ phase, respectively, and were not found to be detrimental to the joints properties.

Li et al. [150] laser butt welded Ti-rich NiTi using a pure Copper interlayer between the interfaces to be joined. Structural analysis by micro X-ray diffraction revealed the presence of $\mathrm{Ni}_{? 4} \mathrm{Ti}_{? 3}$ and a significant amount of intermetallics Cu-based compounds: $\mathrm{CuTi}, \mathrm{Cu}_{? 4} \mathrm{Ti}_{? 3}, \mathrm{Ti}_{? 4} \mathrm{Cu}_{? 3}$ and $\mathrm{Cu}_{? 3} \mathrm{Ti}_{? 2}$. These precipitates were found to increase the hardness of the welded joint compared to the base material. Tensile tests of the welded joints revealed a $50 \%$ decrease on the mechanical proprieties when compared to the as-welded joint. This significant decrease may be related to the formation of Cu-based intermetallics which contributed to a mixed ductile-brittle morphology on the fracture surface of the FZ. The welded joint presented shape memory effect after welding (recovery of $99 \%$ of the imposed deformation).

In theory, different filler materials can be used to obtain different properties of the welded joints, namely Au, Co, Fe, Hf, $\mathrm{Pd}$, Pt or Zr, as they are all elements which can create NiTiX shape memory alloys, being X a given element [2,258]. The main

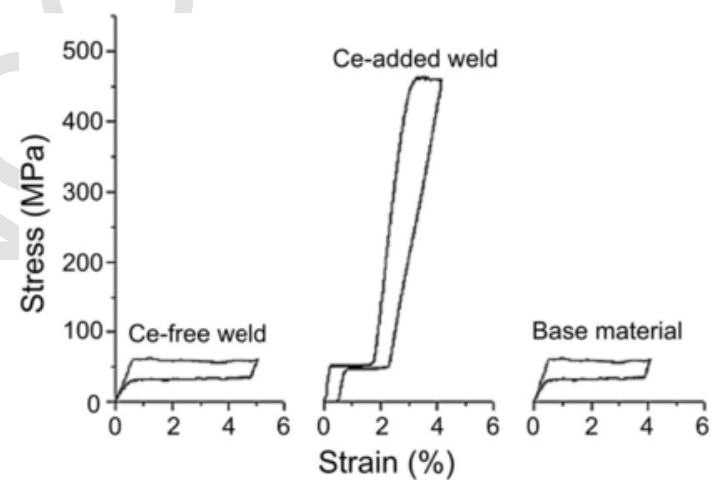

Fig. 41. Stress/strain behaviour of base material and laser welded NiTi joints with and without Cerium addition (adapted from [149]). 

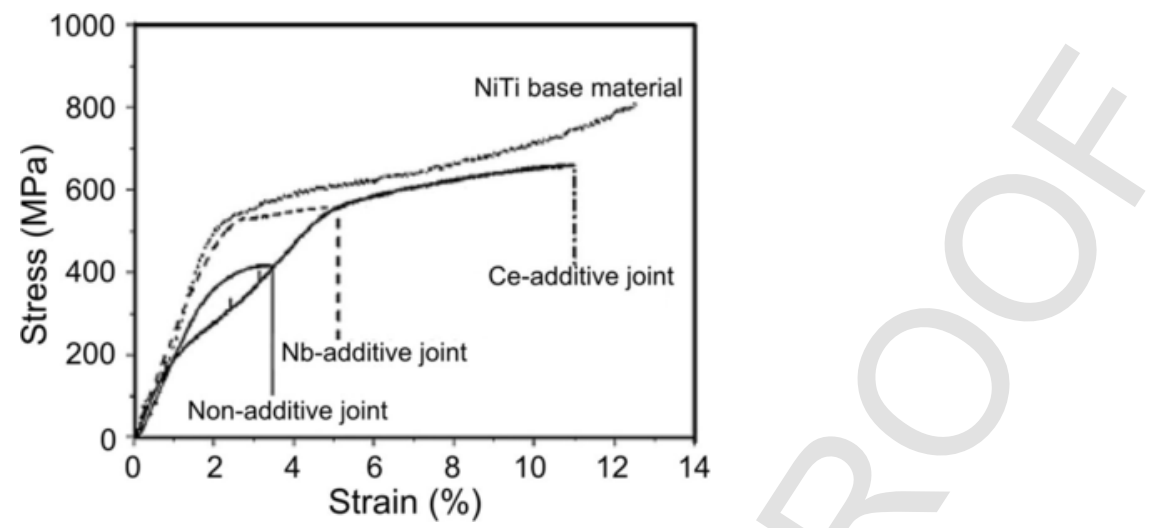

Fig. 42. Tensile tests on base material and both additive and non-additive joints (adapted from [257]).

problem to overcome would be to properly select the thickness of the filler material so that, its amount, in the FZ, could create an alloy with the appropriate composition to exhibit shape memory and/or superelastic properties.

\subsection{Laser welding of dissimilar joints involving NiTi}

Multimaterial components involving different materials are facing increasing applications for both technical and economic reasons, and these constitute a challenge as far as welding and joining are concerned. These multimaterial joints can provide better and more flexible solutions, as they can take benefit of the individual properties exhibited by the materials involved. For example: heat, wear and corrosion resistances can be optimized [259,260]. However, the different thermo-physical and chemical properties of the materials pose difficult welding problems related to the formation of brittle phases and segregations, as well as the existence of significant residual stresses due to physical mismatch of the welded materials. Although some of these problems can be solved using solid state techniques, such as friction-stir welding or adhesive bonding, others may arise. For example, a specific joint geometry can make friction-stir welding unfeasible; diffusion welding can have superior technical benefits to obtain dissimilar metals combinations, but such technique is time consuming, leading to increased costs during the manufacturing process [259]. Laser welding has significant advantages in these cases. In particular, the high power density of the process, the possibility to have reduced thermal affected regions, easy to control process, flexibility and reproducibility, makes it a suitable joining technique for promoting dissimilar joining of metals [260]. However, the effectiveness of laser welding to promote sound dissimilar joints, is highly dependent on the physical properties of the materials to be welded [261]. Electron beam welding can be a competitor, but the need of a vacuum system is a disadvantage towards laser welding, as higher production rates can be obtained with the latter technique.

The transport phenomena, namely heat transfer, fluid flow and elements distribution, can be numerically modelled for laser welding of dissimilar metals [262]. It must be noticed that the metallurgical phenomena involved (due to Marangoni effect and convection in the weld pool alongside with melting and mixing) on welding of dissimilar metal combinations can be extremely complex. Nonetheless, mathematical modelling and simulation can be used to get a better knowledge on the physical processes which occur in the FZ [263-265].

Dissimilar laser welding of NiTi mainly involves three engineering materials: carbon steel, stainless steel and Ti alloys, particularly, Ti6Al4V. However, other dissimilar combinations have been studied. As such, this section is divided in three sub-sections. This review aims to discuss NiTi/steel and NiTi/Ti6Al4V welding, due to their industrial importance, but also other attempts of joining different materials to NiTi are reported. This discussion includes microstructural effects and mechanical properties of the joints. The corrosion behaviour of the dissimilar welded joints is also discussed (whenever applicable).

\subsubsection{NiTi/steel}

Due to the biocompatibility of austenitic stainless steel [266,267] and the functional properties of NiTi, joining these materials is highly desired for biomedical applications $[268]$ as clamping and/or crimping methods would be easily replaced. However, due to the alloying elements in steels several intermetallic compounds can occur in fusion based processes. Thus, highly focused heat sources with reduced thermal affected regions are envisaged for these applications. Some of the possible intermetallics to be formed in the $\mathrm{FZ}$ of dissimilar NiTi/steels joints are $\mathrm{Ti}_{{ }_{2}} \mathrm{Fe}, \mathrm{Ti}_{{ }_{2}} \mathrm{Cr}, \mathrm{Ti}_{? 2} \mathrm{Ni}$ and $\mathrm{Fe}_{?_{2}} \mathrm{Ti}$, for example.

By carefully controlling the process parameters, Gugel et al. [128] were able to obtain faultless NiTi/austenitic steel joints. Optical microscopy of the dissimilar joints did not reveal a coarse grain microstructure, in opposition to the similar NiTi/NiTi joints described previously. Hardness measurements in the FZ were significantly affected by the presence of brittle intermetallics: while the maximum hardness in the NiTi and steel base materials were of 300 and $600 \mathrm{HV}$, respectively, and the FZ had a maximum of $950 \mathrm{HV}$. The dissimilar joints fractured at the end of either the NiTi FZ or the steel HAZ. 
Of particular importance in Gugel et al. work [128] is the fact that the joint strength was of about $620 \mathrm{MPa}$, that is higher than the onset for the superelastic behaviour of $\mathrm{NiTi}(\approx 400 \mathrm{MPa}[269])$. So, it was possible to obtain superelastic behaviour of the $\mathrm{NiTi} / \mathrm{steel} \mathrm{joints} \mathrm{opening} \mathrm{a} \mathrm{wide} \mathrm{range} \mathrm{of} \mathrm{possibilities} \mathrm{in} \mathrm{different} \mathrm{industries.} \mathrm{The} \mathrm{superelastic} \mathrm{behaviour} \mathrm{of} \mathrm{the} \mathrm{dissimilar} \mathrm{joints}$ was studied for a total of $10 \mathrm{load} /$ unload cycles up to $2.5 \%$ strain. The superelastic plateau was observed slightly before $1 \%$ strain and an almost negligible irrecoverable strain after each unloading was recorded. It must be noticed that the authors stated that although it is possible to obtain sound joints in very thin wires, as in [128], similar results may be difficult to obtain when trying to joint bulk material. This is due to the significant differences in the relative importance of the brittle intermetallics formed in the FZ of thin wires, when compared to plates or wires of higher calibre.

Similarly to carbon steels, dissimilar joining NiTi to stainless steel can originate severe metallurgical problems as a consequence of the formation of brittle intermetallics in the FZ. These metallurgical problems were described by Pouquet et al. [172] for overlap welding thin foils of NiTi and stainless steel. The joint configuration was found to be of great importance to promote full penetration: when NiTi was placed on top of stainless steel a higher energy was required. Homogenization of the weld pool could also be manipulated by controlling the pulse duration, as better mixing was obtained when the pulsed duration increased. Without the addition of filler material several defects were observed in the FZ due to presence of brittle intermetallics, such as $\mathrm{Fe}_{? 2} \mathrm{Ti}$. In order to minimize, or suppress, these intermetallic compounds, a Ni interlayer was positioned between the base materials. Cracking in the $\mathrm{FZ}$ was reduced due to the suppression of $\mathrm{Fe}_{{ }_{2}} \mathrm{Ti}$, while $\gamma(\mathrm{FeNi})$ and $\mathrm{Ni}_{{ }_{3}} \mathrm{Ti}$ were observed. Similar results were presented by Mirshekari et al. [143] using a butt joint configuration. The dissimilar joints presented poor UTS (200 MPa) and fracture occurred along the weld centreline with brittle characteristics. X-ray diffraction analysis revealed the existence of several brittle intermetallics compounds: $\mathrm{Fe}_{? 2} \mathrm{Ti}, \mathrm{Cr}_{? 2} \mathrm{Ti}, \mathrm{FeTi}, \mathrm{Ni}_{? 3} \mathrm{Ti}$ and $\mathrm{Ti}_{? 2} \mathrm{Ni}$. It is evident that, from the aforementioned results, that a careful control of the process parameters, joint configuration and use of filler materials determine the ability to obtain sound $\mathrm{NiTi} /$ steel joints.

Such a precise control of the conditions to promote a sound joining between NiTi and stainless steel was already achieved by some authors $[17,19,173,174,176,177]$. Vannod et al. [17] presented a very in-depth study on the characterization of NiTi/ stainless steels joints using wires. Crack-free joints were obtained and the UTS of the welds was above the superelastic plateau of NiTi. Using in-situ tensile testing it was possible to observe that a crack appeared at the begging of the superelastic plateau of the welded joint, in the transition zone between the melted region and NiTi. However, it did not evolve during the plateau. In fact, only at the end of the superelastic plateau, where an increased stress is required to continue deformation, the crack propagated along the perimeter of the weld. The sudden crack opening has reduced the cross section of the welded joint and, as such, an increased stress was observed at which the joint failed $(\approx 620 \mathrm{MPa})$. SEM imaging of the dissimilar welded joint just before the end of the superelastic plateau is shown in Fig. 43. The cracks (marked by dashed white circles) are formed in the transition between the fusion and HAZ on the NiTi side propagating almost parallel to this region.

In order to understand the mechanism that justified the observed cracking and subsequent failure, a model was developed in order to investigate the stress-strain behaviour of the welded joint. It was observed that the contact of NiTi with a much harder zone, the FZ, confined the largest stresses to the region where the cracks were initiated. Another fact that contributed to this increased stress in the neighbourhood of NiTi, was the fact that this region was in tension not only along the axial component, but also in both hoop and radial components [17].

This peculiar site for crack initiation and propagation was studied in more detail [175] by a new 3D-EDS technique combining both FIB and SEM. With such configuration it was possible to obtain multiple EDS spectra of the region of interest and different heights (steps of $100 \mathrm{~nm}$, with a total of 352 EDS maps). From the 3D stacks of EDS measurements, based on the Fe-Ni-Ti ternary phase diagram, it was possible to identify the phases, which had coarse structures, such as dendrites and these were Fe ${ }_{? 2} \mathrm{Ti}$ and $\gamma-(\mathrm{Fe}, \mathrm{Ni})$. For finer structures, as eutectics, 3D scattered electron images were able to resolve these microstructures $(\gamma-(\mathrm{Fe}$, $\mathrm{Ni} / \mathrm{Fe}_{? 2} \mathrm{Ti}$ and $(\mathrm{Fe}, \mathrm{Ni}) \mathrm{Ti} / \mathrm{Ni}_{? 3} \mathrm{Ti}$ ). From this study it was retained that the region where the cracks initiate during tensile tests did not comprise any intermetallics layer, but rather a complex mixture of intermetallic compounds originated from different solidification conditions during welding.

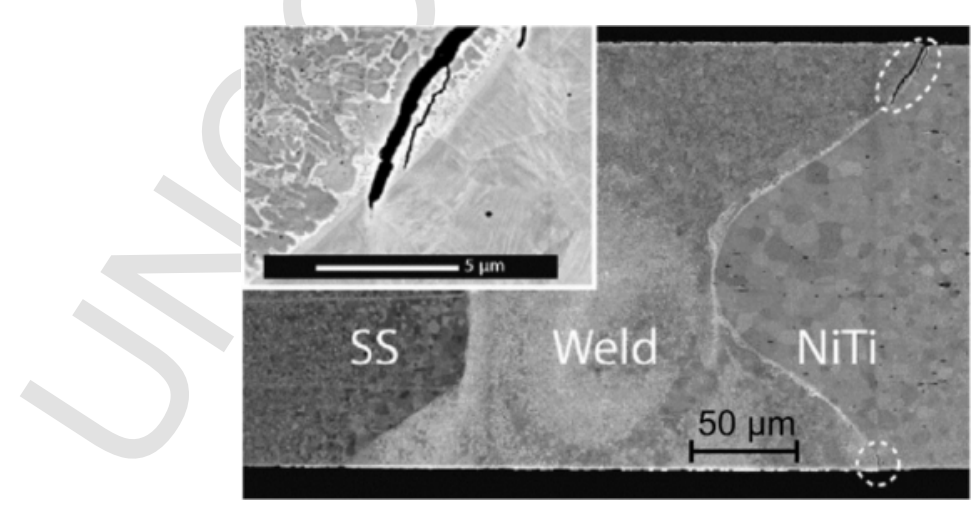

Fig. 43. SEM image of the NiTi/stainless steel joint deformed up to end of the superelastic plateau (adapted from [17]). 
From the aforementioned studies on laser welding of NiTi to steels (stainless included) the dimensions of the base materials are rather small (up to $1 \mathrm{~mm}$ in thickness or diameter), which limits their use in structural applications. An interesting approach was made by Hahnlen et al. [173] when welding thick tubes (5.08 and $9.53 \mathrm{~mm}$ of outer diameter) of NiTi to 304 stainless steel using Ni filler between both base materials. The welding procedure consisted on rotating the base materials while a laser was pulsed, creating a continuous FZ. While in similar joints three different regions are usually observed (base material, heat affected and fusion zone), two extra regions were identified by Hahnlen et al. [173]: partially mixed zone and unmixed zone. It must be noticed that within the FZ it was possible to identify several partially mixed zones, with different compositions. The unmixed zone - occurred when the melted base material had no mixing with the remaining FZ. An increase in hardness was observed in the thermal affected regions of the dissimilar joints. However, by diluting the weld pool, the Ni filler was able to partially suppress the formation of brittle intermetallics. The mechanical behaviour of the welded joints was evaluated by torsional tests; while the samples were being loaded, the applied torque and the angular displacement were measured (Fig. 44, corresponding to the $5.08 \mathrm{~mm}$ thick tubes). Elastic loading of twinned martensite was followed by detwinning of this phase, at a low torque-angle slope. Afterwards, elastic deformation of detwinned martensite preceded the plastic deformation region, where fracture occurred. The corresponding ultimate shear stresses of the welded samples ranged from 312 to $481 \mathrm{MPa}$. Pinhole defects were observed on the joint that presented the lower mechanical properties. These defects acted as stress concentration points causing premature failure $[270]$.

A different torque-angular displacement relationship was observed for $9.53 \mathrm{~mm}$ thick laser welded tubes (Fig. 45). The higher thickness of the tubes promoted a significant stress gradient along the tube. Thus, it was possible that NiTi was completely detwinned in the outer surface, while the inner surface had not yet reached the critical stress for the onset of detwinning. Nonetheless, it is apparent that some detwinning occurs for these large welded tubes and the shape memory effect can be triggered with a temperature raise above $\mathrm{A}_{\text {?f }}$ of the NiTi base material. It was also observed that the stainless steel was plastically deformed during mechanical testing, suggesting that the joint strength was higher than the yield strength of the stainless steel base material. Fracture of all welded samples occurred with brittle characteristics along the fusion boundary on the NiTi side. The

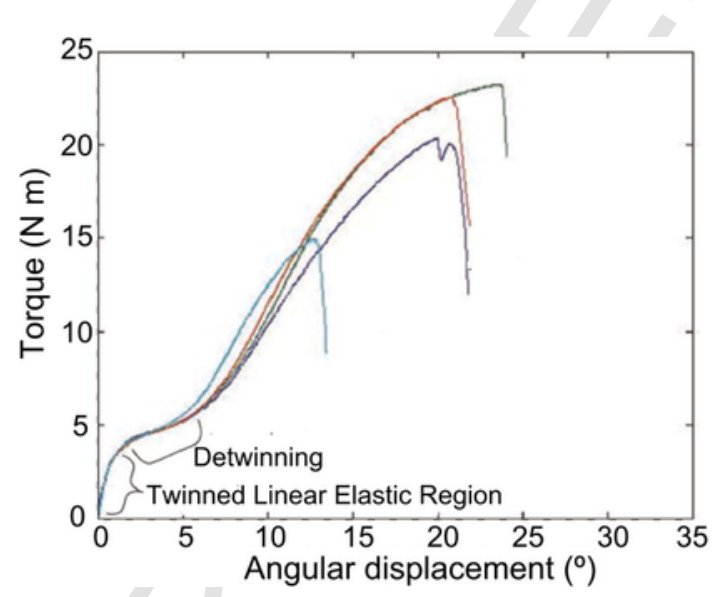

Fig. 44. Torque-angular displacement plot for different samples of $5.08 \mathrm{~mm}$ dissimilar welded tubes (adapted from [173]).

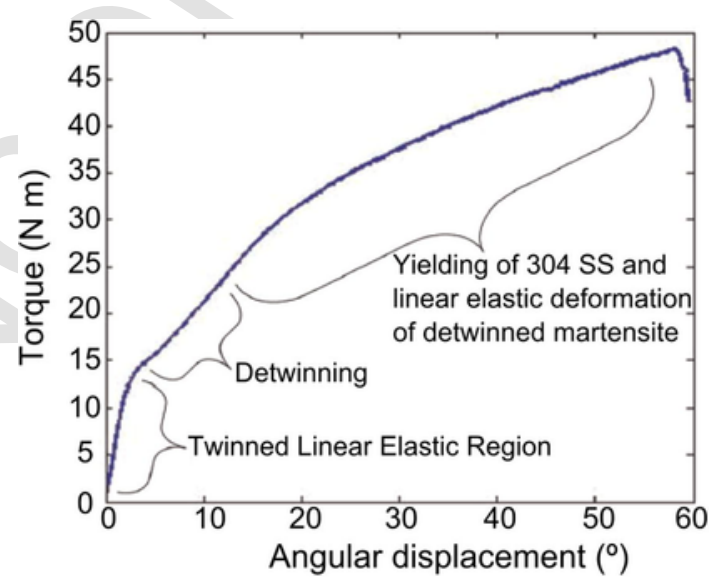

Fig. 45. Torque-angular displacement plot for different samples of $9.53 \mathrm{~mm}$ dissimilar welded tubes (adapted from [173]). 
mechanical properties exhibited by the welded joints in Hahnlen et al. study [173] is of significant importance as far as structural applications are concerned, as these joints were able to overcome the onset for martensite detwinning and the yield strength of AISI 304 stainless steel.

Similarly to Pouquet et al. [172] the use of filler materials between NiTi and stainless steel in butt joint configuration was performed by Li et al. in $[19,176,177]$ using $\mathrm{Co}, \mathrm{Ni}$ and $\mathrm{Cu}$ interlayers, respectively. In these studies a similar finding is observed: interlayers can promote better mechanical properties of the welded joints as they reduce the amount of brittle precipitates, such as: $\mathrm{Fe}_{? 2} \mathrm{Ti}$ or $\mathrm{Cr}_{? 2} \mathrm{Ti}$. However, excess of filler material inside the $\mathrm{FZ}$ may promote the formation of other intermetallics based on the added element such as $\mathrm{Ti}_{33} \mathrm{Cu}, \mathrm{Ti}_{33} \mathrm{Co}$, and $\mathrm{Ni}_{33} \mathrm{Ti}$, for $\mathrm{Cu}$, Co and $\mathrm{Ni}$ interlayers, respectively. Although the results are similar, the effect of each element on the welded joints has a particular role.

For the Ni interlayer [176], it was observed that the dilution of the FZ occurred by increasing the interlayer thickness (ranging from 10 to $100 \mu \mathrm{m}$ ), as depicted in Fig. 46. As $\mathrm{Ni}$ is a $\gamma$-stabilizer, the increase in Ni content promoted the formation of $\gamma$-Fe. Confirming the evolution of the weld content with interlayer thickness, structural characterization by means of X-ray diffraction revealed a decrease in the intensity peaks of $\mathrm{Cr}_{?_{2}} \mathrm{Ti}$ and $\mathrm{Ti}_{{ }_{2}} \mathrm{Ni}$. However, excess of $\mathrm{Ni}$ content in the $\mathrm{FZ}$, aside from introducing defects such as shrinkage cavities and increase the susceptibility to gas pores, promoted the formation of $\mathrm{Ti}_{33} \mathrm{Ni}$. The mechanical properties of the welded joints were also related to the interlayer thickness. The maximum strength was observed for a thickness between 40 and $60 \mu \mathrm{m}(\approx 370 \mathrm{MPa})$. All welded joints fractured along the FZ on the NiTi side in a brittle-like mode.

Addition of Co into the FZ [19] was also investigated, since the analysis of the binary phase diagrams of $\mathrm{Fe}-\mathrm{Co}, \mathrm{Ni}-\mathrm{Co}, \mathrm{Cr}-\mathrm{Co}$ and $\mathrm{Ti}-\mathrm{Co}$, it can be observed that $\mathrm{Co}$ and $\mathrm{Fe}, \mathrm{Ni}, \mathrm{Cr}$ and $\mathrm{Ti}$ have full solubility in the liquid state, while in the solid state there is limited solubility [271]. The influence of Co addition on the hardness of the FZ is clearly depicted in Fig. 47. Improvement of the mechanical properties of the joints was achieved after insertion of the Co interlayer (UTS of $345 \mathrm{MPa}$ vs $200 \mathrm{MPa}$ for the joint without interlayer). These improved mechanical properties were caused by the decrease of intermetallics compounds, such as: $\mathrm{Fe}_{{ }_{2}} \mathrm{Ti}$ or $\mathrm{Cr}_{? 2} \mathrm{Ti}$, which were partially replaced by $\mathrm{TiCo}, \mathrm{Ti}_{{ }_{2}} \mathrm{Co}$ and $\mathrm{Co}_{{ }_{2}} \mathrm{Ti}$ as identified by X-ray diffraction.

Regarding the use of $\mathrm{Cu}$ interlayer between NiTi and stainless steel [177], it was observed that, above a critical thickness of the interlayer $(80 \mu \mathrm{m}), \mathrm{Cu}$ segregation areas were encountered in the FZ. The hardness of the FZ could also be tuned by control-

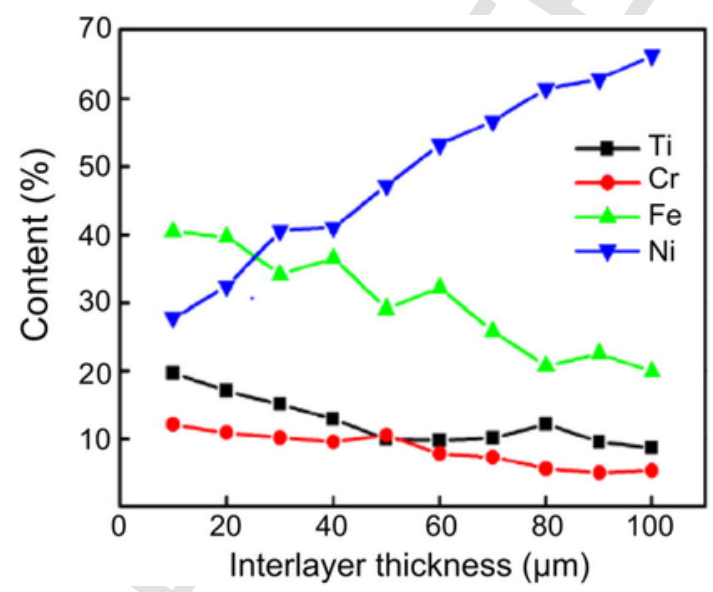

Fig. 46. Effect of Ni interlayer thickness on the contents of Ti, $\mathrm{Cr}$, Fe and Ni within the FZ (adapted from [176]).

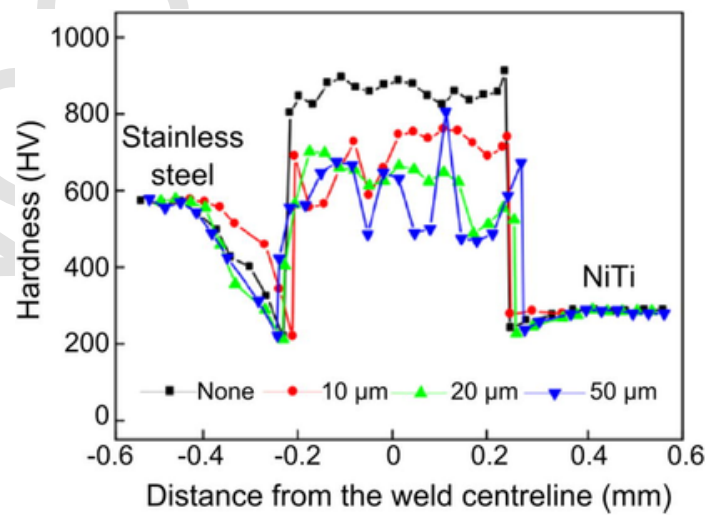

Fig. 47. Influence of Co interlayer thickness on hardness of NiTi/stainless steel dissimilar joints (adapted from [19]). 
ling the interlayer thickness: the higher the thickness the lower the hardness. This was due to the formation of Cu-based intermetallics, which are softer than $\mathrm{Ti}_{? 2} \mathrm{Ni}$ or $\mathrm{Fe}_{? 2} \mathrm{Ti}$, for example. The UTS of the welded joints reached a maximum when the interlayer thickness was of $80 \mu \mathrm{m}$ : $520 \mathrm{MPa}$ and 4.8\% strain (Fig. 48). Fracture of the dissimilar joints also occurred on the NiTi side on the FZ. The shape memory effect of these dissimilar joints was also tested through bending tests. However, from the experimental details, it is perceived that the FZ was not subjected to bending, but rather the base material, preventing to truly assess the shape memory effect of the welds.

It is apparent that, although the insertion of interlayers between NiTi and stainless steel is capable of promoting better joints with superior mechanical properties in comparison with dissimilar joints without interlayers, a precise control of the interlayer type and thickness is needed. From the aforementioned Li et al. works [19,176,177], the highest UTS of joints with Co, Ni and $\mathrm{Cu}$ interlayers, was of 345,370 and $520 \mathrm{MPa}$, respectively. Thus, despite suppressing or decreasing the amount of brittle intermetallics such as $\mathrm{Ti}_{?_{2}} \mathrm{Ni}$ and $\mathrm{Fe}_{2} \mathrm{Ti}$, other brittle compounds can form within the $\mathrm{FZ}$ as a consequence of the interlayer. One possibility that was not explored properly yet for NiTi/stainless steel dissimilar joints was the use of high temperature interlayers, which could create a physical barrier between both base materials. However, a thorough study of phase diagrams of the base materials and the envisaged interlayer must be performed in order to select a filler material that does not create brittle compounds either in the HAZ and FZ.

The only study employing high temperature interlayers was done by $\mathrm{Ng}$ et al. [174]. In this work the authors used a Ta interlayer, which, aside from its high melting point, also possesses good corrosion resistance [272], as well as, high biocompatibility [96]. Ta interlayer was positioned between the two base materials, in a butt joint configuration. The influence of the interlayer thickness, and thus, the amount of Ta that was diluted into the FZ was studied and similar findings to those of the $\mathrm{Cu}$, $\mathrm{Co}$ and $\mathrm{Ni}$ interlayers were observed: the Ta interlayer partially suppressed the formation of intermetallics such as $\mathrm{CrFe}$, giving raise to others Ta-based $\left(\mathrm{Cr}_{? 2} \mathrm{Ta}\right.$ and $\left.\mathrm{Ni}_{? 3} \mathrm{Ta}\right)$; increasing the interlayer thickness resulted in lower hardness values in the FZ. An optimum interlayer thickness of $50 \mu \mathrm{m}$ was found to increase the mechanical properties when compared to the dissimilar joint without filler material (250 MPa vs $125 \mathrm{MPa}$, respectively). However, the tensile strength of the joint is not high enough to promote the superelastic behaviour, thus limiting the possible applications of such combination.

Due to the possible use of these dissimilar welded joints for biomedical applications, it is important to understand the corrosion behaviour of the joints. From the studies of $\mathrm{Li}$ et al. [177], using $\mathrm{Cu}$ interlayer to achieve the higher tensile properties reported for $\mathrm{NiTi} /$ stainless steel joints, Zhang et al. evaluated its susceptibility to static [178] and stress corrosion [179] in artificial saliva and they observed that $\mathrm{Cu}$ release was dependent on the protein amount in the artificial saliva: the higher the protein content, the lower the $\mathrm{Cu}$ release. The influence of protein content on the corrosion behaviour of the welded joints is crucial if dissimilar joints using $\mathrm{Cu}$ interlayers are envisaged in orthodontic devices. Another major issue is that the corrosion performance of these joints was seen to be highly susceptible to $\mathrm{pH}$ : in more acidic environments, the corrosion resistance decreased. With applied stresses, the protective oxide films created can be damaged, leading to a significant release of $\mathrm{Cu}$ [179]. Thus, prior to the use of these NiTi/ stainless joints, biomedical studies are still required in order to confirm that the patient's health is not affected by the orthodontic device.

Aside from the study in artificial saliva, Zhang et al. [180] studied the stress corrosion of the dissimilar joints using Cu interlayer in fluoride medium. With increasing fluoride concentration the corrosion resistance of the joint is decreased. This effect is exacerbated when stress is imposed to the weld as it damages the oxide protective film and thus the corrosion susceptibility is increased. However, it must be noticed that the $\mathrm{Cu}$ release is below harmful levels for the human body; as such, it may, in principle, be used as a biomedical device.

Aiming at biomedical applications, namely orthodontic wires, Watanabe et al. [181] welded NiTi to stainless steel by laser. When compared to autogenous welding of $\mathrm{NiTi} / \mathrm{NiTi}$ and stainless steel/stainless steel, the dissimilar joints exhibited very poor

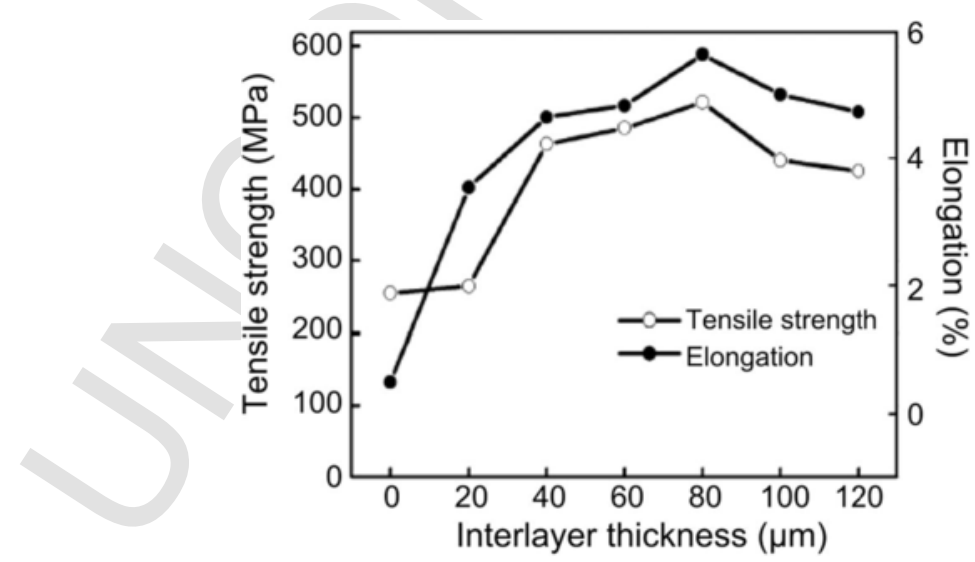

Fig. 48. Influence of $\mathrm{Cu}$ interlayer thickness on UTS and elongation of dissimilar laser welded NiTi/stainless steel joints (adapted from [177]). 
mechanical properties, making impossible its use for medical applications. So, it seems that the insertion of filler materials between NiTi and stainless steel is the only way to enable the use of these dissimilar joints in the biomedical industry.

Up to now no studies have address the influence of post-weld heat treatments on dissimilar joints. This may be related to the fact that, NiTi and stainless steels required specific heat treatments to improve its properties. However, this problem may be overcome by performing local heat treatments in a controlled procedure.

\subsubsection{NiTi/Ti6Al4V}

Titanium and its alloys are very attractive for several industrial sectors. The most used Titanium alloys is the biphasic $\alpha+\beta$ Ti6Al4V [273]. In the biomedical industry, they are highly considered due to its high specific strength and excellent biocompatibility [274], where can substitute hard tissues [275]. In aerospace structures and propulsion systems, this alloys is commonly used due to the exceptional combination of mechanical and corrosion properties, associated with low weight [276]. Ti6A14V can also be used in both chemical/acid, marine and industrial environments, due to is ability to form a protective oxide in a significant range of temperatures [277]. It is thus evident that joining NiTi to Ti6Al4V would be of great interest as it could provide a combination of the functional properties presented by NiTi with the mechanical and corrosion properties of Ti6Al4V. However, Ti6Al4V, as all Titanium alloys, is extremely reactive to oxygen [278] and to hydrogen pick-up [279]. As such, embrittlement of the alloy may occur when welding this material.

Significant metallurgical problems arise when welding NiTi to Ti6Al4V. Assessment of the weldability of NiTi to Ti6Al4V was investigated by Miranda et al. [182]. Regardless of the heat input introduced during welding, to control the cooling rate upon solidification, cracking was always observed in the FZ. SEM analysis of fracture surfaces revealed the presence of brittle $\mathrm{Ti}_{22} \mathrm{Ni}$ which caused transgranular cracking upon cooling. The formation of $\mathrm{Ti}_{2} \mathrm{Ni}$ is promoted by the migration of Nickel, from NiTi, to the liquid Titanium. As such, it is apparent that the solution for overcoming the embrittlement of NiTi/Ti6Al4V welded joints can be made by introducing an element that either inhibits or decreases the amount of brittle intermetallics formed in the FZ.

The insertion of an interlayer was tried by Zoeram et al. [183,184], using Cu. The embrittlement of the welded joint was reduced, as the amount of $\mathrm{Ti}_{{ }_{2}} \mathrm{Ni}$ decreased when compared to the joint welded without interlayer. Nonetheless, some other $\mathrm{Cu}$-based intermetallics were formed due to the presence of the $\mathrm{Cu}$ interlayer, namely $\mathrm{Ti}_{22} \mathrm{Cu}, \mathrm{Cu}_{22} \mathrm{Ti}_{1} \mathrm{Cu}_{23} \mathrm{Ti}$ and $\mathrm{Cu}_{? 4} \mathrm{Ti}$. Hardness measurements on the FZ revealed higher values than both base materials, despite a significant decrease when compared to the $\mathrm{FZ}$ of the joint welded without the $\mathrm{Cu}$ interlayer. The thickness of the interlayer used, and thus the amount of $\mathrm{Cu}$ introduced into the FZ, has been seen to play a significant role on the properties of the joints. As the thickness of the interlayer increased (up to $75 \mu \mathrm{m}$ ), the $\mathrm{Cu}$-rich areas also increased in the FZ. However, further increase of the interlayer thickness promoted formation of shrinkage cavities and increasing the interlayer thickness was found to be detrimental to the joints properties due to the formation of brittle $\mathrm{Cu}$-based intermetallics. An optimum interlayer thickness was found to be of $75 \mu \mathrm{m}$, and the correspondent welded joint experienced rupture at $300 \mathrm{MPa}$ and $3.3 \%$ strain, without any indication of superelastic plateau.

Oliveira et al. [18], succeeded to avoid the formation of intermetallic compounds in the FZ, while ensuring a sound joint between NiTi and Ti6Al4V by using a high temperature Nb interlayer. In order to do so, the laser was positioned on the Ti6Al4V side, which is less prone to degradation of its properties at high temperatures. Fusion and subsequent solidification of the Ti6Al4V base material ensured joining with the $\mathrm{Nb}$ interlayer, without any intermetallic compounds formed. $\mathrm{Nb}$ was incorporated in the $\mathrm{Ti}$ alloy by diffusion into the liquid bath. $\mathrm{Nb}$ forms an eutectic with $\mathrm{NiTi}$ [91] and so, a precise control of the laser positioning on the Ti side was required so that the heat transfer was enough to promote the eutectic reaction between NiTi and Nb. The eutectic microstructure observed in the $\mathrm{NiTi} / \mathrm{Nb}$ interface is depicted in Fig. 49. The use of the high temperature interlayer ensured a physical barrier to the mixing of both NiTi and Ti6Al4V preventing the formation of brittle intermetallics which are detrimental to the joint properties. Mechanical characterization of the welded joint revealed an UTS that matched that of $\mathrm{Nb}$ (about $300 \mathrm{MPa}$ ). Although no superelastic plateau was observed, this kind of approach may allow the use of other high temperature interlayers, which must have an UTS higher than the onset for the superelastic plateau of the NiTi base material.

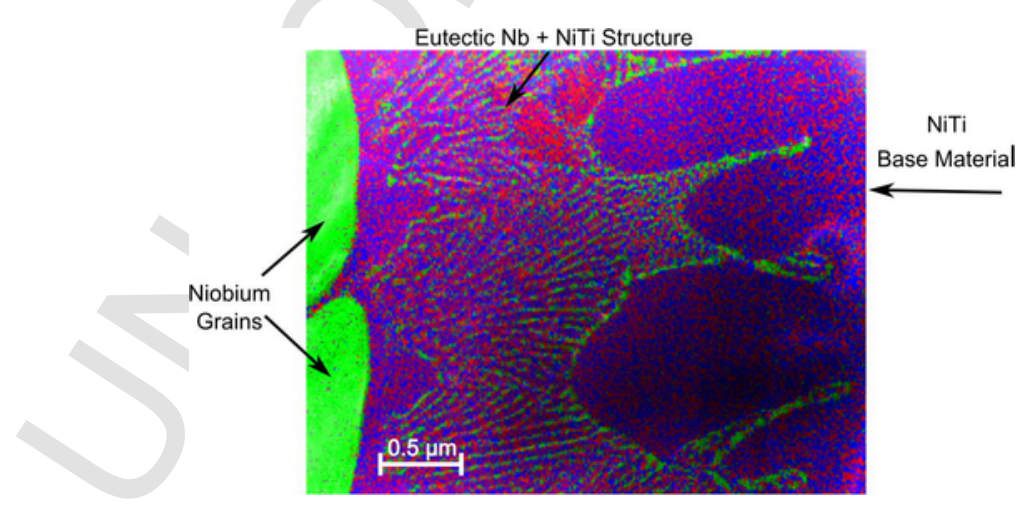

Fig. 49. Eutectic microstructure on the $\mathrm{NiTi} / \mathrm{Nb}$ interface observed in TEM (adapted from [18]). 
Other materials can be used as possible interlayer to promote a favourable joining between NiTi and Ti6Al4V, such as Fe or Co as they are all known to form shape memory alloys in the form of NiTiX, being X one of those elements [2]. Ideally, preventing Nickel migration into the liquid Titanium would be preferred as, this way, formation of brittle $\mathrm{Ti}_{2} \mathrm{Ni}$ would be inhibited. Thus, in theory, it may be expected that superelastic properties can be presented by the welded joints, allowing new applications in both aerospace and biomedical industries. The use of high temperature materials, such as Ta or W may also be considered an interesting option for this dissimilar combination, but it was not yet studied.

\subsubsection{NiTi/other engineering materials}

Despite most of the work on dissimilar laser welding involving NiTi aims at obtaining NiTi/Stainless steel and NiTi/Ti6Al4V sound joints, other combinations have been also tested either by laser welding NiTi to pure metals or to specific metallic alloys.

Haas et al. [129] reported laser welding of NiTi to both Niobium and Tantalum. In the NiTi/Niobium welds, hardness measurements revealed that the FZ had a hardening effect, which was not observed in the NiTi/Tantalum joints. In the latter case, the FZ revealed a fine grained microstructure, which can be interpreted as a favourable metallurgical compatibility between both materials. Nonetheless, due to the very high melting points of both Niobium $\left(2477^{\circ} \mathrm{C}\right)[280\rceil$ and Tantalum $\left(3017^{\circ} \mathrm{C}\right)[280\rceil$ compared to NiTi $\left(1310^{\circ} \mathrm{C}\right)[2]$, process optimization was required.

Tuissi et al. 127$\rceil$ performed butt joints of NiTi to Monel, Inconel and Ni, without filler. In the NiTi/Monel case, transversal cracks along the thickness of the joint were observed due to the very different thermal conductivities of both base materials. These differences give raise to thermal stresses during solidification, which cause the initiation of cracks. Cu-based segregations were observed in the FZ due to the existence of Copper in Monel-400. Tensile test of the welded joint revealed, as expected, poor mechanical properties $(\approx 150 \mathrm{MPa})$ due to the aforementioned cracking phenomena and $\mathrm{Cu}$-based phases.

$\mathrm{NiTi}$ /Inconel joints, similarly to the NiTi/Monel ones, exhibited macrofractures in the FZ. Hardness measurements revealed very high hardness $(\approx 1000 \mathrm{HV}$ vs $\approx 300 \mathrm{HV}$ for NiTi and Inconel), which explained the poor mechanical properties of the welded joint.

Although in NiTi/Ni dissimilar welds no cracks were observed by optical microscopy, no tensile tests were performed. Nevertheless, hardness measurements revealed, once more, hardness values above $1000 \mathrm{HV}$ in the FZ. As such, a significant decrease in the ductility of the dissimilar joint was expected.

NiTi, aside from its functional properties, presents also good radiopacity [234]. Nonetheless, the methods to enhance the visibility under X-ray radiation may include the addition of noble metals, such as gold or platinum [281]. Tantalum is used in biomedical devices and can improve the radiopacity of other materials [282]. Steegmuller et al. [185] presented NiTi stents welded with $\mathrm{Au}, \mathrm{Pt}$ or Ta to improve the radiopacity of the welded material. Smooth surfaces were obtained and no gaps between the NiTi and the other elements were discernible, as shown in Fig. 50. Increased radiopacity of the welded stents was confirmed for all dissimilar combinations.

The corrosion behaviour of the welded stents was found to be intimately related to the dissimilar combination chosen. While the NiTi stent welded with Ta presented a corrosion behaviour similar to the NiTi base material, for the other combinations pitting corrosion occurred at a low breakdown potential. As such, it appeared that only NiTi/Ta welded stents can be used to improve of the radiopacity of such devices. The fatigue behaviour of these welded joints is of great interest to be studied as it can give a good indication on the viability of using such dissimilar combination for applications in stents.

In the biomedical industry orthodontic wires can be made of $\mathrm{NiTi}$, stainless steel, $\beta$-Titanium and based on Cobalt-Chromium [283]. Each of these wires has different characteristics, such as Young's modulus and its ability to be manipulated. Within the mouth of a patient, sometimes it is required that the orthodontic wires can exert different actuating forces along wires [284]. As such, it would be beneficial to use the different mechanical properties of the orthodontic wires in order to obtain a biomedical device that could be more suitable for the patient requirements. Watanabe et al. [181] reported such study. Aside from welding $\mathrm{NiTi}$ orthodontic wires to stainless steel, dissimilar laser welded joints of $\mathrm{NiTi} / \mathrm{Co}-\mathrm{Cr}$ and NiTi/ $\beta$-Ti were also performed. When compared to the homogenous similar combinations (NiTi/NiTi, Co-Cr/Co-Cr, stainless steel/stainless steel and $\beta$-Ti/ $\beta$-Ti), the dissimilar joints presented a decrease in mechanical properties, measured by three-point bending tests. This decrease was related to the low affinity between NiTi and stainless steel and $\mathrm{Co}-\mathrm{Cr}$ wires, thus, not promoting a suitable microstructure. Although $\mathrm{NiTi} / \beta$-Ti joints presented better mechanical properties than the other dissimilar combinations, these were not enough to ensure its appropriate use in clinical environments.
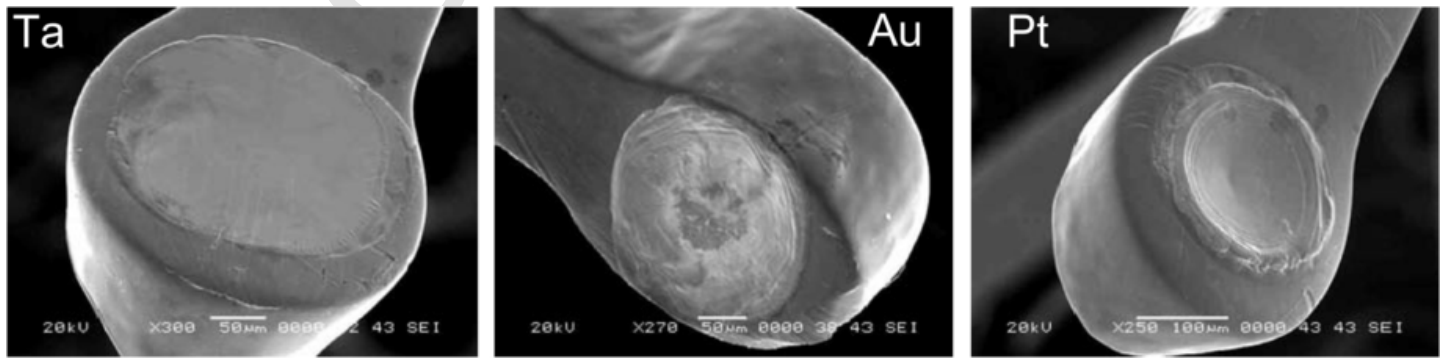

Fig. 50. NiTi stent welded with: Tantalum (left); Gold (middle); Platinum (right) (adapted from [185]). 
NiTi was also laser welded to MP35N (an age hardened Ni-Co-based alloy) by Panton et al. [186]. The composition of the FZ was seen to be affected by laser offsetting. Solid solution strengthening in the FZ and formation of Ti-based intermetallics (such as $\mathrm{Ti}_{{ }_{2}} \mathrm{Ni}$, $\mathrm{Ti}_{{ }_{2}} \mathrm{Co}$ and/or $\mathrm{Cr}_{? 2} \mathrm{Ti}$ ) were pointed out as responsible for a significant increase of the hardness in the $\mathrm{FZ}$, when compared to the base materials. Titanium mixing with the alloying element of MP35N was minimized when the laser was positioned on the MP35N base material, resulting in lower hardness values when compared to the joint made with the laser positioned on the materials interface or offset to the NiTi side. Macroscopic cracks were observed in the FZ, under optical microscopy, when the laser was positioned on the NiTi side or at the contact interface between both materials. However, when the laser was positioned on the MP35N side, micro-cracks could only be observed by SEM imaging. These solidification cracks, together with the formation of brittle precipitates and increased hardness of the FZ, explained the decrease of the mechanical properties of the welded joint ( $66 \%$ of the base material).

Recently, Zheng et al. reported the first successful study on laser welding of NiTi to Copper [187]. By selecting suitable welding parameters, the authors were able to improve the mechanical properties of the joint. The tensile strength was above that of the superelastic plateau of NiTi. As such, superelasticity can be used in this dissimilar combination. As far as the possible applications are concerned, such ability to promote sound joining between these two materials is of major relevance, especially for integration of NiTi into electromechanical systems. Non-conventional geometries for sensors or actuators can thus be designed taking profit of the freedom that this welding technology permits in project and design. Table 3 summarizes the existing studies on dissimilar laser welding of NiTi.

\section{Applications}

Owing to the interesting properties of the laser welded NiTi joints, applications have been developed while others are currently under study and development.

Although laser welding of NiTi to itself and to other engineering materials has been studied for several years now, only few applications have been developed. However, over the last years an increasing trend on using laser welding for NiTi has widespread the use of the welded joints (both similar and dissimilar), especially for the biomedical industry. As such, some of the more relevant applications (already developed but still under development) are briefly presented.

A microforcep for endoscopic brain surgery was presented in [129,188]. Fatigue testing of the laser welded microforcep was compared to the monolithic forcep and no significant differences were found: the life cycle of the laser welded device was not affected by the welding procedure. Haas et al. [129] also presented laser welded NiTi tubes with different diameters $(0.8$ and $0.9 \mathrm{~mm}$ ) to be used as catheters. The ability to obtain catheters with different diameters along its length may decrease the difficulty to obtain these devices with variable diameters [285], while reducing production costs by decreasing the manufacturing time provided by laser welding.

Although NiTi has good radiopacity properties [234], researchers have tried to improve those properties by joining NiTi to Ta, Au and Pt as mentioned and shown before (Fig. 50) $[185,189]$. The aim was to produce NiTi stents that could be more easily seen during medical examinations. Only Tantalum has proven to be a suitable choice as, despite the other elements increase the radiopacity of the welded joints, its corrosion behaviour in the human body was poor, which was not the case with NiTi/Ta joints.

Several studies have been focused on laser welding orthodontic wires, either in similar or dissimilar joints. The reason for these attempts lies on the fact that different types of orthodontic wires have different mechanical characteristics, and joining such distinct materials may improve the treatment of the patient, as to correct different tooth movements requires different actua-

Table 3

Overview of dissimilar laser welded combinations involving NiTi.

\begin{tabular}{|c|c|c|c|c|}
\hline Dissimilar combination & Base material shape & Joint configuration & Filler material/interlayer & Reference \\
\hline NiTi/steel & Wire & Butt & n.a. & {$[128]$} \\
\hline \multirow[t]{6}{*}{$\mathrm{NiTi} /$ stainless steel } & Wire & Butt & n.a. & {$[17,143,175,181]$} \\
\hline & Wire & Butt & Co & {$[19]$} \\
\hline & Plate & Overlap & $\mathrm{Ni}$ & {$[172]$} \\
\hline & Wire & Butt & $\mathrm{Ni}$ & {$[176]$} \\
\hline & Wire & Butt & $\mathrm{Cu}$ & {$[177-180]$} \\
\hline & Wire & Butt & $\mathrm{Ta}$ & {$[174\rceil$} \\
\hline \multirow[t]{3}{*}{ NiTi/Ti6Al4V } & Plate & Butt & n.a. & {$[182]$} \\
\hline & Plate & Butt & $\mathrm{Cu}$ & {$[183,184]$} \\
\hline & Plate & Butt & $\mathrm{Nb}$ & [18] \\
\hline NiTi/Monel & Plate & Butt & n.a. & {$[127]$} \\
\hline NiTi/Inconel & Plate & Butt & n.a. & \\
\hline $\mathrm{NiTi} / \mathrm{Ni}$ & Plate & Butt & n.a. & \\
\hline $\mathrm{NiTi} / \mathrm{Ta}$ & Plate & Butt & n.a. & [129] \\
\hline $\mathrm{NiTi} / \mathrm{Co}-\mathrm{Cr}$ & Wire & Butt & n.a. & {$[181]$} \\
\hline $\mathrm{NiTi} / \mathrm{X}$ & Stents & Overlap & n.a. & {$[185]$} \\
\hline \multicolumn{5}{|l|}{$X=T a, A u, P t$} \\
\hline NiTi/MP35N & Wire & Butt & n.a. & {$[186]$} \\
\hline $\mathrm{NiTi} / \mathrm{Cu}$ & Wire & Overlap & n.a. & {$[187,191]$} \\
\hline
\end{tabular}


tion forces [284]. Such distinct actuation was observed by Sevilla et al. [145], when welding NiTi to NiTiCu. The joints presented two superelastic plateaus in the stress-strain curve which corresponded to the different base materials used. Although the presence of $\mathrm{Cu}$ in the welded joint decreased its corrosion properties, the Ni release was considered to be safe for the human health. Similarly, two step plateaus were evidence by the same authors when joining NiTi with different compositions and hence with different onsets for the stress induced transformation. It was thus proved that laser welding can be efficiently used for joining different orthodontic wires. However, the choice of the dissimilar combination greatly affects the mechanical properties of these joints: while for NiTi/NiTiCu good mechanical properties were obtained, the same did not occur for NiTi/stainless steel, NiTi/ $\mathrm{Co}-\mathrm{Cr}$ and $\mathrm{NiTi} / \beta-\mathrm{Ti}[181]$ due to low affinity of NiTi to the other elements. The characteristics of laser welded NiTi orthodontics wires was also studied and considered to be acceptable for clinical use [141].

The problem of laser welding NiTi to stainless steel suffered a great turn around with the results from Li et al. [177] using a $\mathrm{Cu}$ interlayer. The superior mechanical properties and the fact that the joint strength was above the superelastic plateau for the stress induced transformation are of great importance. In order to understand the viability of such dissimilar joints for biomedical applications, corrosion tests were performed. Despite the corrosion properties of the welded joints decreased with increasing fluoride content and in more acidic environments, the $\mathrm{Cu}$ release was below harmful levels than can be dangerous for human beings. However, prior to being able to use such welded joints in orthodontic applications (or others), a better mechanical characterization, namely fatigue strength, is still required.

Some interesting properties presented by similar NiTi joints can be used in the future for sensors or actuators. In particular, when joining NiTi with different compositions [126,156], the shape memory effect of the welds can be depicted in two steps, as the different compositions of the base materials give raise to different transformation temperatures. The distinct shape memory effect presented by the thermal affected regions when compared to the original base material $[168\rceil$ may also be used for such applications.

One final note regarding the use of laser in NiTi: Hagiwara et al. [190] presented a novel method to remove debris from broken endodontic NiTi files. Basically, the authors had an extractor tube, with an optical fibre inside. The broken endodontic files were positioned inside the extractor and the laser was fired promoting joining between the NiTi file and the extractor. The retention force, which is required to remove the debris inside the root canals, was measured and considered to be sufficient to be used in patients. An interesting issue about this study was the fact that the oral temperature only increase by $4{ }^{\circ} \mathrm{C}$ due to the laser; as such, no harm would be done to the patient. This innovative technique may soon start being used in dental clinics, as fracture of such NiTi files inside root canals is considered a problem of major importance for the industry, the clinics and the patients [286,287].

\section{Summary and future outlook}

In this paper, a comprehensive review on welding NiTi is presented addressing the following aspects: welding processes, influence of process parameters, microstructural transformations, mechanical performance, functional properties, corrosion behaviour and industrial applications.

NiTi has a set of weldability problems mostly related to: grain size heterogeneities along the joint; formation of brittle intermetallics; and compositional variations in the thermal affected zones due to preferential volatilization (in the fusion zone) and precipitation phenomena (in the heat affected zone).

Laser welding is, by far, the most studied process due to minimal thermal effect on the base materials, and thus a large number of experimental studies exist and have been described. So, a detailed discussion was devoted to this process, presenting the characteristics of the microstructural changes observed, under a materials science perspective, and its influence on the mechanical properties of the welds, evaluated by tensile, bending and cycling tests and shape memory effect.

Concerning dissimilar welding of NiTi, there is still limited research work on this topic. Since both mechanical and thermo-physical properties of materials involved are quite different, successful joining mostly requires the use of interlayers. These interlayers aim at reducing or prevent mixing of the liquids of the base materials involved in the fusion zone and formation of brittle intermetallics. For this purpose, high melting temperature materials have to be used. However, few types of interlayers have, so far, been tested and the existing knowledge is mainly experimental.

Despite the ongoing research on welding and joining shape memory alloys, some areas still need to be addressed and these are:

- Similar joints

- As discussed in Section 3, limited experiments have been performed on in-situ analysis of the mechanical behaviour of welded joints. This would be beneficial to provide further understanding on the load transfer mechanisms in the different regions of the joints, based on micromechanical models that take into account the microstructural changes induced by the welding process.

- The authors agree that, in the future, joining can be used to simultaneously produce structures with a controlled functional gradient of transformation characteristics.

- Dissimilar joints

- It was observed that joining NiTi to other materials is not effective in the absence of a filler material. So, new filler materials/ interlayers have to be studied to increase joining efficiency and both mechanical and corrosion behaviours. 
- A better knowledge on the joining mechanisms, namely through the use of thermodynamic calculations, will allow to optimize materials selection for the interlayer.

- The ability to join dissimilar combinations by solid state processes could be a viable alternative to fusion-based processes, as long as, the functional properties of NiTi can be preserved.

- Joining NiTi to Cu-based shape memory alloys, may also be of great interest in order to get an interesting combination of functional characteristics, alongside with high thermal and electrical conductivity, typical of Cu-based systems.

- Further research on new base material combinations, involving distinct shape memory alloys, to produce parts for high added-value applications, is also a challenge.

\section{Acknowledgements}

JPO and FMBF acknowledge funding by National Funds through the Portuguese Foundation for Science and Technology (FCT-MCTES), Reference UID/CTM/50025/2013 and FEDER funds through the COMPETE 2020 Programme under the project number POCI-01-0145-FEDER-007688. RMM acknowledges FCT-MCTES for its financial support via the project PEst-OE/ EME/UI0667/2014 (UNIDEMI). JPO acknowledges FCT-MCTES for funding PhD grant SFRH/BD/85047/2012.

\section{References}

[1] J. Van Humbeeck, Non-medical applications of shape memory alloys, Mater Sci Eng, A 273-275 (1999) 134-148, http://dx.doi.org/10.1016/ S0921-5093(99)00293-2.

[2] K. Otsuka, X. Ren, Physical metallurgy of Ti-Ni-based shape memory alloys, Prog Mater Sci 50 (2005) 511-678, http://dx.doi.org/10.1016/j.pmatsci. 2004.10.001.

[3] M. Bram, A. Ahmad-Khanlou, A. Heckmann, B. Fuchs, H.P. Buchkremer, D. Stöver, Powder metallurgical fabrication processes for NiTi shape memory alloy parts, Mater Sci Eng, A 337 (2002) 254-263, http://dx.doi.org/10.1016/S0921-5093(02)00028-X.

[4] Y.Y. Liu, Y.Y. Liu, J. Van Humbeeck, J.V.A.N. Humbeeck, Two-way shape memory effect developed by martensite deformation in NiTi, Acta Mater 47 (1998) 199-209, http://dx.doi.org/10.1016/S1359-6454(98)00325-5.

[5] M. Dolce, D. Cardone, Mechanical behaviour of shape memory alloys for seismic applications 2. Austenite NiTi wires subjected to tension, Int J Mech Sci 43 (2001) 2657-2677, http://dx.doi.org/10.1016/S0020-7403(01)00050-9.

[6] Lagoudas DC. Shape memory alloys: modeling and engineering applications. New York: Springer; 2008. http://dx.doi.org/10.1007/978-0-387-47685-8.

[7] J.K. Allafi, X. Ren, G. Eggeler, The mechanism of multistage martensitic transformations in aged Ni-rich NiTi shape memory alloys, Acta Mater 50 (2002) 793-803, http://dx.doi.org/10.1016/S1359-6454(01)00385-8.

[8] J. Seo, Y. Kim, J. Hu, Pilot study for investigating the cyclic behavior of slit damper systems with recentering shape memory alloy (SMA) bending bars used for seismic restrainers, Appl Sci 5 (2015) 187-208, http://dx.doi.org/10.3390/app5030187.

[9] Y. Liu, A. Mahmud, F. Kursawe, T.H. Nam, Effect of pseudoelastic cycling on the Clausius-Clapeyron relation for stress-induced martensitic transformation in NiTi, J Alloys Compd 449 (2008) 82-87, http://dx.doi.org/10.1016/j.jallcom.2006.02.080.

[10] J. Khalil-Allafi, A. Dlouhy, G. Eggeler, $\mathrm{Ni}_{24} \mathrm{Ti}_{23}$-precipitation during aging of NiTi shape memory alloys and its influence on martensitic phase transformations, Acta Mater 50 (2002) 4255-4274, http://dx.doi.org/10.1016/s1359-6454(02)00257-4.

[11] M.F.X. Wagner, S.R. Dey, H. Gugel, J. Frenzel, C. Somsen, G. Eggeler, Effect of low-temperature precipitation on the transformation characteristics of Ni-rich NiTi shape memory alloys during thermal cycling, Intermetallics 18 (2010) 1172-1179, http://dx.doi.org/10.1016/j.intermet.2010.02.048.

[12] M. Nishida, C.M. Wayman, T. Honma, Precipitation processes in near-equiatomic TiNi shape memory alloys, Metall Trans A 17 (1986) 1505-1515, http://dx.doi.org/10.1007/BF02650086.

[13] J. Khalil-Allafi, G. Eggeler, A. Dlouhy, W.W. Schmahl, C. Somsen, On the influence of heterogeneous precipitation on martensitic transformations in a Ni-rich NiTi shape memory alloy, Mater Sci Eng, A 378 (2004) 148-151, http://dx.doi.org/10.1016/j.msea.2003.10.335.

[14] K. Weinert, V. Petzoldt, Machining NiTi micro-parts by micro-milling, Mater Sci Eng, A 481-482 (2008) 672-675, http://dx.doi.org/10.1016/j.msea. 2006.10.220.

[15] K.C. Mills, B.J. Keene, R.F. Brooks, A. Shirali, Marangoni effects in welding, Philos Trans R Soc A: Math Phys Eng Sci 356 (1998) 911-925, http://dx. doi.org/10.1098/rsta.1998.0196.

[16] P.C. Hall, Laser welding nitinol to stainless steel, in: G. Wang (Ed.), Proc SMST 1997, 1997.

[17] J. Vannod, M. Bornert, J.-E. Bidaux, L. Bataillard, A. Karimi, J.-M. Drezet, et al., Mechanical and microstructural integrity of nickel-titanium and stainless steel laser joined wires, Acta Mater 59 (2011) 6538-6546, http://dx.doi.org/10.1016/j.actamat.2011.06.031.

[18] J.P. Oliveira, B. Panton, Z. Zeng, C.M. Andrei, Y. Zhou, R.M. Miranda, et al., Laser joining of NiTi to Ti6Al4V using a niobium interlayer, Acta Mater 105 (2016) 9-15, http://dx.doi.org/10.1016/j.actamat.2015.12.021.

[19] H. Li, D. Sun, X. Cai, P. Dong, X. Gu, Laser welding of TiNi shape memory alloy and stainless steel using Co filler metal, Opt Laser Technol 45 (2013) 453-460, http://dx.doi.org/10.1016/j.optlastec.2012.06.010.

[20] C. Van Der Eijk, H. Fostervoll, Z.K. Sallom, O.M. Akselsen, Plasma welding of NiTi to NiTi, stainless steel and hastelloy C276, Solutions (2003) $13-15$.

[21] E.T.F. Chau, C.M. Friend, D.M. Allen, J. Hora, J.R. Webster, A technical and economic appraisal of shape memory alloys for aerospace applications, Mater Sci Eng, A 438-440 (2006) 589-592, http://dx.doi.org/10.1016/j.msea.2006.02.201.

[22] M. Kutz, Mechanical engineers' handbook, 3rd ed., John Wiley \& Sons Inc., Hoboken, 2014http://dx.doi.org/10.1002/9781118985960.

[23] J.F. Lancaster, Metallurgy of welding, 6th ed., Woodhead Publishing Limited, Cambridge, 1999.

[24] Thomas M, Nicholas E, Needham J, Murch M, Templesmith M, Dawes C. Improvements relating to friction welding; 1991.

[25] X. He, F. Gu, A. Ball, A review of numerical analysis of friction stir welding, Prog Mater Sci 65 (2014) 1-66, http://dx.doi.org/10.1016/j.pmatsci.2014. 03.003 .

[26] T.G. Santos, R.M. Miranda, P. Vilaça, Friction stir welding assisted by electrical Joule effect, J Mater Process Technol 214 (2014) 2127-2133, http://dx. doi.org/10.1016/j.jmatprotec.2014.03.012.

[27] X. Liu, C. Wu, G.K. Padhy, Characterization of plastic deformation and material flow in ultrasonic vibration enhanced friction stir welding, Scripta Mater 102 (2015) 95-98, http://dx.doi.org/10.1016/j.scriptamat.2015.02.022.

[28] Buehler J, Wiley R. The properties of TiNi and associated phases; 1961. $<$ http://oai.dtic.mil/oai/oai?verb=getRecord\&metadataPrefix $=$ html\& identifier $=$ AD0266607>. 
[29] A. Ikai, K. Kimura, H. Tobushi, TIG welding and shape memory effect of TiNi shape memory alloy, J Intell Mater Syst Struct 7 (1996) 646-655, http:// dx.doi.org/10.1177/1045389X9600700604.

[30] Q. Yunlian, D. Ju, H. Quan, Z. Liying, Electron beam welding, laser beam welding and gas tungsten arc welding of titanium sheet, Mater Sci Eng, A 280 (2000) 177-181, http://dx.doi.org/10.1016/S0921-5093(99)00662-0.

[31] Y.T. Hsu, Y.R. Wang, S.K. Wu, C. Chen, Effect of $\mathrm{CO}_{? 2}$ laser welding on the shape-memory and corrosion characteristics of TiNi alloys, Metall Mater Trans A 32 (2001) 569-576, http://dx.doi.org/10.1007/s11661-001-0073-2.

[32] J.P. Oliveira, D. Barbosa, F.M.B. Fernandes, R.M. Miranda, Tungsten inert gas (TIG) welding of Ni-rich NiTi plates: functional behavior, Smart Mater Struct 25 (2016) 03LT01, http://dx.doi.org/10.1088/0964-1726/25/3/03LT01.

[33] G. Fox, R. Hahnlen, M.J. Dapino, Fusion welding of nickel-titanium and 304 stainless steel tubes: part II: tungsten inert gas welding, J Intell Mater Syst Struct 24 (2013) 962-972, http://dx.doi.org/10.1177/1045389X12461076.

[34] S.X. Lü, Z.L. Yang, H.G. Dong, Welding of shape memory alloy to stainless steel for medical occluder, Trans Nonferr Met Soc Chin Engl Ed 23 (2013) 156-160, http://dx.doi.org/10.1016/S1003-6326(13)62442-5.

[35] J. Weng, J. Chang, K. Chen, J. He, Solid/liquid erosion behavior of gas tungsten arc welded TiNi overlay, Wear 255 (2003) 219-224, http://dx.doi.org/ 10.1016/S0043-1648(03)00120-0.

[36] D. Yang, H.C. Jiang, M.J. Zhao, L.J. Rong, Microstructure and mechanical behaviors of electron beam welded NiTi shape memory alloys, Mater Des 57 (2014) 21-25, http://dx.doi.org/10.1016/j.matdes.2013.12.039.

[37] D. Yang, H.C. Jiang, M.J. Zhao, L.J. Rong, Effect of post-weld annealing on microstructure and properties of NiTi welding joints, Mater Res Innov 18 (2014) http://dx.doi.org/10.1179/1432891714Z.000000000751. S4-588-S4-591.

[38] Steen WM, Mazumder J. Laser material processing. London: Springer; 2010. http://dx.doi.org/10.1007/978-1-84996-062-5.

[39] L. Quintino, A. Costa, R. Miranda, D. Yapp, V. Kumar, C.J. Kong, Welding with high power fiber lasers - a preliminary study, Mater Des 28 (2007) 1231-1237, http://dx.doi.org/10.1016/j.matdes.2006.01.009.

[40] B. Tam, A. Pequegnat, M.I. Khan, Y. Zhou, Resistance microwelding of Ti-55.8 wt pct Ni nitinol wires and the effects of pseudoelasticity, Metall Mater Trans A: Phys Metall Mater Sci 43 (2012) 2969-2978, http://dx.doi.org/10.1007/s11661-012-1115-7.

[41] V. Delobelle, P. Delobelle, Y. Liu, D. Favier, H. Louche, Resistance welding of NiTi shape memory alloy tubes, J Mater Process Technol 213 (2013) 1139-1145, http://dx.doi.org/10.1016/j.jmatprotec.2013.01.013.

[42] Blazynski T. Explosive welding, forming and compaction. Netherlands, Dordrecht: Springer; 1983. http://dx.doi.org/10.1007/978-94-011-9751-9.

[43] C.A. Zimmerly, O.T. Inal, R.H. Richman, Explosive welding of a near-equiatomic nickel-titanium alloy to low-carbon steel, Mater Sci Eng, A 188 (1994) 251-254, http://dx.doi.org/10.1016/0921-5093(94)90379-4.

[44] R. Richman, D. Associates, M. Kew, Cavitation erosion of NiTi explosively welded to steel, Wear 181-183 (1995) 80-85, http://dx.doi.org/10.1016/ 0043-1648(94)07029-6.

[45] R.H. Richman, W.P. McNaughton, A metallurgical approach to improved cavitation-erosion resistance, J Mater Eng Perform 6 (1997) 633-641, http:// dx.doi.org/10.1007/s11665-997-0057-5.

[46] R. Prummer, D. Stockel, Nitinol - stainless steel compound materials made by explosive welding, in: K. Staudhammer, L. Murr (Eds.), Proc 2000 int conf fundam issues appl shock-wave high-strain-rate phenom, Elsevier, 2001, pp. 581-585.

[47] S. Belyaev, V. Rubanik, N. Resnina, V. Rubanik, O. Rubanik, V. Borisov, Martensitic transformation and physical properties of "steel-TiNi" bimetal composite, produced by explosion welding, Phase Transitions 83 (2010) 276-283, http://dx.doi.org/10.1080/01411591003656757.

[48] S.P. Belyaev, V.V. Rubanik, N.N. Resnina, V.V. Rubanik, O.E. Rubanik, Effect of annealing on martensitic transformations in "steel - TiNi alloy" explosion welded bimetallic composite, Met Sci Heat Treat 52 (2011) 432-436, http://dx.doi.org/10.1007/s11041-010-9310-x.

[49] S. Belyaev, V. Rubanik, N. Resnina, V. Rubanik Jr, O. Rubanik, V. Borisov, et al., Functional properties of bimetal composite of "stainless steel-TiNi alloy" produced by explosion welding, Phys Proc 10 (2010) 52-57, http://dx.doi.org/10.1016/j.phpro.2010.11.074.

[50] T. Xing, Y. Zheng, L. Cui, Transformation and damping characteristics of NiTi/NiTi alloys synthesized by explosive welding, Mater Trans 47 (2006) 658-660, http://dx.doi.org/10.2320/matertrans.47.658.

[51] J. Li, Y. Zheng, L. Cui, Transformation characteristics of TiNi/TiNi alloys synthesized by explosive welding, Front Mater Sci Chin 1 (2007) 351-355, http://dx.doi.org/10.1007/s11706-007-0065-2.

[52] L. Juntao, Z. Yanjun, C. Lishan, Effects of severe plastic deformation and heat treatment on transformation behavior of explosively welded duplex TiNi-TiNi, Pet Sci 4 (2007) 107-112, http://dx.doi.org/10.1007/BF03187464.

[53] Z. Yan, L. Cui, Y. Zhen, Microstructure and martensitic transformation behaviors of explosively welded NiTi/NiTi laminates, Chin J Aeronaut 20 (2007) 168-171, http://dx.doi.org/10.1016/S1000-9361(07)60027-2.

[54] T. Xing, Y. Zheng, L. Cui, X. Mi, Influence of aging on damping behavior of TiNi/TiNi alloys synthesized by explosive welding, Trans Nonferr Met Soc Chin 19 (2009) 1470-1473, http://dx.doi.org/10.1016/S1003-6326(09)60053-4.

[55] X. Jiang, D. Jiang, Y. Zheng, L. Cui, Transformation behavior of explosively welded TiNi/TiNi laminate after diffusion annealing and aging, Mater Res Bull 48 (2013) 5033-5035, http://dx.doi.org/10.1016/j.materresbull.2013.04.031.

[56] A. No, E.P. De Montre, E.D.T. Supe, M.C. Piedboeuf, R. Gauvin, M. Thomas, Damping behaviour of shape memory alloys: strain amplitude, frequency and temperature effects, J Sound Vib 214 (1998) 885-901, http://dx.doi.org/10.1006/jsvi.1998.1578.

[57] R.J. Clifton, Response of materials under dynamic loading, Int J Solids Struct 37 (2000) 105-113, http://dx.doi.org/10.1016/S0020-7683(99)00082-7.

[58] Yilbas BS, Sahin AZ. Friction welding - thermal and metallurgical characteristics. Berlin, Heidelberg: Springer; 2014. http://dx.doi.org/10.1007/ 978-3-642-54607-5.

[59] Blau P. Friction science and technology from concepts to applications, 2nd ed. CRC Press; 2008. http://dx.doi.org/10.1201/9781420054101.

[60] A. Vairis, M. Frost, High frequency linear friction welding of a titanium alloy, Wear 217 (1998) 117-131, http://dx.doi.org/10.1016/ S0043-1648(98)00145-8.

[61] P. Sketchley, P. Threadgill, I. Wright, Rotary friction welding of an $\mathrm{Fe}_{23} \mathrm{Al}$ based ODS alloy, Mater Sci Eng, A 329-331 (2002) 756-762, http://dx.doi. org/10.1016/S0921-5093(01)01656-2.

[62] H. Potente, M. Uebbing, Friction welding of polyamides, Polym Eng Sci 37 (1997) 726-737, http://dx.doi.org/10.1002/pen.11716.

[63] L. D'Alvise, E. Massoni, S.J. Walloe, L. D'Alvise, S.J. Walløe, Finite element modelling of the inertia friction welding process between dissimilar materials, J Mater Process Technol 125 (2002) 387-391, http://dx.doi.org/10.1016/S0924-0136(02)00349-7.

[64] R. Nandan, T. Debroy, H.K.D.H. Bhadeshia, Recent advances in friction-stir welding - process, weldment structure and properties, Prog Mater Sci 53 (2008) 980-1023, http://dx.doi.org/10.1016/j.pmatsci.2008.05.001.

[65] R.S. Mishra, Z.Y. Ma, Friction stir welding and processing, Mater Sci Eng R Rep 50 (2005) 1-78, http://dx.doi.org/10.1016/j.mser.2005.07.001.

[66] T. Shinoda, T. Tsuchiyta, H. Takahashi, Functional characteristics of friction welded near-equiatomic TiNi shape memory alloy, Trans Jpn Weld Soc 22 (1991) 102-108. <http://ci.nii.ac.jp/naid/110003380338/>.

[67] T. Shinoda, T. Tsuchiya, H. Takahashi, Friction welding of shape memory alloy, Weld Int 6 (1992) 20-25, http://dx.doi.org/10.1080/ 09507119209548136. 
[68] T. Shinoda, T. Owa, V. Magula, Microstructural analysis of friction welded joints in TiNi alloy, Weld Int 13 (1999) 180-185, http://dx.doi.org/10.1080/ 09507119909447361.

[69] B. London, J. Fino, A. Pelton, C. Fuller, M. Mahoney, Friction stir processing of nitinol, in: K. Jata, M. Mahoney, R. Mishra, T. Lienert (Eds.), Frict stir weld process III, Dover, 2005, pp. 67-74.

[70] A. Barcellona, L. Fratini, D. Palmeri, C. Maletta, M. Brandizzi, Friction stir processing of NiTi shape memory alloy: microstructural characterization, Int J Mater Form 3 (2010) 1047-1050, http://dx.doi.org/10.1007/s12289-010-0950-6.

[71] M. Dixit, J.W. Newkirk, R.S. Mishra, Properties of friction stir-processed Al 1100-NiTi composite, Scripta Mater 56 (2007) 541-544, http://dx.doi.org/ 10.1016/j.scriptamat.2006.11.006.

[72] D.R. Ni, J.J. Wang, Z.N. Zhou, Z.Y. Ma, Fabrication and mechanical properties of bulk NiTip/Al composites prepared by friction stir processing, J Alloys Compd 586 (2014) 368-374, http://dx.doi.org/10.1016/j.jallcom.2013.10.013.

[73] J.P. Oliveira, J.F. Duarte, P. Inácio, N. Schell, R.M. Miranda, T.G. Santos, Production of Al/NiTi composites by friction stir welding assisted by electrical current, Mater Des 113 (2017) 311-318, http://dx.doi.org/10.1016/j.matdes.2016.10.038.

[74] S. Fukumoto, T. Inoue, S. Mizuno, K. Okita, T. Tomita, A. Yamamoto, Friction welding of TiNi alloy to stainless steel using Ni interlayer, Sci Technol Weld Join 15 (2010) 124-130, http://dx.doi.org/10.1179/136217109X12577814486692.

[75] C.Y. Kong, R.C. Soar, P.M. Dickens, Ultrasonic consolidation for embedding SMA fibres within aluminium matrices, Compos Struct 66 (2004) 421-427, http://dx.doi.org/10.1016/j.compstruct.2004.04.064.

[76] R.J.J. Friel, R.A.A. Harris, Ultrasonic additive manufacturing a hybrid production process for novel functional products, Proc CIRP 6 (2013) 35-40, http://dx.doi.org/10.1016/j.procir.2013.03.004.

[77] R. Hahnlen, M.J. Dapino, M. Short, K. Graff, Aluminum-matrix composites with embedded Ni-Ti wires by ultrasonic consolidation, Proc SPIE 7290 (2009) http://dx.doi.org/10.1117/12.817036. 729009-729009-12.

[78] G. Habenicht, Applied adhesive bonding, 1st ed., Wiley-VCH Verlag GmbH \& Co. KGaA, Weinheim, 2008http://dx.doi.org/10.1002/9783527626458.

[79] S. Ebnesaijad, Surface treatment of materials for adhesive bonding, 2nd ed., Elsevier, Amsterdam, 2014http://dx.doi.org/10.1016/B978-0-323-26435-8. 00004-6.

[80] Brockmann W, Gei PL, Klingen J, Schrder B. Adhesive bonding, 1st ed. Weinheim: Wiley-VCH Verlag GmbH \& Co. KGaA. http://dx.doi.org/10.1002/ 9783527623921

[81] D. Dillard, Advances in structural adhesive bonding, 1st ed., Woodhead Publishing Limited, Cambridge, 2010.

[82] H.C. Man, N.Q. Zhao, Enhancing the adhesive bonding strength of NiTi shape memory alloys by laser gas nitriding and selective etching, Appl Surf Sci 253 (2006) 1595-1600, http://dx.doi.org/10.1016/j.apsusc.2006.02.057.

[83] F. Niccoli, M. Alfano, L. Bruno, F. Furgiuele, C. Maletta, Mechanical and functional properties of nickel titanium adhesively bonded joints, J Mater Eng Perform 23 (2014) 2385-2390, http://dx.doi.org/10.1007/s11665-014-0890-2.

[84] D. Jacobson, G. Humpston, Principles of brazing, 1st ed., ASM International, Ohio, 2005.

[85] M. Schwartz, Brazing, 2nd ed., ASM International, Ohio, 2003http://dx.doi.org/10.1036/1097-8542.094100.

[86] T. Tetsui, Effects of brazing filler on properties of brazed joints between TiAl and metallic materials, Intermetallics 9 (2001) 253-260, http://dx.doi.org/ 10.1016/S0966-9795(00)00129-1.

[87] Y. Nakao, K. Shinozaki, M. Hamada, Diffusion bonding of intermetallic compound TiAl, ISIJ Int 31 (1991) 1260-1266, http://dx.doi.org/10.2355/ isijinternational.31.1260.

[88] R. Shiue, S. Wu, S. Chen, Infrared brazing of TiAl intermetallic using BAg-8 braze alloy, Acta Mater 51 (2003) 1991-2004, http://dx.doi.org/10.1016/ S1359-6454(02)00606-7.

[89] R.R. Wang, G.E. Welsch, Joining titanium materials with tungsten inert gas welding, laser welding, and infrared brazing, J Prosthet Dent 74 (1995) 521-530, http://dx.doi.org/10.1016/S0022-3913(05)80356-7.

[90] T.Y. Yang, R.K. Shiue, S.K. Wu, Infrared brazing of $\mathrm{Ti}_{250} \mathrm{Ni}_{250}$ shape memory alloy using pure $\mathrm{Cu}$ and $\mathrm{Ti}-15 \mathrm{Cu}-15 \mathrm{Ni}$ foils, Intermetallics 12 (2004) 1285-1292, http://dx.doi.org/10.1016/i.intermet.2004.03.020.

[91] D.S. Grummon, J.A. Shaw, J. Foltz, Fabrication of cellular shape memory alloy materials by reactive eutectic brazing using niobium, Mater Sci Eng, A $438-440$ (2006) 1113-1118, http://dx.doi.org/10.1016/j.msea.2006.03.113.

[92] Grummon DS, Low K-B, Foltz J, Shaw Ja. A new method for brazing nitinol based on the quasibinary TiNi-Nb system. In: 48th AIAA/ASME/ASCE/ AHS/ASC struct struct dyn mater conf; 2007. p. 1-7.

[93] J.A. Shaw, D.S. Grummon, J. Foltz, Superelastic NiTi honeycombs: fabrication and experiments, Smart Mater Struct 16 (2007) S170-S178, http://dx. doi.org/10.1088/0964-1726/16/1/S17.

[94] Shaw JA, Churchill C, Triantafyllidis N, Michailidis P, Grummon D, Foltz J. Shape memory alloy honeycombs: experiments \& simulation. In: 48th AIAA/ASME/ASCE/AHS/ASC struct struct dyn mater conf, vol. 1; 2007. p. 428-36. <http://pdf.aiaa.org/preview/CDReadyMSDM07 1473/PV2007 1739.pdf>.

[95] L. Wang, C. Wang, D.C. Dunand, Microstructure and strength of NiTi-Nb eutectic braze joining NiTi wires, Metall Mater Trans A 46 (2015) 1433-1436, http://dx.doi.org/10.1007/s11661-015-2781-z.

[96] H. Matsuno, A. Yokoyama, F. Watari, M. Uo, T. Kawasaki, Biocompatibility and osteogenesis of refractory metal implants, titanium, hafnium, niobium, tantalum and rhenium, Biomaterials 22 (2001) 1253-1262, http://dx.doi.org/10.1016/S0142-9612(00)00275-1.

[97] W. Siegert, K. Neuking, M. Mertmann, G.F. Eggeler, Influence of $\mathrm{Nb}$ content and processing conditions on microstructure and functional properties of NiTiNb shape-memory alloys, Mater Sci Forum 394-395 (2002) 361-364, http://dx.doi.org/10.4028/www.scientific.net/MSF.394-395.361.

[98] X. Zhao, X. Yan, Y. Yang, H. Xu, Wide hysteresis NiTi(Nb) shape memory alloys with low Nb content (4.5 at.\%), Mater Sci Eng, A 438-440 (2006) 575-578, http://dx.doi.org/10.1016/j.msea.2006.03.110.

[99] R.H. Shiue, S.K. Wu, Infrared brazing of $\mathrm{Ti}_{250} \mathrm{Ni}_{250}$ shape memory alloy using two $\mathrm{Ag}-\mathrm{Cu}-\mathrm{Ti}$ active braze alloys, Intermetallics 14 (2006) 630-638, http://dx.doi.org/10.1016/j.intermet.2005.10.012.

[100] C. van der Eijk, Z.K. Sallom, O.M. Akselsen, Microwave brazing of NiTi shape memory alloy with Ag-Ti and Ag-Cu-Ti alloys, Scripta Mater 58 (2008) 779-781, http://dx.doi.org/10.1016/j.scriptamat.2007.12.017.

[101] X.K. Zhao, J.W. Tang, L. Lan, J.H. Haung, H. Zhang, Y. Wang, Vacuum brazing of NiTi alloy by AgCu eutectic filler, Mater Sci Technol 25 (2009) 1495-1497, http://dx.doi.org/10.1179/174328409X405625.

[102] W.F. Gale, Y. Guan, Microstructural development in copper-interlayer transient liquid phase bonds between martensitic NiAl and NiTi, J Mater Sci 32 (1997) 357-364.

[103] K. Oikawa, L. Wulff, T. Iijima, F. Gejima, T. Ohmori, A. Fujita, et al., Promising ferromagnetic Ni-Co-Al shape memory alloy system, Appl Phys Lett 79 (2001) 3290-3292, http://dx.doi.org/10.1063/1.1418259.

[104] M.G. Li, D.X.Q. Sun, X.M. Qiu, D.X.Q. Sun, S.Q. Yin, Effects of laser brazing parameters on microstructure and properties of TiNi shape memory alloy and stainless steel joint, Mater Sci Eng, A 424 (2006) 17-22, http://dx.doi.org/10.1016/j.msea.2006.01.054.

[105] M.G. Li, D.Q. Sun, X.M. Qiu, S.Q. Yin, Corrosion behavior of the laser-brazed joint of TiNi shape memory alloy and stainless steel in artificial saliva, Mater Sci Eng, A 441 (2006) 271-277, http://dx.doi.org/10.1016/j.msea.2006.08.052. 
[106] X.M. Qiu, M.G. Li, D.Q. Sun, W.H. Liu, Study on brazing of TiNi shape memory alloy with stainless steels, J Mater Process Technol 176 (2006) 8-12, http://dx.doi.org/10.1016/j.jmatprotec.2005.06.004.

[107] G.V. Newman, Epoxy adhesives for orthodontic attachments: progress report, Am J Orthod 51 (1965) 901-912, http://dx.doi.org/10.1016/ 0002-9416(65)90203-4.

[108] G. Satoh, L. Yao, Laser autogeneous brazing - a new method for joining dissimilar metals, Proc Int Congr Appl Lasers Electro-Optics (2011) 315-324.

[109] Satoh G, Brandal GB, Naveed S, Yao YL. Laser autogenous brazing of biocompatible, dissimilar metals in tubular geometries. In: Proceeding north am manuf res inst; 2013. p. 1-10.

[110] X.K. Zhao, L. Lan, H.B. Sun, J.H. Huang, H. Zhang, Preparation of NiTi/NiTiNb laminated alloys by vacuum brazing, Adv Mater Res $97-101$ (2010) 1653-1656, http://dx.doi.org/10.4028/www.scientific.net/AMR.97-101.1653.

[111] L. Quintino, L. Liu, A. Hu, R.M. Miranda, Y. Zhou, Fracture analysis of Ag nanobrazing of NiTi to Ti alloy, Soldag Inspeção 18 (2013) 281-286, http:// dx.doi.org/10.1590/S0104-92242013000300010.

[112] T.G. Santos, F.B. Fernandes, G. Bernardo, R.M. Miranda, Analyzing mechanical properties and nondestructive characteristics of brazed joints of NiTi shape memory alloys to carbon steel rods, Int J Adv Manuf Technol 66 (2013) 787-793, http://dx.doi.org/10.1007/s00170-012-4366-y.

[113] C.J. Munez, M.A. Garrido, J. Rams, A. Ureña, Experimental study of W-Eurofer laser brazing for divertor application, J Nucl Mater 418 (2011) 239-248, http://dx.doi.org/10.1016/j.jnucmat.2011.07.008.

[114] G. Janeschitz, K. Borrass, G. Federici, Y. Igitkhanov, A. Kukushkin, H.D. Pacher, et al., The ITER divertor concept, J Nucl Mater 220-222 (1995) 73-88, http://dx.doi.org/10.1016/0022-3115(94)00447-1.

[115] N.F. Kazakov, Diffusion bonding of materials, 1st ed., Pergamon Press, Oxford, 1985.

[116] A. Hill, E.R. Wallach, Modelling solid-state diffusion bonding, Acta Metall 37 (1989) 2425-2437, http://dx.doi.org/10.1016/0001-6160(89)90040-0.

[117] N. Orhan, T.I. Khan, M. Ero?lu, Diffusion bonding of a microduplex stainless steel to Ti-6Al-4V, Scripta Mater 45 (2001) 441-446, http://dx.doi.org/10. 1016/S1359-6462(01)01041-7.

[118] H. Kejanli, M. Taşkin, S. Kolukisa, P. Topuz, Transient liquid phase (TLP) diffusion bonding of $\mathrm{Ti}_{245} \mathrm{Ni}_{249} \mathrm{Cu}_{26} \mathrm{P} / \mathrm{M}$ components using Cu interlayer, Int J Adv Manuf Technol 44 (2009) 695-699, http://dx.doi.org/10.1007/s00170-008-1860-3.

[119] B. Derby, E.R. Wallach, Theoretical model for diffusion bonding, Met Sci 16 (1982) 49-56, http://dx.doi.org/10.1179/030634582790427028.

[120] K.S. Senkevich, S.D. Shlyapin, Investigation of the process of diffusion bonding of alloys based on titanium nickelide, Weld Int 26 (2012) 736-738, http://dx.doi.org/10.1080/09507116.2011.653156.

[121] K.S. Senkevich, A study of the microstructure of diffusion joints of TiNi-base alloys, Met Sci Heat Treat 55 (2014) 675-679, http://dx.doi.org/10.1007/ s11041-014-9689-x.

[122] K.S. Senkevich, M.I. Knyazev, Y.E. Runova, S.D. Shlyapin, Special features of formation of a TiNi - VT6 diffusion joint, Met Sci Heat Treat 55 (2013) 419-422, http://dx.doi.org/10.1007/s11041-013-9647-z.

[123] A.J. Cavaleiro, A.S. Ramos, F.M. Braz Fernandes, N. Schell, M.T. Vieira, In situ characterization of NiTi/Ti6Al4V joints during reaction-assisted diffusion bonding using Ni/Ti multilayers, J Mater Eng Perform 23 (2014) 1625-1629, http://dx.doi.org/10.1007/s1 1665-014-0930-y.

[124] J. Cao, J.C. Feng, Z.R. Li, Microstructure and fracture properties of reaction-assisted diffusion bonding of TiAl intermetallic with Al/Ni multilayer foils, J Alloys Compd 466 (2008) 363-367, http://dx.doi.org/10.1016/j.jallcom.2007.11.033.

[125] T. Araki, A. Hirose, M. Uchihara, W. Kohno, K. Honda, M. Kondoh, Characteristics and fracture morphology of Ti-Ni type shape memory alloy and its laser weld joint, J Soc Mater Sci Jpn 38 (1989) 478-483, http://dx.doi.org/10.2472/jsms.38.478.

[126] A. Hirose, T. Araki, M. Uchihara, K. Honda, M. Kondoh, Laser welding of Ti-Ni type shape memory alloy, J Jpn Inst Met Mater 54 (1990) $262-269$.

[127] A. Tuissi, P. Bassani, M. Gerosa, D. Mauri, M. Pini, E. Capello, et al., $\mathrm{CO}_{? 2}$ laser welding of NiTi/Ni-based alloys, in: A. Pelton, T. Duerig (Eds.), Proc int conf shape mem superelastic technol, 2004, pp. 229-238, http://dx.doi.org/10.1361/cp2003smst229.

[128] H. Gugel, A. Schuermann, W. Theisen, Laser welding of NiTi wires, Mater Sci Eng, A 481-482 (2008) 668-671, http://dx.doi.org/10.1016/j.msea.2006. 11.179 .

[129] Haas T, Schuessler A. Welding and joining of TiNi shape memory alloys: engineering aspects and medical applications. In: Proc int conf shape mem superelastic technol; 1999. p. 1-11.

[130] A. Falvo, F.M.M. Furgiuele, C. Maletta, Functional behaviour of a NiTi-welded joint: two-way shape memory effect, Mater Sci Eng, A $481-482$ (2008) 647-650, http://dx.doi.org/10.1016/j.msea.2006.11.178.

[131] B. Panton, J.P. Oliveira, Z. Zeng, Y.N. Zhou, M.I. Khan, Thermomechanical fatigue of post-weld heat treated NiTi shape memory alloy wires, Int J Fatigue $92(2016) 1-7$, http://dx.doi.org/10.1016/j.ijfatigue.2016.06.012.

[132] C.W. Chan, H.C. Man, T.M. Yue, Effects of process parameters upon the shape memory and pseudo-elastic behaviors of laser-welded NiTi thin foil, Metall Mater Trans A Phys Metall 42 (2011) 2264-2270, http://dx.doi.org/10.1007/s11661-011-0623-1.

[133] C.W. Chan, H.C. Man, Laser welding of thin foil nickel-titanium shape memory alloy, Opt Lasers Eng 49 (2011) 121-126, http://dx.doi.org/10.1016/j. optlaseng.2010.08.007.

[134] C.W. Chan, H.C. Man, T.M. Yue, Effect of post-weld heat-treatment on the oxide film and corrosion behaviour of laser-welded shape memory NiTi wires, Corros Sci 56 (2012) 158-167, http://dx.doi.org/10.1016/j.corsci.2011.11.020.

[135] Schuessler A. Laser processing of nitinol materials. In: Proc int conf shape mem superelastic technol; 2001. p. 25-32.

[136] Schlossmacher P. Laser welding of Ni-rich TiNi shape memory alloy - pseudoelastic properties. In: Proc int conf shape mem superelastic technol; 1997. p. 137-42.

[137] A. Tuissi, S. Besseghini, T. Ranucci, F. Squatrito, M. Pozzi, Effect of Nd-YAG laser welding on the functional properties of the Ni-49.6 at.\%Ti, Mater Sci Eng, A 273-275 (1999) 813-817, http://dx.doi.org/10.1016/S0921-5093(99)00422-0.

[138] A. Falvo, F.M. Furgiuele, C. Maletta, Laser welding of a NiTi alloy: mechanical and shape memory behaviour, Mater Sci Eng, A 412 (2005) 235-240, http://dx.doi.org/10.1016/j.msea.2005.08.209.

[139] B. Tam, M.I. Khan, Y. Zhou, Mechanical and functional properties of laser-welded Ti-55.8 wt pet Ni nitinol wires, Metall Mater Trans A 42 (2011) 2166-2175, http://dx.doi.org/10.1007/s11661-011-0639-6.

[140] L.A. Vieira, F.M.M.B. Fernandes, R.M.M. Miranda, R.J.C. Silva, L. Quintino, A. Cuesta, et al., Mechanical behaviour of Nd:YAG laser welded superelastic NiTi, Mater Sci Eng, A 528 (2011) 5560-5565, http://dx.doi.org/10.1016/j.msea.2011.03.089.

[141] M. Ijijima, W.A. Brantley, T. Yuasa, T. Muguruma, I. Kawashima, I. Mizoguchi, Joining characteristics of orthodontic wires with laser welding, J Biomed Mater Res Part B Appl Biomater 84B (2008) 147-153, http://dx.doi.org/10.1002/jbm.b.30856.

[142] F.M. Braz Fernandes, K.K. Mahesh, C.M. Craciunescu, J.P. Oliveira, N. Schell, R.M. Miranda, et al., In situ structural characterization of laser welded NiTi shape memory alloys, Mater Sci Forum 738-739 (2013) 338-343, http://dx.doi.org/10.4028/www.scientific.net/MSF.738-739.338.

[143] G.R. Mirshekari, A. Saatchi, A. Kermanpur, S.K. Sadrnezhaad, Laser welding of NiTi shape memory alloy: comparison of the similar and dissimilar joints to AISI 304 stainless steel, Opt Laser Technol 54 (2013) 151-158, http://dx.doi.org/10.1016/j.optlastec.2013.05.014.

[144] Schlossmacher P, Haas T, Schussler A. Laser welding of Ni-Ti shape memory alloys. In: Proc int conf shape mem superelastic technol; 1994. p. 85-90.

[145] P. Sevilla, F. Martorell, C. Libenson, J.A. Planell, F.J. Gil, Laser welding of NiTi orthodontic archwires for selective force application, J Mater Sci Mater Med 19 (2008) 525-529, http://dx.doi.org/10.1007/s10856-007-0164-8. 
[146] P. Schlossmacher, T. Haas, A.S. Ussler, Laser-welding of a Ni-rich TiNi shape memory alloy: mechanical behavior, J Phys IV 7 (1997) http://dx.doi.org/ 10.1051/jp4:1997539. C5-251-C5-256.

[147] X.J. Yan, D.Z. Yang, X.P. Liu, Corrosion behavior of a laser-welded NiTi shape memory alloy, Mater Charact 58 (2007) 623-628, http://dx.doi.org/10. 1016/j.matchar.2006.07.010

[148] X. Zhao, W. Wang, L. Chen, F. Liu, J. Huang, H. Zhang, Microstructures of cerium added laser weld of a TiNi alloy, Mater Lett 62 (2008) 1551-1553, http://dx.doi.org/10.1016/j.matlet.2007.09.021.

[149] X. Zhao, W. Wang, L. Chen, F. Liu, G. Chen, J. Huang, et al., Two-stage superelasticity of a Ce-added laser-welded TiNi alloy, Mater Lett 62 (2008) 3539-3541, http://dx.doi.org/10.1016/j.matlet.2008.03.042.

[150] H. Li, W. Wang, P. Dong, Laser welding of TiNi shape memory alloy using pure Cu as interlayer, J Mater Eng (2010) 9-12. <http://jme.biam.ac.cn/EN/ Y2010/V0/I10/9>.

[151] C.W. Chan, S.H.J. Chan, H.C. Man, P. Ji, Constitutive model for localized Lüders-like stress-induced martensitic transformation and super-elastic behaviors of laser-welded NiTi wires, Comput Mater Sci 63 (2012) 197-206, http://dx.doi.org/10.1016/j.commatsci.2012.06.009.

[152] D. Otibar, C. Rathmann, K. Lygin, D. Kreimeier, P. Szymansky, Analyzing laser-welded NiTi-NiTi-joints for actuator applications using design of experiments, J Mech Eng Autom 5 (2015) 76-81, http://dx.doi.org/10.17265/2159-5275/2015.02.003.

[153] C.W. Chan, H.C. Man, T.M. Yue, Effect of postweld heat treatment on the microstructure and cyclic deformation behavior of laser-welded NiTi-shape memory wires, Metall Mater Trans A 43 (2012) 1956-1965, http://dx.doi.org/10.1007/s11661-011-1062-8.

[154] X.J.J. Yan, D.Z.Z. Yang, M. Qi, Rotating-bending fatigue of a laser-welded superelastic NiTi alloy wire, Mater Charact 57 (2006) 58-63, http://dx.doi. org/10.1016/j.matchar.2005.12.009.

[155] C.W. Chan, H.C. Man, F.T. Cheng, Fatigue behavior of laser-welded NiTi wires in small-strain cyclic bending, Mater Sci Eng, A 559 (2013) 407-415, http://dx.doi.org/10.1016/j.msea.2012.08.119.

[156] Y.G.G. Song, W.S.S. Li, L. Li, Y.F.F. Zheng, The influence of laser welding parameters on the microstructure and mechanical property of the as-jointed NiTi alloy wires, Mater Lett 62 (2008) 2325-2328, http://dx.doi.org/10.1016/j.matlet.2007.11.082.

[157] X. Yan, D. Yang, X. Liu, Electrochemical behavior of YAG laser-welded NiTi shape memory alloy, Trans Nonferr Met Soc Chin 16 (2006) 572-576, http://dx.doi.org/10.1016/s1003-6326(06)60100-3.

[158] D. Ruhlig, H. Gugel, A. Schulte, W. Theisen, W. Schuhmann, Visualization of local electrochemical activity and local nickel ion release on laser-welded NiTi/steel joints using combined alternating current mode and stripping mode SECM, Analyst 133 (2008) 1700-1706, http://dx.doi.org/10.1039/ b804718a.

[159] C.W. Chan, H.C. Man, T.M. Yue, Susceptibility to stress corrosion cracking of NiTi laser weldment in Hanks' solution, Corros Sci 57 (2012) 260-269, http://dx.doi.org/10.1016/j.corsci.2011.12.010.

[160] C.W. Chan, H.C. Man, T.M. Yue, Susceptibility to environmentally induced cracking of laser-welded NiTi wires in Hanks' solution at open-circuit potential, Mater Sci Eng, A 544 (2012) 38-47, http://dx.doi.org/10.1016/j.msea.2012.02.087.

[161] C.W. Chan, I. Hussain, D.G. Waugh, J. Lawrence, H.C. Man, In vitro mesenchymal stem cell responses on laser-welded NiTi alloy, Mater Sci Eng, C 33 (2013) 1344-1354, http://dx.doi.org/10.1016/j.msec.2012.12.035.

[162] X.J.J. Yan, D.Z.Z. Yang, X.P.P. Liu, Influence of heat treatment on the fatigue life of a laser-welded NiTi alloy wire, Mater Charact 58 (2007) 262-266, http://dx.doi.org/10.1016/j.matchar.2006.05.001.

[163] X. Yan, Y. Ge, Influence of post-weld annealing on transformation behavior and mechanical properties of laser-welded NiTi alloy wires, J Mater Eng Perform 23 (2014) 3474-3479, http://dx.doi.org/10.1007/s11665-014-1156-8.

[164] C.W. Chan, H.C. Man, Reduction of environmentally induced cracking of laser-welded shape memory NiTi wires via post-weld heat-treatment, Mater Sci Eng, A 588 (2013) 388-394, http://dx.doi.org/10.1016/j.msea.2013.09.051.

[165] X.J. Yan, D.Z. Yang, Corrosion resistance of a laser spot-welded joint of NiTi wire in simulated human body fluids, J Biomed Mater Res A 77 (2006) 97-102, http://dx.doi.org/10.1002/jbm.a.30378.

[166] J.P. Oliveira, R.M. Miranda, N. Schell, F.M. Braz Fernandes, N. Schell, F.M. Braz Fernandes, High strain and long duration cycling behavior of laser welded NiTi sheets, Int J Fatigue 83 (2016) 195-200, http://dx.doi.org/10.1016/j.ijfatigue.2015.10.013.

[167] J.P. Oliveira, F.M. Braz Fernandes, R.M. Miranda, N. Schell, On the mechanisms for martensite formation in YAG laser welded austenitic NiTi, Shape Mem Superelast 2 (2016) 114-120, http://dx.doi.org/10.1007/s40830-016-0058-z.

[168] J.P. Oliveira, F.M.B. Fernandes, N. Schell, R.M. Miranda, Shape memory effect of laser welded NiTi plates, Funct Mater Lett 8 (2015) 1550069, http:// dx.doi.org/10.1142/S1793604715500691.

[169] J.P. Oliveira, F.M.B. Fernandes, R.M. Miranda, N. Schell, J.L. Ocaña, Residual stress analysis in laser welded NiTi sheets using synchrotron X-ray diffraction, Mater Des 100 (2016) 180-187, http://dx.doi.org/10.1016/j.matdes.2016.03.137.

[170] J.P. Oliveira, F.M. Braz Fernandes, R.M. Miranda, N. Schell, J.L. Ocaña, Effect of laser welding parameters on the austenite and martensite phase fractions of NiTi, Mater Charact 119 (2016) 148-151, http://dx.doi.org/10.1016/j.matchar.2016.08.001.

[171] J.P. Oliveira, F.M.B. Fernandes, N. Schell, R.M. Miranda, Martensite stabilization during superelastic cycling of laser welded NiTi plates, Mater Lett 171 (2016) 273-276, http://dx.doi.org/10.1016/j.matlet.2016.02.107.

[172] J. Pouquet, R.M. Miranda, L. Quintino, S. Williams, Dissimilar laser welding of NiTi to stainless steel, Int J Adv Manuf Technol 61 (2012) 205-212, http://dx.doi.org/10.1007/s00170-011-3694-7.

[173] R. Hahnlen, G. Fox, M.J. Dapino, Fusion welding of nickel-titanium and 304 stainless steel tubes: part I: laser welding, J Intell Mater Syst Struct 24 (2012) 945-961, http://dx.doi.org/10.1177/1045389X12461075.

[174] C.H. Ng, E.S.H. Mok, H.C. Man, Effect of Ta interlayer on laser welding of NiTi to AISI 316L stainless steel, J Mater Process Technol 226 (2015) 69-77, http://dx.doi.org/10.1016/j.jmatprotec.2015.06.039.

[175] P. Burdet, J. Vannod, A. Hessler-Wyser, M. Rappaz, M. Cantoni, Three-dimensional chemical analysis of laser-welded NiTi-stainless steel wires using a dual-beam FIB, Acta Mater 61 (2013) 3090-3098, http://dx.doi.org/10.1016/j.actamat.2013.01.069.

[176] H.M. Li, D.Q. Sun, X.L. Cai, P. Dong, W.Q. Wang, Laser welding of TiNi shape memory alloy and stainless steel using Ni interlayer, Mater Des 39 (2012) 285-293, http://dx.doi.org/10.1016/j.matdes.2012.02.031.

[177] H. Li, D. Sun, X. Gu, P. Dong, Z. Lv, Effects of the thickness of Cu filler metal on the microstructure and properties of laser-welded TiNi alloy and stainless steel joint, Mater Des 50 (2013) 342-350, http://dx.doi.org/10.1016/j.matdes.2013.03.014.

[178] C. Zhang, X. Sun, X. Hou, H. Li, D. Sun, The corrosion resistance of composite arch wire laser-welded by NiTi shape memory alloy and stainless steel wires with Cu interlayer in artificial saliva with protein, Int J Med Sci 10 (2013) 1068-1072, http://dx.doi.org/10.7150/ijms.5878.

[179] C. Zhang, X. Sun, Susceptibility to stress corrosion of laser-welded composite arch wire in acid artificial saliva, Adv Mater Sci Eng 3 (2013) 1-8, http:// dx.doi.org/10.1155/2013/738954.

[180] C. Zhang, S. Zhao, X. Sun, D. Sun, X. Sun, Corrosion of laser-welded NiTi shape memory alloy and stainless steel composite wires with a copper interlayer upon exposure to fluoride and mechanical stress, Corros Sci 82 (2014) 404-409, http://dx.doi.org/10.1016/j.corsci.2014.01.040.

[181] E. Watanabe, G. Stigall, W. Elshahawy, I. Watanabe, Deflection load characteristics of laser-welded orthodontic wires, Angle Orthod 82 (2012) 698-702, http://dx.doi.org/10.2319/061411-393.1. 
[182] R.M. Miranda, E. Assunção, R.J.C. Silva, J.P. Oliveira, L. Quintino, Fiber laser welding of NiTi to Ti-6Al-4V, Int J Adv Manuf Technol 81 (2015) 1533-1538, http://dx.doi.org/10.1007/s00170-015-7307-8.

[183] A. Shojaei, S.A.A. Zoeram, Akbari Mousavi, Laser welding of Ti-6Al-4V to nitinol, Mater Des 61 (2014) 185-190, http://dx.doi.org/10.1016/j.matdes. 2014.04.078.

[184] A. Shojaei, S.A.A. Zoeram, Akbari Mousavi, Effect of interlayer thickness on microstructure and mechanical properties of as welded Ti6Al4V/Cu/NiTi joints, Mater Lett 133 (2014) 5-8, http://dx.doi.org/10.1016/j.matlet.2014.06.141.

[185] R. Steegmüller, M. Strobel, E. Flaxmeier, A. Schüßler, Micro-welding for improved radiopacity of nitinol-stents, Proc Int Conf Shape Mem Superelastic Technol (2004) 591-596.

[186] B. Panton, A. Pequegnat, Y.N. Zhou, Dissimilar laser joining of NiTi SMA and MP35N wires, Metall Mater Trans A Phys Metall Mater Sci 45 (2014) 3533-3544, http://dx.doi.org/10.1007/s11661-014-2280-7.

[187] Z. Zeng, B. Panton, J.P. Oliveira, A. Han, Y.N. Zhou, Dissimilar laser welding of NiTi shape memory alloy and copper, Smart Mater Struct 24 (2015) 125036, http://dx.doi.org/10.1088/0964-1726/24/12/125036.

[188] Guber AE, Giordano N, Schussler A, Baldinus O, Loser M, Wieneke P. Nitinol-based microinstruments for endoscopic neurosurgery. In: Proceedings actuator $96-5$ th int conf new actuators; 1996. p. 375-8.

[189] G. Siekmeyer, B. Schrader, A. Hegel, R. Steegmüller, M. Strobel, A. Schuessler, Novel micro-joining techniques to improve stent radiopacity: a comparison of welding and riveting processes, Adv Mater Process 163 (2005) 72.

[190] R. Hagiwara, M. Suehara, R. Fujii, H. Kato, K. Nakagawa, Y. Oda, Laser welding method for removal of instruments debris from root canals, Bull Tokyo Dent Coll 54 (2013) 81-88. <http://www.ncbi.nlm.nih.gov/pubmed/23903578>.

[191] Z. Zeng, M. Yang, J.P. Oliveira, D. Song, B. Peng, Laser welding of NiTi shape memory alloy wires and tubes for multi-functional design applications, Smart Mater Struct 25 (2016) 85001, http://dx.doi.org/10.1088/0964-1726/25/8/085001.

[192] J. Ion, Laser processing of engineering materials, 1st ed., Elsevier, Amsterdam, 2005http://dx.doi.org/10.1007/s13398-014-0173-7.2.

[193] S. Kou, Welding metallurgy, 2nd ed., John Wiley \& Sons Inc., Hoboken, 2002http://dx.doi.org/10.1002/0471434027.

[194] K. Weinert, V. Petzoldt, Machining of NiTi based shape memory alloys, Mater Sci Eng, A 378 (2004) 180-184, http://dx.doi.org/10.1016/j.msea.2003. 10.344 .

[195] C.P. Frick, A.M. Ortega, J. Tyber, A.E.M.E.M. Maksound, H.J. Maier, Y. Liu, et al., Thermal processing of polycrystalline NiTi shape memory alloys, Mater Sci Eng, A 405 (2005) 34-49, http://dx.doi.org/10.1016/j.msea.2005.05.102.

[196] R. Dinnebier, S. Billinge, Powder diffraction: theory and practice, 1st ed., Royal Society of Chemistry, Cambridge, 2008http://dx.doi.org/10.1039/ 9781847558237.

[197] R.S. Dutta, K. Madangopal, H.S. Gadiyar, S. Banerjee, Biocompatibility of Ni-Ti shape memory alloy, Br Corros J 28 (1993) 217-221, http://dx.doi. org/10.1179/000705993798318560.

[198] W. Tirry, D. Schryvers, Quantitative determination of strain fields around $\mathrm{Ni}_{24} \mathrm{Ti}_{23}$ precipitates in NiTi, Acta Mater 53 (2005) 1041-1049, http://dx.doi. org/10.1016/j.actamat.2004.10.049.

[199] D. Schryvers, W. Tirry, Z.Q. Yang, Measuring strain fields and concentration gradients around $\mathrm{Ni}_{? 4} \mathrm{Ti}_{93}$ precipitates, Mater Sci Eng, A $438-440$ (2006) 485-488, http://dx.doi.org/10.1016/j.msea.2006.02.166.

[200] K. Wada, Y. Liu, Shape recovery of NiTi shape memory alloy under various pre-strain and constraint conditions, Smart Mater Struct 14 (2005) S273-S286, http://dx.doi.org/10.1088/0964-1726/14/5/016.

[201] Y.O. Liu, S.P. Galvin, Criteria for pseudoelasticity in near-equiatomic NiTi shape memory alloys, Acta Mater 45 (1997) 4431-4439, http://dx.doi.org/ 10.1016/S1359-6454(97)00144-4.

[202] Y. Liu, H. Xiang, Apparent modulus of elasticity of near-equiatomic NiTi, J Alloys Compd 270 (1998) 154-159, http://dx.doi.org/10.1016/ S0925-8388(98)00500-3.

[203] Y. Liu, H. Yang, The concern of elasticity in stress-induced martensitic transformation in NiTi, Mater Sci Eng, A 260 (1999) 240-245, http://dx.doi.org/ 10.1016/S0921-5093(98)00959-9.

[204] Y. Liu, H. Yang, Strain dependence of the Clausius-Clapeyron relation for thermoelastic martensitic transformations in NiTi, Smart Mater Struct 16 (2007) S22-S27, http://dx.doi.org/10.1088/0964-1726/16/1/S03.

[205] P. Sittner, Y. Liu, V. Novak, On the origin of Lüders-like deformation of NiTi shape memory alloys, J Mech Phys Solids 53 (2005) 1719-1746, http:// dx.doi.org/10.1016/j.jmps.2005.03.005.

[206] G. Tan, Y. Liu, P. Sittner, M. Saunders, Lüders-like deformation associated with stress-induced martensitic transformation in NiTi, Scripta Mater 50 (2004) 193-198, http://dx.doi.org/10.1016/j.scriptamat.2003.09.018.

[207] C.W. Chan, S.H.J. Chan, H.C. Man, P. Ji, 1-D constitutive model for evolution of stress-induced R-phase and localized Lüders-like stress-induced martensitic transformation of super-elastic NiTi wires, Int J Plast 32-33 (2012) 85-105, http://dx.doi.org/10.1016/j.ijplas.2011.12.003.

[208] H. Tobushi, Y. Shimeno, T. Hachisuka, K. Tanaka, Influence of strain rate on superelastic properties of TiNi shape memory alloy, Mech Mater 30 (1998) 141-150, http://dx.doi.org/10.1016/S0167-6636(98)00041-6.

[209] P. Sedmák, P. Šittner, J. Pilch, C. Curfs, Instability of cyclic superelastic deformation of NiTi investigated by synchrotron X-ray diffraction, Acta Mater 94 (2015) 257-270, http://dx.doi.org/10.1016/j.actamat.2015.04.039.

[210] W. Chrzanowski, J. Szade, A.D. Hart, J.C. Knowles, M.J. Dalby, Biocompatible, smooth, plasma-treated nickel-titanium surface - an adequate platform for cell growth, J Biomater Appl 26 (2012) 707-731, http://dx.doi.org/10.1177/0885328211416023.

[211] T. Saburi, S. Nenno, Y. Nishimoto, M. Zeniya, Effects of thermo-mechanical treatment on the shape memory effect and the pseudoelasticity of Ti-50.2Ni and Ti-47.5Ni-2.5Fe alloys, Iron Steel Inst Jpn 72 (1986) 571-578. <https://www.jstage.jst.go.jp/article/tetsutohagane1955/72/6/72_6 571/ article>.

[212] P.H. Lin, H. Tobushi, K. Tanaka, T. Hattori, M. Makita, Pseudoelastic behaviour of TiNi shape memory alloy subjected to strain variations, J Intell Mater Syst Struct 5 (1994) 694-701, http://dx.doi.org/10.1177/1045389X9400500514.

[213] T. Saburi, M. Yoshida, S. Nenno, Deformation behavior of shape memory Ti-Ni alloy crystals, Scr Metall 18 (1984) 363-366, http://dx.doi.org/10.1016/ 0036-9748(84)90453-8.

[214] G. Eggeler, E. Hornbogen, A. Yawny, A. Heckmann, M. Wagner, Structural and functional fatigue of NiTi shape memory alloys, Mater Sci Eng, A 378 (2004) 24-33, http://dx.doi.org/10.1016/j.msea.2003.10.327.

[215] K. Gall, J. Tyber, G. Wilkesanders, S.W. Robertson, R.O. Ritchie, H.J. Maier, Effect of microstructure on the fatigue of hot-rolled and cold-drawn NiTi shape memory alloys, Mater Sci Eng, A 486 (2008) 389-403, http://dx.doi.org/10.1016/j.msea.2007.11.033.

[216] J. Schaffer, Structure-property relationships in conventional and nanocrystalline NiTi intermetallic alloy wire, J Mater Eng Perform 18 (2009) 582-587, http://dx.doi.org/10.1007/s11665-009-9369-y.

[217] K. Mukherjee, S. Sircar, N.B. Dahotre, Thermal effects associated with stress-induced martensitic transformation in a Ti-Ni alloy, Mater Sci Eng 74 (1985) 75-84, http://dx.doi.org/10.1016/0025-5416(85)90111-9.

[218] A.L. McKelvey, R.O. Ritchie, Fatigue-crack growth behavior in the superelastic and shape-memory alloy nitinol, Metall Mater Trans A: Phys Metall Mater Sci 32 (2001) 731-743, http://dx.doi.org/10.1007/s11661-001-0089-7. 
[219] Q. Pan, C. Cho, The investigation of a shape memory alloy micro-damper for MEMS applications, Sensors 7 (2007) 1887-1900, http://dx.doi.org/10. 3390/s7091887.

[220] S. Miyazaki, Y. Ohmi, K. Otsuka, Y. Suzuki, Characteristics of deformation and transformation pseudoelasticity in Ti-Ni Alloys, J Phys 43 (1982) C4225-C4260, http://dx.doi.org/10.1007/s00338-002-0215-z.

[221] T.G. Bradley, W.a. Brantley, B.M. Culbertson, Differential scanning calorimetry (DSC) analyses of superelastic and nonsuperelastic nickel-titanium orthodontic wires, Am J Orthod Dentofac Orthop 109 (1996) 589-597, http://dx.doi.org/10.1016/S0889-5406(96)70070-7.

[222] J.A. Shaw, C.B. Churchill, M.A. Iadicola, Tips and tricks for characterizing shape memory alloy wire: part 1-differential scanning calorimetry and basic phenomena, Exp Tech 32 (2008) 55-62, http://dx.doi.org/10.1111/j.1747-1567.2008.00410.x.

[223] J. Uchil, K.K. Mahesh, K.G. Kumara, Dilatometric study of martensitic transformation in NiTiCu and NiTi shape memory alloys, J Mater Sci 36 (2001) 5823-5827, http://dx.doi.org/10.1023/A:1012908222409.

[224] J. Uchil, K.K. Mahesh, K.G. Kumara, Electrical resistivity and strain recovery studies on the effect of thermal cycling under constant stress on R-phase in NiTi shape memory alloy, Phys B Condensed Matter 324 (2002) 419-428, http://dx.doi.org/10.1016/S0921-4526(02)01462-X.

[225] V. Novák, P. Šittner, G.N. Dayananda, F.M. Braz-Fernandes, K.K. Mahesh, Electric resistance variation of NiTi shape memory alloy wires in thermomechanical tests: experiments and simulation, Mater Sci Eng, A 481-482 (2008) 127-133, http://dx.doi.org/10.1016/j.msea.2007.02.162.

[226] J. Frenzel, E.P. George, A. Dlouhy, C. Somsen, M.F.-X. Wagner, G. Eggeler, Influence of Ni on martensitic phase transformations in NiTi shape memory alloys, Acta Mater 58 (2010) 3444-3458, http://dx.doi.org/10.1016/j.actamat.2010.02.019.

[227] D.A. Miller, D.C. Lagoudas, Influence of cold work and heat treatment on the shape memory effect and plastic strain development of NiTi, Mater Sci Eng, A 308 (2001) 161-175, http://dx.doi.org/10.1016/S0921-5093(00)01982-1.

[228] P. Šittner, M. Landa, P. Lukáš, V. Novák, R-phase transformation phenomena in thermomechanically loaded NiTi polycrystals, Mech Mater 38 (2006) 475-492, http://dx.doi.org/10.1016/j.mechmat.2005.05.025.

[229] T. Kurita, H. Matsumoto, H. Abe, Transformation behavior in rolled NiTi, J Alloys Compd 381 (2004) 158-161, http://dx.doi.org/10.1016/j.jallcom. 2004.03.108.

[230] F.J. Gil, J.M. Manero, J.A. Planell, Effect of grain size on the martensitic transformation in NiTi alloy, J Mater Sci 30 (1995) 2526-2530, http://dx.doi. org/10.1007/BF00362129.

[231] M.I. Khan, Y. Zhou, Effects of local phase conversion on the tensile loading of pulsed Nd:YAG laser processed Nitinol, Mater Sci Eng, A 527 (2010) 6235-6238, http://dx.doi.org/10.1016/j.msea.2010.06.025.

[232] M.I. Khan, A. Pequegnat, Y.N. Zhou, Multiple memory shape memory alloys, Adv Eng Mater 15 (2013) 386-393, http://dx.doi.org/10.1002/adem. 201200246.

[233] M.C. Carroll, C. Somsen, G. Eggeler, Multiple-step martensitic transformations in Ni-rich NiTi shape memory alloys, Scripta Mater 50 (2004) 187-192, http://dx.doi.org/10.1016/j.scriptamat.2003.09.020.

[234] C. Trepanier, M. Tabrizian, L. Yahia, L. Bilodeau, D.L. Piron, Effect of modification of oxide layer on NiTi stent corrosion resistance, J Biomed Mater Res 48 (1999) 433-440, http://dx.doi.org/10.1002/(SICI) 1097-4636(199824)43:4<433::AID-JBM11>3.0.CO;2-\#.

[235] T.-H. Lee, T.-K. Huang, S.-Y. Lin, L.-K. Chen, M.-Y. Chou, H.-H. Huang, Corrosion resistance of different nickel-titanium archwires in acidic fluoride-containing artificial saliva, Angle Orthod 80 (2010) 547-553, http://dx.doi.org/10.2319/042909-235.1.

[236] N. Figueira, T.M. Silva, M.J. Carmezim, J.C.S. Fernandes, Corrosion behaviour of NiTi alloy, Electrochim Acta 54 (2009) 921-926, http://dx.doi.org/ 10.1016/j.electacta.2008.08.001

[237] S.A. Shabalovskaya, Surface, corrosion and biocompatibility aspects of nitinol as an implant material, Biomed Mater Eng 12 (2002) 69-109. <http:// www.ncbi.nlm.nih.gov/pubmed/11847410>.

[238] D. Stoeckel, A. Pelton, T. Duerig, Self-expanding nitinol stents: material and design considerations, Eur Radiol 14 (2004) 292-301, http://dx.doi.org/10. 1007/s00330-003-2022-5.

[239] T. Eliades, A.E. Athanasiou, In vivo aging of orthodontic alloys: implications for corrosion potential, nickel release, and biocompatibility, Angle Orthod 72 (2002) 222-237, http://dx.doi.org/10.1043/0003-3219(2002) 072<0222:IVAOOA>2.0.CO;2.

[240] R.W.Y. Poon, J.P.Y. Ho, X. Liu, C.Y. Chung, P.K. Chu, K.W.K. Yeung, et al., Improvements of anti-corrosion and mechanical properties of NiTi orthopedic materials by acetylene, nitrogen and oxygen plasma immersion ion implantation, Nucl Instrum Methods Phys Res Sect B Beam Interact Mater Atoms 237 (2005) 411-416, http://dx.doi.org/10.1016/j.nimb.2005.05.030.

[241] M. Es-Souni, M. Es-Souni, H. Fischer-Brandies, On the properties of two binary NiTi shape memory alloys. Effects of surface finish on the corrosion behaviour and in vitro biocompatibility, Biomaterials 23 (2002) 2887-2894, http://dx.doi.org/10.1016/S0142-9612(01)00416-1.

[242] H. Man, Z. Cui, T. Yue, Corrosion properties of laser surface melted NiTi shape memory alloy, Scripta Mater 45 (2001) 1447-1453, http://dx.doi.org/10. 1016/S1359-6462(01)01182-4.

[243] J. Wang, N. Li, G. Rao, E.H. Han, W. Ke, Stress corrosion cracking of NiTi in artificial saliva, Dent Mater 23 (2007) 133-137, http://dx.doi.org/10. 1016/j.dental.2006.01.001.

[244] J. Racek, P. Šittner, L. Heller, J. Pilch, P. Sedlák, L. Kadeřávek, Electrochemistry of NiTi wires/springs subjected to static/cyclic loadings, Mater Today Proc 2 (2015) S965-S969, http://dx.doi.org/10.1016/j.matpr.2015.07.442.

[245] K. Yokoyama, K. Kaneko, K. Moriyama, K. Asaoka, J. Sakai, M. Nagumo, Hydrogen embrittlement of Ni-Ti superelastic alloy in fluoride solution, J Biomed Mater Res 65A (2003) 182-187, http://dx.doi.org/10.1002/jbm.a.10457.

[246] K. Yokoyama, T. Ogawa, A. Fujita, K. Asaoka, J. Sakai, Fracture of Ni-Ti superelastic alloy under sustained tensile load in physiological saline solution containing hydrogen peroxide, J Biomed Mater Res, Part A 82A (2007) 558-567, http://dx.doi.org/10.1002/jbm.a.31173.

[247] A.I. Caplan, Mesenchymal stem cells, J Orthop Res 9 (1991) 641-650, http://dx.doi.org/10.1002/jor.1100090504.

[248] G. Altankov, F. Grinnell, T. Groth, Studies on the biocompatibility of materials: fibroblast reorganization of substratum-bound fibronectin on surfaces varying in wettability, J Biomed Mater Res 30 (1996) 385-391, http://dx.doi.org/10.1002/(SICI)1097-4636(199603)30:3<385::AID-JBM13>3.0.CO;2-J.

[249] J.R. Cho, B.Y. Lee, Y.H. Moon, C.J. Van Tyne, Investigation of residual stress and post weld heat treatment of multi-pass welds by finite element method and experiments, J Mater Process Technol 155-156 (2004) 1690-1695, http://dx.doi.org/10.1016/j.jmatprotec.2004.04.325.

[250] K.N. Krishnan, The effect of post weld heat treatment on the properties of 6061 friction stir welded joints, J Mater Sci 37 (2002) 473-480, http://dx.doi. org/10.1023/A:1013701104029.

[251] K. Elangovan, V. Balasubramanian, Influences of post-weld heat treatment on tensile properties of friction stir-welded AA6061 aluminum alloy joints, Mater Charact 59 (2008) 1168-1177, http://dx.doi.org/10.1016/j.matchar.2007.09.006.

[252] K. Otsuka, X.B. Ren, Recent developments in the research of shape memory alloys, Intermetallics 7 (1999) 511-528, http://dx.doi.org/10.1016/ s0966-9795(98)00070-3.

[253] C.B. Ke, S.S. Cao, X. Ma, X.P. Zhang, Modeling of $\mathrm{Ni}_{24} \mathrm{Ti}_{93}$ precipitation during stress-free and stress-assisted aging of bi-crystalline NiTi shape memory alloys, Trans Nonferr Met Soc Chin 22 (2012) 2578-2585, http://dx.doi.org/10.1016/S1003-6326(11)61503-3.

[254] A.S. Paula, K.K. Mahesh, C.M.L. dos Santos, F.M. Braz Fernandes, C.S. da Costa Viana, Thermomechanical behavior of Ti-rich NiTi shape memory alloys, Mater Sci Eng, A 481-482 (2008) 146-150, http://dx.doi.org/10.1016/j.msea.2007.02.142. 
[255] H. Sitepu, W. Schmahl, J. Allafi, G. Eggeler, A. Dlouhy, D. Toebbens, et al., Neutron diffraction phase analysis during thermal cycling of a Ni-rich NiTi shape memory alloy using the Rietveld method, Scripta Mater 46 (2002) 543-548, http://dx.doi.org/10.1016/S1359-6462(02)00032-5.

[256] C.T. Dawes, Laser welding: a practical guide, 1st ed., Abington Publishing, Cambridge, 1992.

[257] X. Zhao, L. Lan, H. Sun, J. Huang, H. Zhang, Mechanical properties of additive laser-welded NiTi alloy, Mater Lett 64 (2010) 628-631, http://dx.doi. org/10.1016/j.matlet.2009.12.025.

[258] W. Cai, X.L. Meng, L.C. Zhao, Recent development of TiNi-based shape memory alloys, Curr Opin Solid State Mater Sci 9 (2005) 296-302, http://dx. doi.org/10.1016/j.cossms.2006.07.002.

[259] Z. Sun, R. Karppi, The application of electron beam welding for the joining of dissimilar metals: an overview, J Mater Process Technol 59 (1996) 257-267, http://dx.doi.org/10.1016/0924-0136(95)02150-7.

[260] Z. Sun, J.C. Ion, Review laser welding of dissimilar metal combinations, J Mater Sci 30 (1995) 4025-4214, http://dx.doi.org/10.1007/BF00361499.

[261] X. Cao, M. Jahazi, J.P. Immarigeon, W. Wallace, A review of laser welding techniques for magnesium alloys, J Mater Process Technol 171 (2006) 188-204, http://dx.doi.org/10.1016/j.jmatprotec.2005.06.068.

[262] G. Phanikumar, K. Chattopadhyay, P. Dutta, Modelling of transport phenomena in laser welding of dissimilar metals, Int J Numer Methods Heat Fluid Flow 11 (2001) 156-174, http://dx.doi.org/10.1108/09615530110381575.

[263] G. Phanikumar, K. Chattopadhyay, P. Dutta, Computational modeling of laser welding of Cu-Ni dissimilar couple, Metall Mater Trans B 35 (2004) 339-350, http://dx.doi.org/10.1007/s11663-004-0034-4.

[264] A.P. Mackwood, R.C. Crafer, Thermal modelling of laser welding and related processes: a literature review, Opt Laser Technol 37 (2005) 99-115, http: //dx.doi.org/10.1016/j.optlastec.2004.02.017.

[265] N. Chakraborty, S. Chakraborty, Modelling of turbulent molten pool convection in laser welding of a copper-nickel dissimilar couple, Int J Heat Mass Transf 50 (2007) 1805-1822, http://dx.doi.org/10.1016/j.ijheatmasstransfer.2006.10.030.

[266] K. Bordjih, J.-Y. Jouzeau, D. Mainard, E. Payan, J.-P. Delagoutte, P. Netter, Evaluation of the effect of three surface treatments on the biocompatibility of 316L stainless steel using human differentiated cells, Biomaterials 17 (1996) 491-500, http://dx.doi.org/10.1016/0142-9612(96)82723-2.

[267] F.L. Nie, S.G. Wang, Y.B. Wang, S.C. Wei, Y.F. Zheng, Comparative study on corrosion resistance and in vitro biocompatibility of bulk nanocrystalline and microcrystalline biomedical 304 stainless steel, Dent Mater 27 (2011) 677-683, http://dx.doi.org/10.1016/j.dental.2011.03.009.

[268] T. Duerig, A. Pelton, D. Stöckel, An overview of nitinol medical applications, Mater Sci Eng, A 273-275 (1999) 149-160, http://dx.doi.org/10.1016/ S0921-5093(99)00294-4.

[269] S. Nemat-Nasser, W.-G.G. Guo, Superelastic and cyclic response of NiTi SMA at various strain rates and temperatures, Mech Mater 38 (2006) 463-474, http://dx.doi.org/10.1016/j.mechmat.2005.07.004.

[270] B. Kinsey, X. Wu, Tailor welded blanks for advanced manufacturing, 1st ed., Woodhead Publishing Limited, Oxford, 2011http://dx.doi.org/10.1533/ 9780857093851.2.118.

[271] J. Davis, Nickel, cobalt, and their alloys, 1st ed., ASM International, Ohio, 2000.

[272] A. Robin, J.L. Rosa, Corrosion behavior of niobium, tantalum and their alloys in hot hydrochloric and phosphoric acid solutions, Int J Refract Met Hard Mater 18 (2000) 13-21, http://dx.doi.org/10.1016/S0263-4368(99)00034-7.

[273] P.-J. Arrazola, A. Garay, L.-M. Iriarte, M. Armendia, S. Marya, F. Le Maitre, Machinability of titanium alloys (Ti6Al4V and Ti555.3), J Mater Process Technol 209 (2009) 2223-2230, http://dx.doi.org/10.1016/j.jmatprotec.2008.06.020.

[274] A. Sidambe, Biocompatibility of advanced manufactured titanium implants - a review, Materials (Basel) 7 (2014) 8168-8188, http://dx.doi.org/10.3390/ ma7128168.

[275] M. Niinomi, Mechanical properties of biomedical titanium alloys, Mater Sci Eng, A 243 (1998) 231-236, http://dx.doi.org/10.1016/ S0921-5093(97)00806-X.

[276] I. Sen, S. Tamirisakandala, D.B. Miracle, U. Ramamurty, Microstructural effects on the mechanical behavior of B-modified Ti-6Al-4V alloys, Acta Mater 55 (2007) 4983-4993, http://dx.doi.org/10.1016/j.actamat.2007.05.009.

[277] I. Gurrappa, Characterization of titanium alloy Ti-6Al-4V for chemical, marine and industrial applications, Mater Charact 51 (2003) 131-139, http://dx. doi.org/10.1016/j.matchar.2003.10.006.

[278] N. Poondla, T.S. Srivatsan, A. Patnaik, M. Petraroli, A study of the microstructure and hardness of two titanium alloys: commercially pure and Ti-6Al-4V, J Alloys Compd 486 (2009) 162-167, http://dx.doi.org/10.1016/j.jallcom.2009.06.172.

[279] E. Tal-Gutelmacher, D. Eliezer, The hydrogen embrittlement of titanium-based alloys, J Miner Met Mater Soc 57 (2005) 46-49, http://dx.doi.org/10. 1007/s11837-005-0115-0.

[280] W. Gale, T. Totemeir, Smithells metals reference book, 8th ed., Elsevier, Oxford, 2004http://dx.doi.org/10.1017/CBO9781107415324.004.

[281] Y. Cheng, W. Cai, H.T. Li, Y.F. Zheng, Surface modification of NiTi alloy with tantalum to improve its biocompatibility and radiopacity, J Mater Sci 41 (2006) 4961-4964, http://dx.doi.org/10.1007/s10853-006-0096-6.

[282] D. Stoeckel, C. Bonsignore, S. Duda, A survey of stent designs, Minim Invasive Ther Allied Technol 11 (2002) 137-147, http://dx.doi.org/10.1080/ 136457002760273340

[283] S. Kapila, P.V. Angolkar, M.G. Duncanson, R.S. Nanda, Evaluation of friction between edgewise stainless steel brackets and orthodontic wires of four alloys, Am J Orthod Dentofac Orthop 98 (1990) 117-126, http://dx.doi.org/10.1016/0889-5406(90)70005-W.

[284] W. Proffit, H. Fields, Orthodontics contemporary, 4th ed., Elsevier, St. Louis, 2007.<http://www.americanbanker.com/issues/179_124/ which-city-is-the-next-big-fintech-hub-new-york-stakes-its-claim-1068345-1.html>.

[285] Crocker M, Hodgson J, Kebede G. Variable diameter balloon dilatation catheter, 5470313; 1995.

[286] O. Peters, Current challenges and concepts in the preparation of root canal systems: a review, J Endod 30 (2004) 559-567, http://dx.doi.org/10.1097/01. DON.0000129039.59003.9D.

[287] P. Spili, P. Parashos, H.H. Messer, The impact of instrument fracture on outcome of endodontic treatment, J Endod 31 (2005) 845-850, http://dx.doi.org/ 10.1097/01.don.0000164127.62864.7c. 